\title{
Development of a Dedicated Ethanol Ultra-Low Emission Vehicle (ULEV): Final Report
}

L. Dodge, G. Bourn, T. Callahan, J. Grogan, D. Leone, D. Naegeli, $K$. Shouse, R. Thring, and K. Whitney

Southwest Research Institute San Antonio, Texas

NREL Technical Monitors:

P. Bergeron and B. Warnock

\author{
Alternative Fuels Hotline: 1-800-423-1DOE \\ Alternative Fuels Data Center World Wide Web Site: http://www.afdc.doe.gov \\ DISTRIBUTION OF THIS DOCUMENT IS UNLMTED
}

National Renewable Energy Laboratory

1617 Cole Boulevard

Golden, Colorado 80401-3393

A national laboratory of the

U.S. Department of Energy

Managed by the Midwest Research Institute

For the U.S. Department of Energy

Under Contract No. DE-AC36-83CH10093

Prepared under Subcontract Number YAW-3-12243-01

September 1998 


\section{NOTICE}

This report was prepared as an account of work sponsored by an agency of the United States government. Neither the United States govemment nor any agency thereof, nor any of their employees, makes any warranty, express or implied, or assumes any legal liability or responsibility for the accuracy, completeness, or usefulness of any information, apparatus, product, or process disclosed, or represents that its use would not infringe privately cwned rights. Reference herein to any specific commercial product, process, or service by trade name, trademark, manufacturer, or otherwise does not necessarily constitute or imply its endorsement, recommendation, or favoring by the United States government or any agency thereof. The views and opinions of authors expressed herein do not necessarily state or reflect those of the United States government or any agency thereof.

Available to DOE and DOE contractors from:

Office of Scientific and Technical Information (OSTI)

P.O. Box 62

Oak Ridge, TN 37831

Prices available by calling (423) $576-8401$

Available to the public from:

National Technical information Service (NTIS)

U.S. Department of Commerce

5285 Port Royal Road

Springfield, VA 22161

(703) $487-4650$ 


\section{DISCLAIMER}

Portions of this document may be illegible in electronic image products. Images are produced from the best available original document. 


\section{Preface}

This work was conducted by Southwest Research Institute (SwRI), San Antonio, Texas, under Subcontract No. YAW-3-12243-01, SwRI project number 03-5901 for the U.S. Department of Energy (DOE) in Washington, D.C., and the National Renewable Energy Laboratory (NREL) in Golden, Colorado. The contributions of technical monitors Dr. Bill Warnock and Brent K. Bailey of NREL, and John Garbak of DOE are gratefully acknowledged. The expertise of Mrs. Susie Schliesing in preparing this report is also greatly appreciated.

The objective of this project was to develop a commercially competitive vehicle powered by ethanol (or an ethanol blend) that can meet California's ultra-low emission vehicle (ULEV) standards and equivalent corporate average fuel economy (CAFE) energy efficiency for a light-duty passenger car application. The definition of commercially competitive is independent of fuel cost, but does include technical requirements for competitive power, performance, refueling times, vehicle range, driveability, fuel handling safety, and overall emissions performance.

This report summarizes the fourth and final phase of this project, and also the overall project. The focus of this report is the technology used to develop a dedicated ethanol-fueled ULEV, and the emissions results documenting ULEV performance. Some of the details for the control system and hardware changes are presented in two appendices that are SAE papers. The demonstrator vehicle has a number of advanced technological features, but it is currently configured with standard original equipment manufacturer (OEM) under-engine catalysts. Close-coupled catalysts would improve emissions results further, but no close-coupled catalysts were available for this testing. Recently, close-coupled catalysts were obtained, but installation and testing will be performed in the future.

This report also briefly summarizes work in several other related areas that supported the demonstrator vehicle work. Task 1 was fuel blending and testing, and included the development of correlations to predict vapor pressure and flammability for ethanol/hydrocarbon blends of various concentrations. Task 2 was fuel storage and fuel system compatibility studies. By starting with a flexible-fuel vehicle designed to operate on M85 ( $85 \%$ methanol, $15 \%$ gasoline) or gasoline, it was determined that the fuel system components were compatible with the ethanol fuel blends. Tasks 3,5, and 6 were directed at developing the engine and control system for the demonstrator vehicle, and calibrating that vehicle to meet ULEV standards. Task 4 was the investigation of advanced aftertreatment systems, and the Federal Test Procedure (FTP) emissions results. Some of this work was reported in the Phase 3 report, but that information is also included in this report. Additionally, the FTP results for the final demonstrator vehicle are reported in the Task 4 section. Task 7 describes the construction of a high-speed data acquisition system for measuring cylinder pressures integrated into the engine control system. 


\section{Executive Summary}

Ethanol is attractive as a transportation fuel because it is a renewable fuel that can be made from plant material, it has a very high octane number, it burns cooler than gasoline, and it typically produces lower carbon monoxide than gasoline because it is an oxygenated fuel. However, its relatively low volatility compared to gasoline raised the question about whether or not an ultra-low emissions vehicle (ULEV) could be produced from an ethanol-gasoline blend fuel. For that reason, the U.S. Department of Energy (DOE) and the National Renewable Energy Laboratory (NREL) contracted with Southwest Research Institute (SwRI) for the development of a demonstrator vehicle fueled by an ethanol blend fuel that could meet the tightest emissions standards in the world, California's ULEV standards.

SwRI obtained two 1993 Ford Taurus flexible-fuel vehicles for supporting development and test work on this project. One vehicle was used for engine development, and the other for advanced aftertreatment development. The engine was removed from the first vehicle, and several modifications were made. The compression ratio was increased from 9.25 to 11.0 by removing material from the cylinder heads and block, and installing new pistons. Air-assist injectors were developed and installed. An improved crank angle sensor from a General Motors (GM) LT-1 engine was used to provide very rapid synchronization of the engine control computer to the engine crank position. The standard idle air control (IAC) and exhaust gas recirculation (EGR) valves were replaced with valves that include pintle position sensors so that valve positions may be more accurately determined and controlled. A differential pressure sensor was installed across the throttle plate to estimate air flows into the intake manifold. A rapid exhaust port oxidation system was used to rapidly heat the catalyst and to burn up some of the exhaust emissions prior to reaching the catalyst. This rapid exhaust port oxidation system consisted of running the engine rich and pumping air into the exhaust ports with external air pumps. Finally, these other modifications required that the standard engine controller be replaced with a SwRIdeveloped full-authority engine controller, and that complete engine control algorithms be developed and implemented.

To control the Ford Taurus 3.0-liter engine, model-based control for both air and fuel flow were developed. The air flow model estimated air flow into the intake manifold based on throttle position and pressure drop across the throttle, IAC position and pressure drop, air-assist injector pressure drop, pollution control valve (PCV) pressure drop, and EGR valve position and pressure drop. Air flow out of the intake manifold was based on speed-density calculations. The difference in air flows into and out of the intake manifold was used to compute intake manifold absolute pressure (MAP) that was used along with the MAP sensor to accurately estimate the true MAP. Fuel flow into the cylinders included a model for wall wetting as a function of engine temperature and engine operating conditions. In addition to model-based control, a number of specialized algorithms were used to control certain parts of the engine cycle. For example, cylinder-event-based logic was used during cranking and startup to allow customized amounts of fuel injection and spark timing for each cylinder event. Closed-loop operation allowed model-based control of switching frequency, as well as adjustable control bands for air-fuel ratio as a function of engine speed.

This vehicle was used with standard original equipment manufacturer (OEM) catalysts mounted under the engine, one in each bank of the V-6 engine. The catalysts reached 50 percent conversion efficiency in about $17 \mathrm{~s}$ with a front face temperature of $400^{\circ} \mathrm{C}$. By $35 \mathrm{~s}$ the hydrocarbon emissions had dropped to 10 or $20 \mathrm{ppmC}$, and stayed in that range for most of the Federal Test Procedure (FTP) test. Even using the OEM catalysts, the demonstrator vehicle met ULEV emission standards as shown in the table below, although more highly loaded, close-coupled catalysts will be required to provide more margin for the non-methane organic gas (NMOG) emissions, and to offset catalyst conversion efficiency losses with mileage. Close-coupled catalysts have been obtained but not tested on the demonstrator vehicle. Durability testing to 50,000 miles was not performed. 


\begin{tabular}{|l|c|c|c|}
\hline & $\begin{array}{c}\text { Demonstrator } \\
\text { Vehicle* }\end{array}$ & ULEV Standards** & OEM Vehicle*** \\
\hline $\mathrm{CO}(\mathrm{g} / \mathrm{mi})$ & 0.879 & 1.7 & 1.702 \\
\hline $\mathrm{NO}_{\mathrm{x}}(\mathrm{g} / \mathrm{mi})$ & 0.085 & 0.2 & 0.077 \\
\hline NMOG x RAF (g/mi)**** & 0.039 & 0.04 & 0.102 \\
\hline Mileage on Ed-85 (mpg) & 13.56 & - & 14.10 \\
\hline $\begin{array}{l}\text { Gasoline Equivalent Mileage } \\
\text { (mpg) }\end{array}$ & 21.2 & - & 22.0 \\
\hline $\begin{array}{l}* \text { Measured at about 6,000 miles } \\
* * \text { At 50,000 miles } \\
* * * \text { Measured at about 4,000 miles } \\
* * * * \text { Estimated. Full speciation not performed }\end{array}$ & & \\
\hline
\end{tabular}

The second 1993 Ford Taurus flexible-fuel vehicle was used for tests of several advanced aftertreatment devices. These tests were conducted with the standard engine since engine tests were being conducted in parallel with the aftertreatment work. The aftertreatment devices included electrically heated catalysts (EHC), a hydrocarbon adsorber, and a combination adsorber/catalyst (adcat). Of these advanced aftertreatment systems, the EHC produced the lowest emissions. Without making any changes to the engine, the EHC system that used a W.R. Grace catalyst followed by a Degussa main catalyst produced ULEV emissions for CO and $\mathrm{NO}_{\mathrm{x}}$, with close to ULEV emissions for NMOG. These results are summarized in the table below.

\begin{tabular}{|l|c|c|c|}
\hline & OEM Vehicle with EHC* & ULEV Standards** & OEM Vehicle* $^{*}$ \\
\hline $\mathrm{CO}(\mathrm{g} / \mathrm{mi})$ & 0.8 & 1.7 & 1.702 \\
\hline $\mathrm{NO}_{\mathrm{x}}(\mathrm{g} / \mathrm{mi})$ & 0.068 & 0.2 & 0.077 \\
\hline $\begin{array}{l}\text { NMOG } \mathrm{RAF} \\
(\mathrm{g} / \mathrm{mi})^{* * *}\end{array}$ & 0.052 & 0.04 & 0.102 \\
\hline $\begin{array}{l}* \text { Measured at about 4,000 miles } \\
* * \text { At 50,000 miles } \\
* * * \text { Estimated. Full speciation not performed }\end{array}$ & & \\
\hline
\end{tabular}

Durability tests were conducted with both the fuel pump and fuel injectors used in the demonstrator vehicle. While operating on neat ethanol (E-100), the injectors survived a 900-million injection cycle test as specified in SAE Recommended Practice J1832. At the end of this test, there was no measurable injector leakage in any of the six injectors, and the calibrations had not changed since the beginning of the test. It was assumed that E-100 would be at least as hard on the injectors and pump as Ed-85, so tests were not conducted with Ed-85. 


\section{List of Abbreviations}

Abbreviation Description

$\begin{array}{ll}\text { ASTM } & \text { American Society for Testing and Materials } \\ \text { BOCLE } & \text { Ball on Cylinder Lubrication Evaluator } \\ \text { CAD } & \text { crank angle degrees } \\ \text { CAFE } & \text { corporate average fuel economy } \\ \text { CARB } & \text { California Air Resources Board } \\ \text { DOE } & \text { U.S. Department of Energy } \\ \text { DSP } & \text { digital signal processor } \\ \text { ECU } & \text { engine control unit } \\ \text { EGR } & \text { exhaust gas recirculation } \\ \text { EHC } & \text { electrically heated catalyst } \\ \text { EPA } & \text { U.S. Environmental Protection Agency } \\ \text { FID } & \text { flame ionization detector (for hydrocarbons) } \\ \text { FIDHC } & \text { hydrocarbons measured by flame ionization detector } \\ \text { FIDRCH 4 } & \text { FID response factor for methane } \\ \text { FIDRETH } & \text { FID response factor for ethanol } \\ \text { FFV } & \text { flexible-fuel vehicle } \\ \text { FTP } & \text { U.S. federal test procedure (light-duty, for emissions testing) } \\ \text { GM } & \text { General Motors } \\ \text { HEGO } & \text { heated exhaust gas oxygen (sensors) } \\ \text { IAC } & \text { idle air control } \\ \text { IMEP } & \text { indicated mean effective pressure } \\ \text { LED } & \text { light-emitting diode } \\ \text { LEV } & \text { low-emission vehicle } \\ \text { LFE } & \text { laminar flow element } \\ \text { MAF } & \text { mass air flow } \\ \text { MAP } & \text { manifold absolute pressure } \\ \text { MBT } & \text { minimum timing advance for best torque } \\ \text { MPDs } & \text { multi-product dispensers } \\ \text { ms } & \text { milliseconds } \\ \text { NMHC } & \text { nonmethane hydrocarbons } \\ \text { NMOG } & \text { nonmethane organic gases } \\ \text { NREL } & \text { National Renewable Energy Laboratory } \\ \text { OEM } & \text { original equipment manufacturer } \\ \text { PANAL } & \text { pressure analysis (SwRI code) } \\ \text { PEI } & \text { Petroleum Equipment Institute } \\ \text { PCV } & \text { pollution control valve } \\ \text { PW } & \text { pulse width } \\ \text { PWM } & \text { pulse-width modulated } \\ \text { RAF } & \text { reactivity factor } \\ \text { REPO } & \text { rapid exhaust port oxidation } \\ \text { RPECS } & \text { rapid prototyping engine control system } \\ \text { RVP } & \text { Reid vapor pressure (at 100'F) } \\ \text { SMD } & \text { Sauter mean diameter } \\ \text { SwRI } & \text { Southwest Research Institute } \\ \text { TDC } & \text { top-dead-center } \\ \text { TESS } & \text { Trajectory and Evaporation of Spray Systems } \\ & \end{array}$


TLEV

ULEV

UNLG

$\mu \mathrm{m}$

transitional low emission vehicle ultra-low emission vehicle unleaded gasoline micrometers 


\section{Table of Contents}

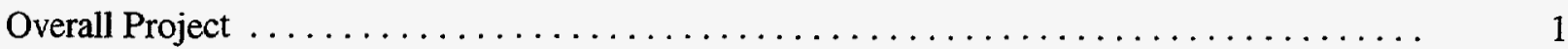

Technical Papers and Presentations $\ldots \ldots \ldots \ldots \ldots \ldots \ldots \ldots \ldots \ldots \ldots \ldots \ldots \ldots \ldots$

Task 1 -Fuel Blending and Testing $\ldots \ldots \ldots \ldots \ldots \ldots \ldots \ldots \ldots \ldots \ldots \ldots \ldots \ldots \ldots \ldots \ldots \ldots$

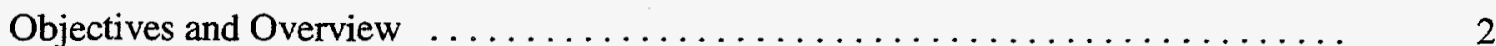

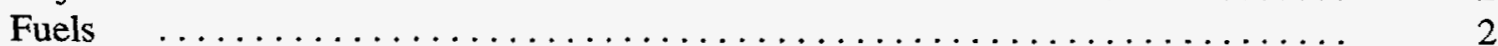

Vapor Pressure Measurements and Correlations . . . . . . . . . . . . . . . . . 3

Flammability Limit Data . . . . . . . . . . . . . . . . . . . . . . . . . 8

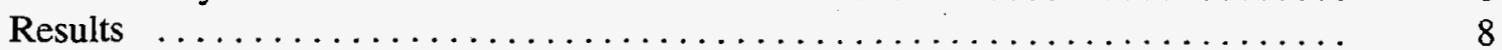

Corrosion and Wear Associated with Ethanol Fuels . . . . . . . . . . . . . 13

Task $2-$ Fuel Storage and Handling System Design $\ldots \ldots \ldots \ldots \ldots \ldots \ldots \ldots \ldots \ldots$

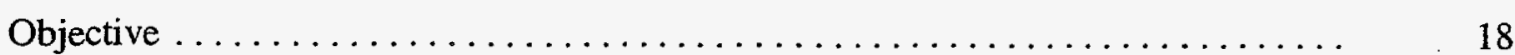

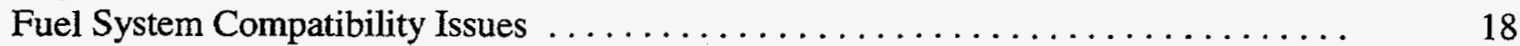

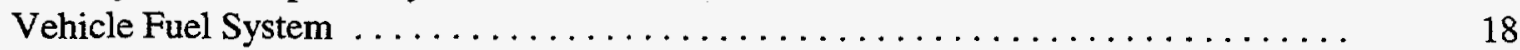

Ethanol Fuel Distribution, Storage, and Dispensing . . . . . . . . . . . . . 19

Effect of Enhanced Evaporative Emissions . . . . . . . . . . . . . . . . . 21

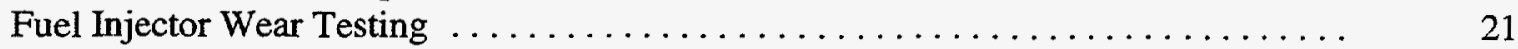

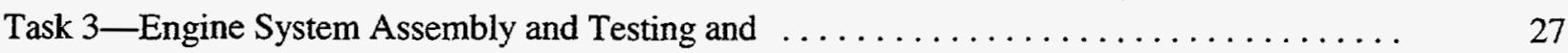

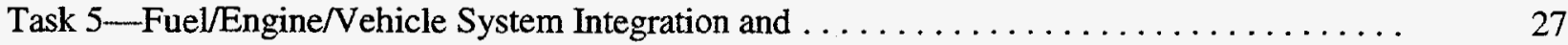

Task 6-Integrated Fuel/Engine System Optimization $\ldots \ldots \ldots \ldots \ldots \ldots \ldots \ldots \ldots \ldots \ldots$

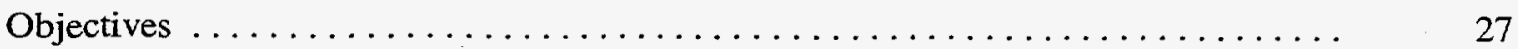

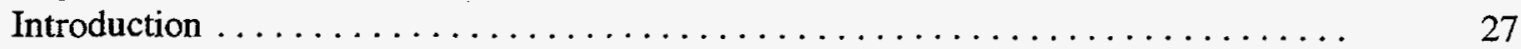

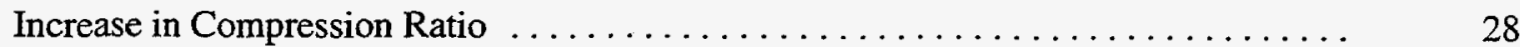

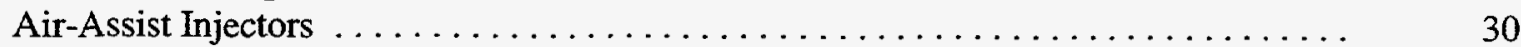

GM Shaft Encoder for Rapid Synchronization . . . . . . . . . . . . . . . . . 37

Rapid Prototyping Electronic Control System (RPECS) . . . . . . . . . . . . 37

Replacement of OEM IAC and EGR Valves with GM EGR Valves with Pintle

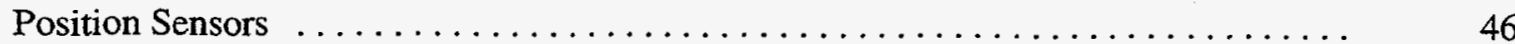

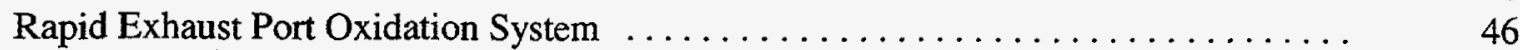

Task $4-$ Emissions Control System Development and Testing $\ldots \ldots \ldots \ldots \ldots \ldots \ldots \ldots$

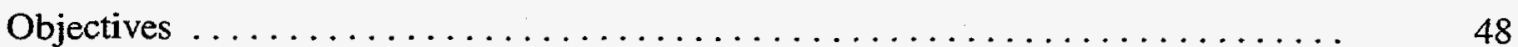

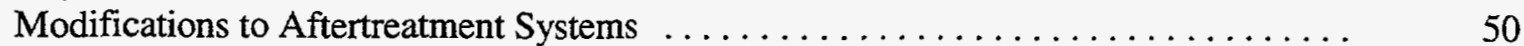

Tests of Adsorber/EHC and Adsorber/Catalyst . . . . . . . . . . . . . 55

Emissions Tests of Modified Engine and Vehicle with Rapid Exhaust Port Oxidation

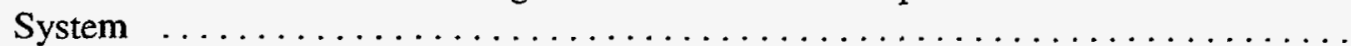




\section{Table of Contents (Concluded)}

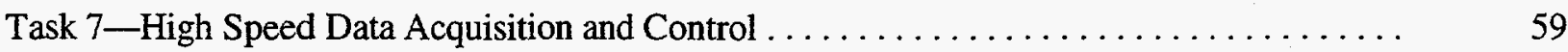

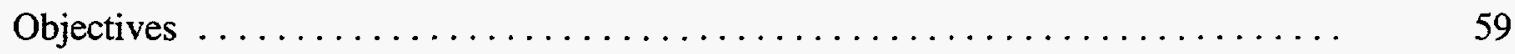

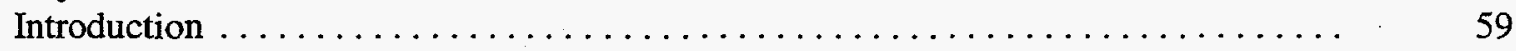

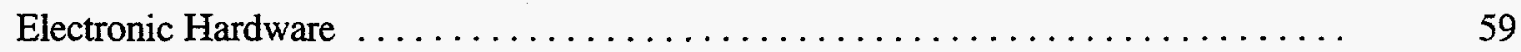

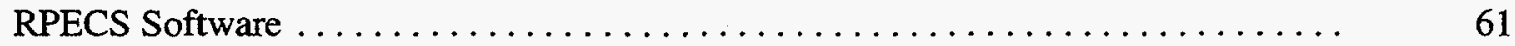

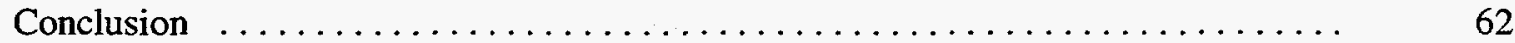

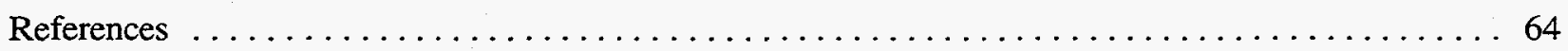

Appendix A SAE Paper No. 970531, "Model-Based Control and Cylinder-Event-Based Logic for an Ultra-Low Emissions Vehicle $\ldots \ldots \ldots \ldots \ldots \ldots \ldots \ldots \ldots \ldots$

Appendix B Draft SAE Paper, "Development of an Ethanol-Fueled Ultra-Low

Emissions Vehicle

\section{List of Illustrations}

Figure

Page

1 Effect of temperature on vapor pressure of ethanol/unleaded gasoline blends $\ldots \ldots \ldots$

2 Effect of temperature on vapor pressure of E-85 blends $\ldots \ldots \ldots \ldots \ldots \ldots \ldots \ldots$

3 Effect of temperature on vapor pressure of E- 85 blends $\ldots \ldots \ldots \ldots \ldots \ldots \ldots$

4 Temperature limits of flammability of ethanol blends containing

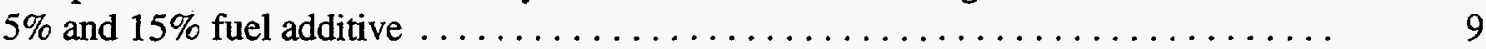

5 Effect of oil sump temperature on iron engine wear with various fuels $\ldots \ldots \ldots \ldots$

6 Schematic of injector durability test stand $\ldots \ldots \ldots \ldots \ldots \ldots \ldots \ldots \ldots \ldots \ldots \ldots$

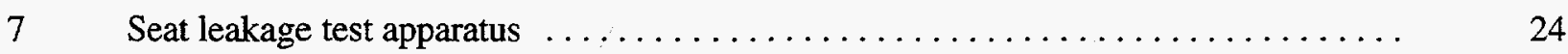

8 Fuel injector durability test results, E-100 (neat ethanol) static and dynamic flow rates

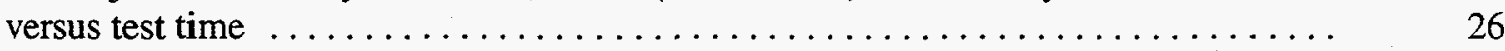

9 Piston and combustion chamber for Ford Taurus $3.0-$ liter $V-6 \ldots \ldots \ldots \ldots \ldots \ldots$

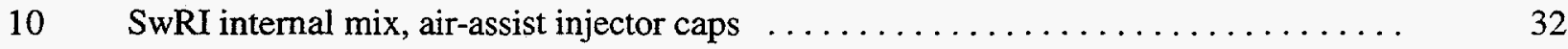

11 SwRI internal mix, air-assist injector cap mounted on conventional pintle injector ... 33

12 Measured air-fuel ratio for $\mathrm{OEM}$ pintle injectors at $32^{\circ} \mathrm{C}$ coolant temperature, $1500 \mathrm{rpm}$,

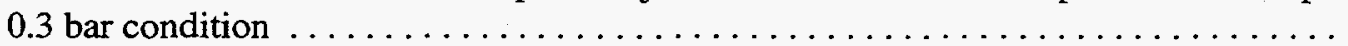


13 Measured air-fuel ratio for first-generation air-assist injectors at $32^{\circ} \mathrm{C}$ coolant

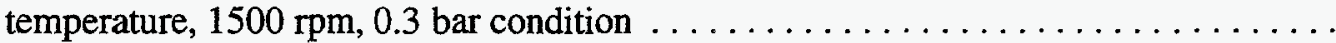

14 Measured air-fuel ratio for second-generation air-assist injectors at $32^{\circ} \mathrm{C}$ coolant temperature, $1500 \mathrm{rpm}, 0.3$ bar condition $\ldots \ldots \ldots \ldots \ldots \ldots \ldots \ldots \ldots \ldots \ldots \ldots \ldots \ldots \ldots$

15 Effect of differential air pressure and pulse width on average drop sizes as measured by the SMD from second-generation air-assist injectors spraying ethanol (E-100) ......

16 The PC-based controller for engine test cell $\ldots \ldots \ldots \ldots \ldots \ldots \ldots \ldots \ldots \ldots \ldots$

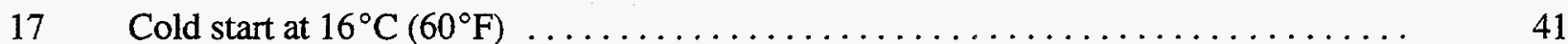

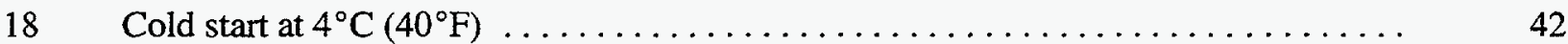

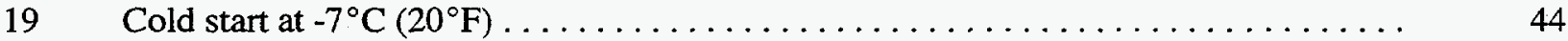

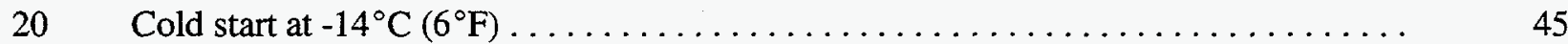

21 Catalyst front-face temperature and hydrocarbon emissions measured downstream of catalyst using clean-start engine modifications and the rapid exhaust port

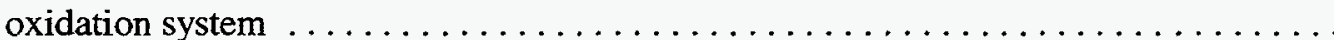

22 Schematic of Standard OEM Exhaust and SwRI Experimental Exhaust System .....

23 Emissions of modified vehicle compared with baseline vehicle and with ultra-low

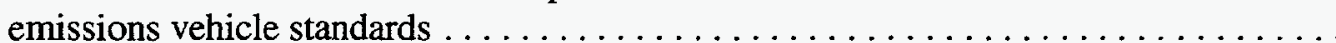

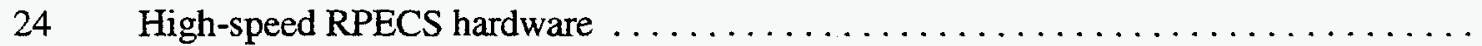

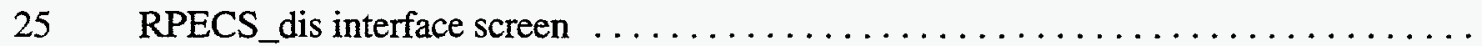

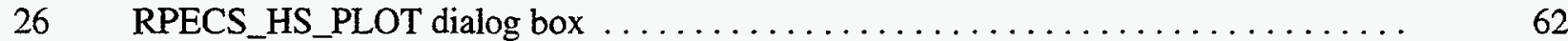

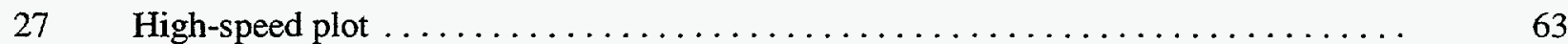




\section{List of Tables}

Table

Page

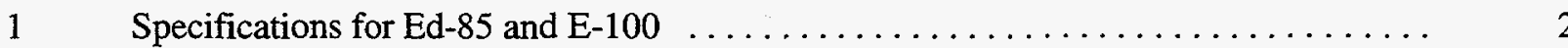

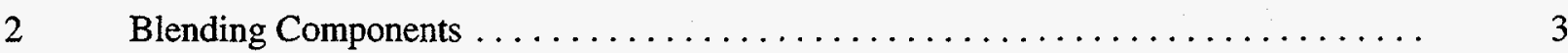

$3 \quad$ Matrix for Test Fuel Blends $\ldots \ldots \ldots \ldots \ldots \ldots \ldots \ldots \ldots \ldots \ldots \ldots \ldots \ldots \ldots$

4 Ethanol and Ethanol-Blend Vapor Pressures as a Function of Temperature . . . . . . 6

5 Correlating Parameters for Vapor Pressure Expression:

$\mathrm{Ln}(\mathrm{P})=\mathrm{A}+\mathrm{B} / \mathrm{T}+\mathrm{C} / \mathrm{T}^{2}$, Units, $\mathrm{P}$ in $\mathrm{kPa}, \mathrm{T}$ in Degrees $\mathrm{K} \ldots \ldots \ldots \ldots \ldots \ldots \ldots$

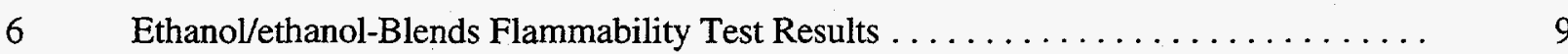

7 Comparison of Calculations with Measured Temperature Limits of Flammability .....

$8 \quad$ Fuel Lubricity Determined from Wear Tests with the Ball on

Cylinder Lubrication Evaluator . . . . . . . . . . . . . 14

9 Ball on Cylinder Lubrication Tests on Alcohols With and Without Oxygen ....... 14

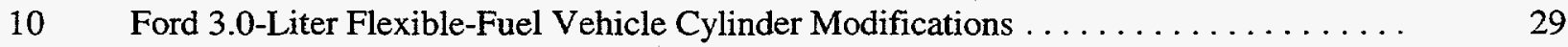

11 Baseline Federal Test Procedure Exhaust Emissions from Ford Flexible-Fuel

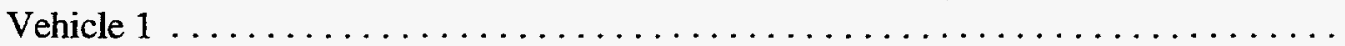

12 Weighted Baseline Federal Test Procedure Exhaust Emissions for Ford Flexible-Fuel

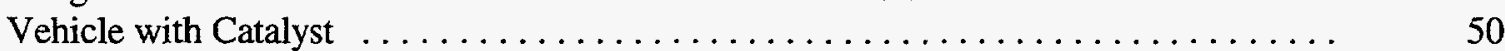

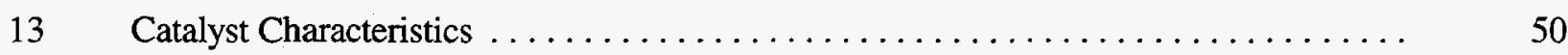

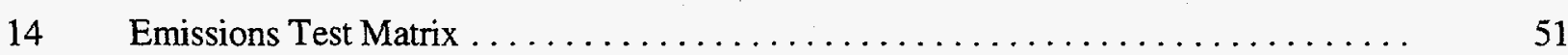

15 Federal Test Procedure Exhaust Emissions from Flexible-Fuel Taurus on Ed-85 . . . 53

16 Federal Test Procedure Emissions from Ford Flexible-Fuel Vehicle $\ldots \ldots \ldots \ldots \ldots$

17 Weighted Federal Test Procedure Exhaust Emissions-EHC Test \#E80-EHC-7cfm ... 54

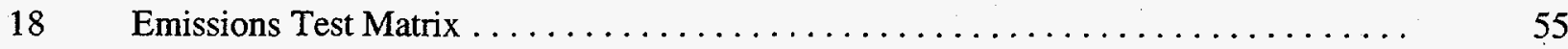

19 Federal Test Procedure Exhaust Emissions from Flexible-Fuel Taurus on Ed-85 $\ldots \ldots \quad 55$

20 Comparison of Hydrocarbon Emissions with $\mathrm{EHC} \ldots \ldots \ldots \ldots \ldots \ldots \ldots \ldots$

21 Emissions Results for the FTP - 75 for Modified 1993 Ford Taurus,

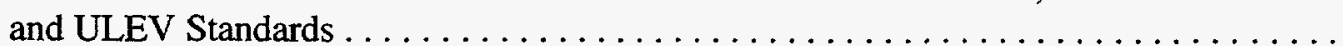




\section{Overall Project}

This report summarizes progress made toward developing an ethanol-fueled ULEV. The effort was divided into seven tasks, and the progress is reported for each task, except that tasks 3,5 , and 6 which all were aimed at the demonstrator vehicle development are reported together. However, a few items were not specific to one task and are discussed in this section.

\section{Technical Papers and Presentations}

Several papers and presentations were made during the course of this project. These are listed below:

"Development of a Dedicated Ethanol ULEV Passenger Car" by R.H. Thring, L.G. Dodge, G.D. Bourn, T.J. Callahan, J. Mulik, D.W. Naegeli, K.R. Shouse, L.R. Smith, and K.A. Whitney was presented at the 1996 Corn Utilization Conference in St. Louis.

"Model-Based Control and Cylinder-Event-Based Logic for an Ultra-Low Emissions Vehicle," by D.M. Leone, L.G. Dodge, K.R. Shouse, J. Grogan, and R.W. Weeks, SAE paper number 970531 (1997), presented at the SAE International Congress \& Exposition, February, 1997.

"Mixture Preparation and Controls for an Ultra-Low Emissions Vehicle," by L.G. Dodge, D.M. Leone, K.R. Shouse, J. Grogan, M. Viele, and R. Weeks, special Southwest Research Institute Dinner Presentation at the SAE International Congress \& Exposition, February, 1997.

"Development of an Ethanol-Fueled Ultra-Low Emissions Vehicle," by L.G. Dodge, K. Shouse, J. Grogan, D.M. Leone, K.A. Whitney, and P.M. Merritt" presented at the SAE International Spring Fuels and Lubricants Meeting and Exposition, Dearborn, Michigan, SAE Paper No. 981358. 


\section{Task 1-Fuel Blending and Testing}

\section{Objectives and Overview}

The objective of Task 1 was to determine the effects of different hydrocarbon additives with ethanol fuel on octane number, corrosion and wear, vapor pressure, and gas tank flammability. This work was completed during the first two phases of the project, and has been previously reported, but is reorganized and reported here for completeness.

Some of these tests were interrelated; others were not. The results are presented in the following order. The baseline fuel is described, along with the octane numbers measured for the baseline fuel and the gasoline used as a blending component. The blending components that were used for the volatility and flammability measurements are discussed. The vapor pressure measurements are described and correlations for vapor pressure are presented. The flammability results are then presented and correlated with the vapor pressure measurements. Finally, the tests to evaluate corrosion and wear in alcohol-fueled engines are discussed.

\section{Fuels}

\section{Baseline Fuel and Octane Number Measurements}

The baseline fuel for the project was a fuel containing 80 percent ethanol and 20 percent gasoline. This fuel is typically referred to as Ed-85 if the 5 percent denaturant is considered part of the ethanol for concentration purposes. "Ed-85" is the nomenclature preferred by the American Society for Testing and Materials (ASTM). Midwest Grain products provided 500 gallons of the Ed-85 fuel and 165 gallons of E-100 from its Atchison, Kansas, facility. Specifications of the Ed-85 are provided in Table 1.

Table 1. Specifications For Ed-85 and E-100

\begin{tabular}{|l|c|c|c|}
\hline & Ed-85 & E-100 & $\begin{array}{c}\text { Unleaded } \\
\text { Gasoline }\end{array}$ \\
\hline RVP kPa (psi) & $53.7(7.79)$ & $17.1(2.48)$ & $89.3(12.96)$ \\
\hline RON & 104.8 & Unknown & 91.5 \\
\hline MON & 99.3 & Unknown & 83.5 \\
\hline$(\mathrm{R}+\mathrm{M}) / 2$ & 102.1 & Unknown & 87.5 \\
\hline Distillation, ${ }^{\circ} \mathrm{C}\left({ }^{\circ} \mathrm{F}\right)$ & & & \\
\hline IBP & $42.8(109)$ & $77.2(171)$ & $22.7(73)$ \\
\hline 50 & $79.4(175)$ & $77.2(171)$ & $89.4(193)$ \\
\hline EP & $178.9(354)$ & $93.9(201)$ & $208.8(408)$ \\
\hline
\end{tabular}

\section{Blend Matrix for Vapor Pressure and Flammability Tests}

The materials in Table 2 were used to blend with E-100 to determine the vapor pressure and flammability limits. A test matrix was designed to determine the vapor pressure and flammability characteristics of the test additives and neat ethanol. This matrix is shown in Table 3 . The blending levels were selected to cover a 
range of expected Reid vapor pressures around a target of $51.8 \mathrm{kPa}$ (7.5 psi) fuel. The components range in vapor pressure from $89.7 \mathrm{kPa}$ (13 psi) to $358.8 \mathrm{kPa}$ (52 psi). With the exception of diethyl ether, the components are present in varying concentrations in gasoline used to denature ethanol.

Table 2. Blending Components

\begin{tabular}{|l|c|c|}
\hline \multicolumn{1}{|c|}{ Component } & Supplier & Quality \\
\hline n-butane & Phillips & $99.8 \mathrm{~mol} \%$ \\
\hline n-pentane & Phillips & $99.44 \%$ vol \\
\hline i-pentane & Phillips & $97.07 \%$ vol \\
\hline C $_{5} \mathrm{C}_{6}$ Isomerate & Texas Refinery & $79 \%$ Mass $\mathrm{C}_{5} \mathrm{~s} / 21 \%$ Mass $\mathrm{C}_{6} \mathrm{~s}$ \\
\hline Diethyl Ether & Fischer Chemical & Reagent Grade \\
\hline
\end{tabular}

Table 3. Matrix for Test Fuel Blends

\begin{tabular}{|l|c|c|c|c|c|c|c|}
\hline \multicolumn{7}{|c|}{ Volume Percent } & \multicolumn{1}{l|}{} \\
\hline n-butane & - & 15 & - & - & - & - & \\
\hline n-pentane & - & - & 15 & - & - & - & - \\
\hline i-pentane & - & - & - & 15 & - & - & - \\
\hline C $_{5}$ C $_{6}$ Isomerate & - & - & - & - & 15 & - & - \\
\hline Diethyl Ether & - & - & - & - & - & 15 & - \\
\hline UNLG & - & - & - & - & - & - & 15 \\
\hline Ethanol & 100 & 85 & 85 & 85 & 85 & 85 & 85 \\
\hline & & Volume Percent & & & & \\
\hline n-butane & 5 & - & - & - & - & - & \\
\hline n-pentane & - & 5 & - & - & - & - & \\
\hline i-pentane & - & - & 5 & - & - & - & \\
\hline C $C_{6}$ Isomerate & - & - & - & 5 & - & - & \\
\hline Diethyl Ether & - & - & - & - & 5 & - & \\
\hline UNLG & - & - & - & - & - & 5 & \\
\hline Ethanol & 95 & 95 & 95 & 95 & 95 & 95 & \\
\hline
\end{tabular}

Physically, the blending of the volatile components with ethanol was conducted in a cold box. The materials were stored in the cold box prior to blending. Finished blends were to be stored in the cold box until tests were performed. This maintained the quality of the material and integrity of the test results.

\section{Vapor Pressure Measurements and Correlations}

Fuel vapor pressure has a direct link to fuel tank flammability. Fuel tank flammability is a safety concern that has been sometimes overlooked because very few (if any) fire-related accidents in automobiles have been attributed to explosions within the fuel tank. Most accidents involving fire are caused by fuel tank rupture. Spilled gasoline is a severe fire hazard because its vapors quickly envelop the vehicle, causing a tumultuous 
conflagration. Other fire hazards involve fuel leaks in the engine compartment where the hot exhaust manifold and corona discharge around ignition wires are potential ignition sources.

At temperatures above $-10^{\circ} \mathrm{C}\left(14^{\circ} \mathrm{F}\right)$, the concentration of gasoline fumes in the vapor space of an automotive fuel tank is above the rich flammability limit (Goodger, 1980). When the fuel temperature is below $\approx-40^{\circ} \mathrm{C}$ $\left(\approx-40^{\circ} \mathrm{F}\right)$ the vapor concentration falls below the lean flammability limit. Between $-10^{\circ} \mathrm{C}\left(14^{\circ} \mathrm{F}\right)$ and $-40^{\circ} \mathrm{C}$ $\left(-40^{\circ} \mathrm{F}\right)$, the vapors are flammable and could be ignited if subjected to a sufficiently strong ignition source. Temperatures that define the flammable range of the fuel vapor are termed the upper and lower temperature limits of flammability. Temperature limits of flammability are affected by the Reid vapor pressure (RVP) and fuel composition.

A primary objective in Task 1 was to develop correlations of vapor pressure with temperature that could be used to predict temperature limits of flammability and cold startability. Cold start depends on the rate at which fuel can evaporate at low temperatures. Vapor phase equilibrium plays an important role in the evaporation of fuel droplets. The results of Task 1 provide important information for evaporation models used to predict cold start in ethanol-fueled engines.

\section{Apparatus and Procedure}

Vapor pressures were measured with a Grabner model CCA-VPS and a Grabner model CCA-VP equipped with a Peltier cooler. A separate fluid cooling apparatus was used to help the Peltier cooler reach temperatures below $-1^{\circ} \mathrm{C}\left(30^{\circ} \mathrm{F}\right)$. The instruments were calibrated with 2,2-dimethyl butane and n-pentane standards. Fresh blends of 5 percent and 15 percent by volume of n-butane, $n$-pentane, i-pentane, isomerate, diethyl ether, and unleaded gasoline (UNLG) with ethanol were prepared. Their vapor pressures were determined at $-14.4^{\circ} \mathrm{C}$ $\left(6^{\circ} \mathrm{F}\right),-1.1^{\circ} \mathrm{C}\left(30^{\circ} \mathrm{F}\right), 21.1^{\circ} \mathrm{C}\left(70^{\circ} \mathrm{F}\right), 37.7^{\circ} \mathrm{C}\left(100^{\circ} \mathrm{F}\right)$, and $54.4^{\circ} \mathrm{C}\left(130^{\circ} \mathrm{F}\right)$.

\section{Results of Vapor Pressure Measurements}

Figures 1 through 3 show Clapeyron-Clausius plots of the vapor pressure data for the ethanol blends in

Table 4. Significant curvature is observed in most of the plots. For each fuel, the data were correlated according to the expression,

$$
\operatorname{Ln}\left(P_{\nu}\right)=A+\frac{B}{T}+\frac{C}{T^{2}}
$$

where $P_{v}$ is the vapor pressure, $T$ is the absolute temperature, and $A, B$, and $C$ are fuel-dependent constants. Equation 1 is an extension of the Clapeyron-Clausius equation where the term, $C / T^{2}$, was added to account for the nonlinearity of the curves shown in Figures 1 through 3 . Table 5 lists the parameters $\mathrm{A}, \mathrm{B}$, and $\mathrm{C}$ for the various fuels that have been examined. 


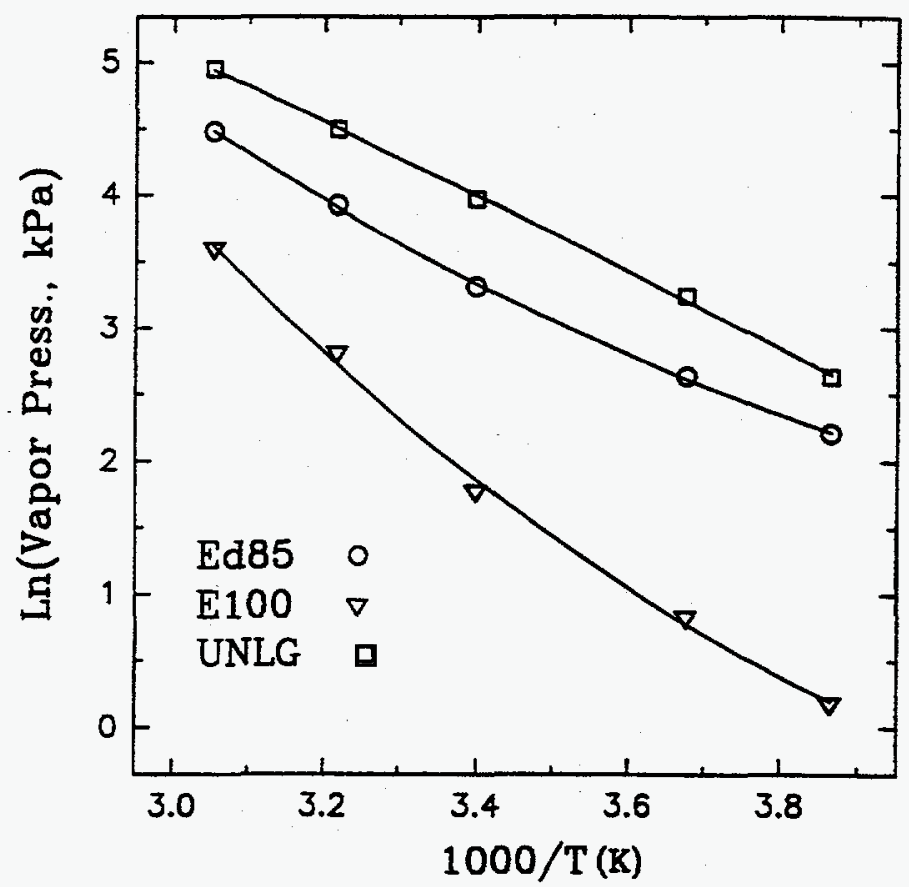

Figure 1. Effect of temperature on vapor pressure of ethanol/unleaded gasoline blends

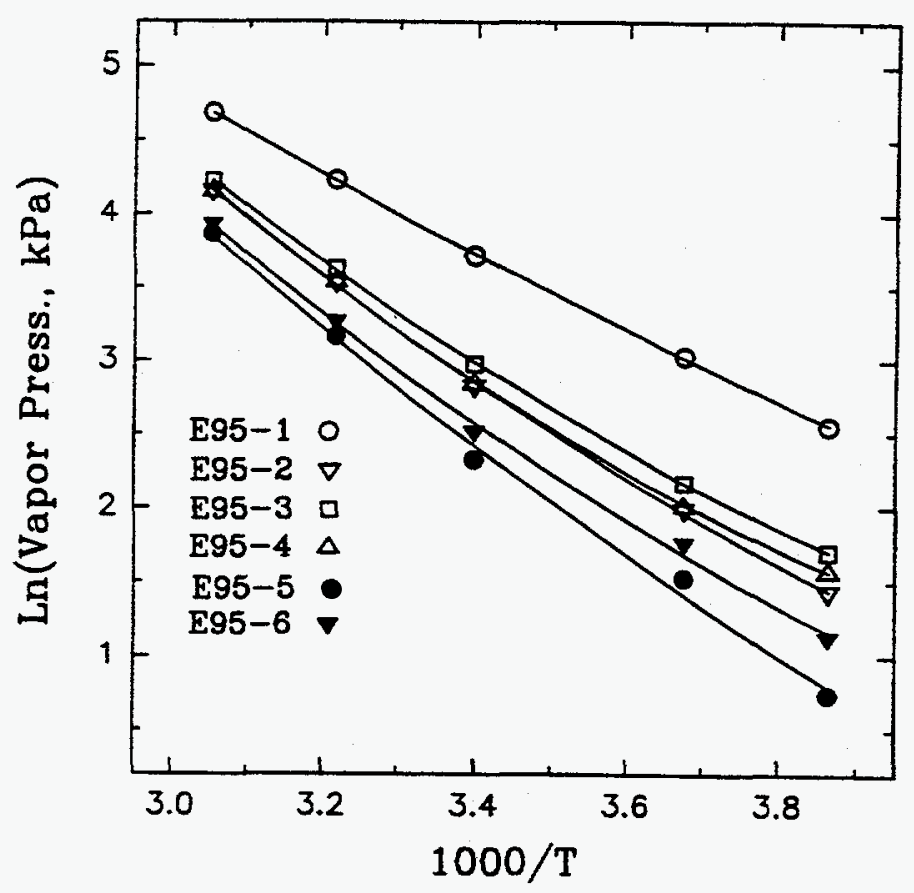

Figure 2. Effect of temperature on vapor pressure of E-85 blends 


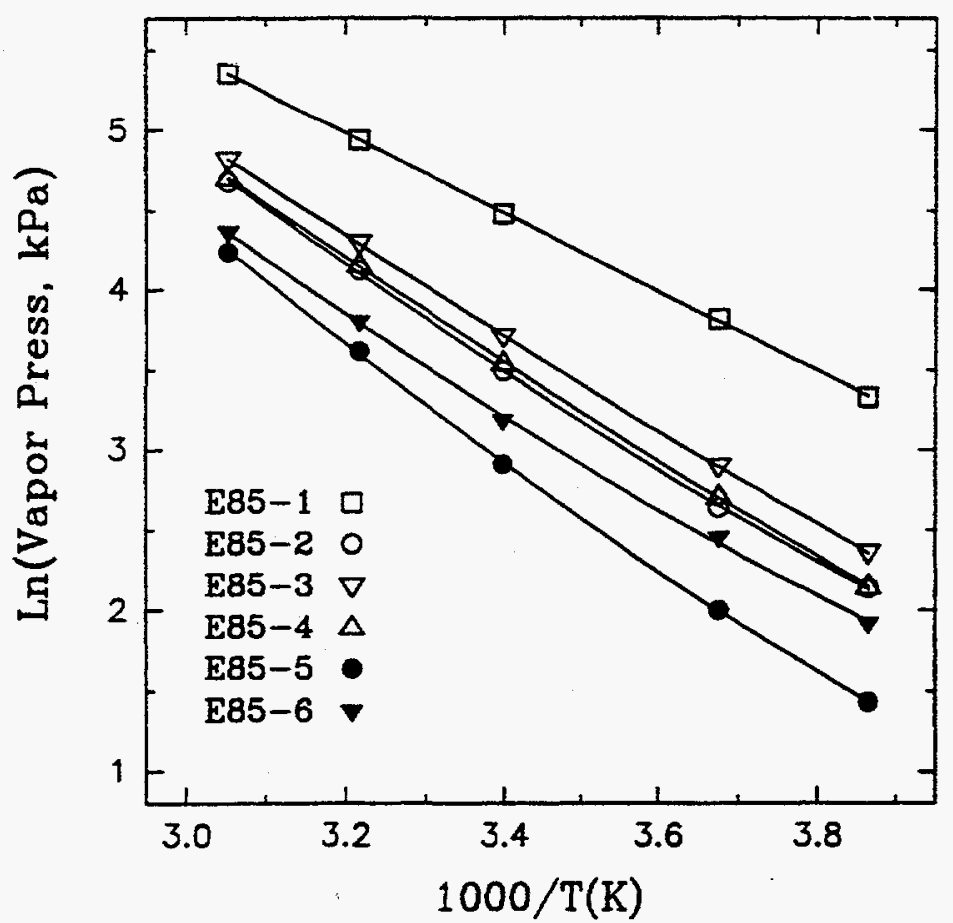

Figure 3. Effect of temperature on vapor pressure of E-85 blends

Table 4. Ethanol and Ethanol-Blend Vapor Pressures as a Function of Temperature

\begin{tabular}{|c|c|c|c|c|c|}
\hline & & Pressur & (psi). & perature & \\
\hline $\begin{array}{c}\text { Sample } \\
\text { (Sample Label) }\end{array}$ & $\begin{array}{l}-14.4^{\circ} \mathrm{C} \\
\left(6.0^{\circ} \mathrm{F}\right)\end{array}$ & $\begin{array}{l}-1.1^{\circ} \mathrm{C} \\
\left(30^{\circ} \mathrm{F}\right)\end{array}$ & $21.1^{\circ} \mathrm{C}$ & $\begin{array}{l}37.7^{\circ} \mathrm{C} \\
\left(100^{\circ} \mathrm{F}\right)\end{array}$ & $\begin{array}{r}54.4^{\circ} \mathrm{C} \\
\left(130^{\circ} \mathrm{F}\right)\end{array}$ \\
\hline Ed-85 & 12.6 & 14.0 & 27.6 & 50.8 & 88.1 \\
\hline & (1.83) & $(2.03)$ & $(4.00)$ & (7.38) & $(12.8$ \\
\hline E-100 & 1.2 & 2.3 & 5.9 & 16.6 & 36.5 \\
\hline & $(0.17)$ & $(0.33)$ & $(0.86)$ & (2.41) & $(5.29)$ \\
\hline UNLG & 4.0 & 25.8 & 53.3 & 89.8 & 141.8 \\
\hline UNLG & $(0.58)$ & $(3.74)$ & (7.73) & (13.0) & (20.6) \\
\hline $85 \%$ Ethanol $+15 \%$ Component & & & & & \\
\hline n-Butane (E85-1) & $\begin{array}{c}28.0 \\
(4.06)\end{array}$ & $\begin{array}{c}45.6 \\
(6.61)\end{array}$ & $\begin{array}{c}88.3 \\
(12.8)\end{array}$ & $\begin{array}{c}140.0 \\
(20.31)\end{array}$ & $\begin{array}{l}212.0 \\
(30.7)\end{array}$ \\
\hline n-Pentane (E85-2) & $\begin{array}{c}8.5 \\
(1.23)\end{array}$ & $\begin{array}{c}14.0 \\
(2.03)\end{array}$ & $\begin{array}{c}33.1 \\
(4.80)\end{array}$ & $\begin{array}{l}62.0 \\
(9.0)\end{array}$ & $\begin{array}{l}108.1 \\
(15.7)\end{array}$ \\
\hline Iso-Pentane (E85-3) & $\begin{array}{c}10.6 \\
(1.54)\end{array}$ & $\begin{array}{c}18.1 \\
(2.63)\end{array}$ & $\begin{array}{c}41.0 \\
(5.95)\end{array}$ & $\begin{array}{c}73.8 \\
(10.7)\end{array}$ & $\begin{array}{l}124.0 \\
(18.0)\end{array}$ \\
\hline & 8.6 & 15.0 & 34.8 & 64.2 & 110.7 \\
\hline Isomerate (E85-4) & $(1.25)$ & $(2.18)$ & $(5.05)$ & $(9.32)$ & $(16.0)$ \\
\hline Diethyl Ether (E-85-5) & $\begin{array}{c}4.2 \\
(0.61)\end{array}$ & $\begin{array}{c}7.4 \\
(1.07)\end{array}$ & $\begin{array}{c}18.4 \\
(2.67)\end{array}$ & $\begin{array}{c}37.4 \\
(5.42)\end{array}$ & $\begin{array}{c}69.5 \\
(10.0)\end{array}$ \\
\hline UNLG (E85-6) & $\begin{array}{c}6.8 \\
(0.99)\end{array}$ & $\begin{array}{c}11.6 \\
(1.68)\end{array}$ & $\begin{array}{c}24.2 \\
(3.51)\end{array}$ & $\begin{array}{c}44.9 \\
(6.51)\end{array}$ & $\begin{array}{c}78.6 \\
(11.4)\end{array}$ \\
\hline $95 \%$ Ethanol $+5 \%$ Component & & & & & \\
\hline n-Butane (E95-1) & $\begin{array}{c}12.9 \\
(1.87)\end{array}$ & $\begin{array}{c}20.8 \\
(3.02)\end{array}$ & $\begin{array}{c}41.1 \\
(5.96)\end{array}$ & $\begin{array}{c}68.6 \\
(9.95)\end{array}$ & $\begin{array}{r}108.5 \\
(15.7)\end{array}$ \\
\hline n-Pentane (E95-2) & $\begin{array}{c}4.2 \\
(0.61)\end{array}$ & $\begin{array}{c}7.3 \\
(1.06)\end{array}$ & $\begin{array}{c}16.9 \\
(2.45)\end{array}$ & $\begin{array}{c}34.1 \\
(4.96)\end{array}$ & $\begin{array}{c}63.7 \\
(9.24)\end{array}$ \\
\hline
\end{tabular}


Table 4. Ethanol and Ethanol-Blend Vapor Pressures as a Function of Temperature (Concluded)

\begin{tabular}{|c|c|c|c|c|c|}
\hline \multirow[b]{2}{*}{$\begin{array}{c}\text { Sample } \\
\text { (Sample Label) }\end{array}$} & \multicolumn{5}{|c|}{ Vapor Pressure, kPa (psi). @ Temperature, ${ }^{\circ} \mathrm{C}\left({ }^{\circ} \mathrm{F}\right)$} \\
\hline & $\begin{array}{l}-14.4^{\circ} \mathrm{C} \\
\left(6.0^{\circ} \mathrm{F}\right)\end{array}$ & $\begin{array}{l}-1.1^{\circ} \mathrm{C} \\
\left(30^{\circ} \mathrm{F}\right)\end{array}$ & $\begin{array}{l}21.1^{\circ} \mathrm{C} \\
\left(70^{\circ} \mathrm{F}\right)\end{array}$ & $\begin{array}{l}37.7^{\circ} \mathrm{C} \\
\left(100^{\circ} \mathrm{F}\right)\end{array}$ & $\begin{array}{l}54.4^{\circ} \mathrm{C} \\
\left(130^{\circ} \mathrm{F}\right)\end{array}$ \\
\hline Ed-85 & $\begin{array}{c}12.6 \\
(1.83)\end{array}$ & $\begin{array}{l}14.0 \\
(2.03)\end{array}$ & $\begin{array}{c}27.6 \\
(4.00)\end{array}$ & $\begin{array}{c}50.8 \\
(7.38)\end{array}$ & $\begin{array}{c}88.1 \\
(12.8)\end{array}$ \\
\hline Iso-Pentane (E95-3) & $\begin{array}{c}5.5 \\
(0.80)\end{array}$ & $\begin{array}{c}8.8 \\
(1.28)\end{array}$ & $\begin{array}{l}19.7 \\
(2.86)\end{array}$ & $\begin{array}{c}37.8 \\
(5.49)\end{array}$ & $\begin{array}{c}68.4 \\
(9.92)\end{array}$ \\
\hline Isomerate (E95-4) & $\begin{array}{c}4.83 \\
(0.70)\end{array}$ & $\begin{array}{c}7.5 \\
(1.09)\end{array}$ & $\begin{array}{c}17.3 \\
(2.51)\end{array}$ & $\begin{array}{c}34.6 \\
(5.03)\end{array}$ & $\begin{array}{c}63.7 \\
(9.24)\end{array}$ \\
\hline Diethyl Ether (E95-5) & $\begin{array}{c}2.1 \\
(0.31)\end{array}$ & $\begin{array}{c}4.6 \\
(0.67)\end{array}$ & $\begin{array}{c}10.3 \\
(1.49)\end{array}$ & $\begin{array}{c}23.7 \\
(5.03)\end{array}$ & $\begin{array}{c}47.7 \\
(6.92)\end{array}$ \\
\hline UNLG (E95-6) & $\begin{array}{c}3.1 \\
(0.45)\end{array}$ & $\begin{array}{c}5.8 \\
(0.84) \\
\end{array}$ & $\begin{array}{c}12.4 \\
(1.80)\end{array}$ & $\begin{array}{c}26.2 \\
(3.81)\end{array}$ & $\begin{array}{c}50.9 \\
(7.38) \\
\end{array}$ \\
\hline
\end{tabular}

Table 5. Correlating Parameters for Vapor Pressure Expressions: $\mathrm{Ln}(\mathrm{P})=\mathrm{A}+\mathrm{B} / \mathrm{T}+\mathrm{C} / \mathrm{T}^{2}$, Units: $\mathrm{P}$ in $\mathrm{kPa}, \mathrm{T}$ in Degrees $\mathrm{K}$

\begin{tabular}{|lcccc|}
\hline \multicolumn{1}{r}{ Fuel Description } & Code Name & A & B & C \\
\hline UNLG & UNLG & 11.34 & $-1,520.0$ & $-1.878 \times 10^{5}$ \\
Neat Ethanol & E100 & 38.36 & $-17,040.0$ & $1.855 \times 10^{6}$ \\
Ethanol - 20\% UNLG & E80 & 37.98 & $-17,660.0$ & $2.193 \times 10^{6}$ \\
Ethanol - 15\% n-Butane & E85-1 & 13.29 & $-2,692.0$ & $3.050 \times 10^{4}$ \\
Ethanol - 15\% n-Pentane & E85-2 & 21.81 & $-7,541.0$ & $6.340 \times 10^{5}$ \\
Ethanol - 15\% iso-Pentane & E85-3 & 18.06 & $-5,365.0$ & $3.368 \times 10^{5}$ \\
Ethanol - 15\% C/ C $_{6}$ Isomerate & E85-4 & 18.87 & $-5,817.0$ & $3.856 \times 10^{5}$ \\
Ethanol - 15\% Diethyl Ether & E85-5 & 23.88 & $-8,768.0$ & $7.661 \times 10^{5}$ \\
Ethanol - 15\% UNLG & E85-6 & 21.61 & $-7,751.0$ & $6.879 \times 10^{5}$ \\
Ethanol - 5\% n-Butane & E95-1 & 16.49 & $-4,853.0$ & $3.236 \times 10^{5}$ \\
Ethanol - 5\% n-Pentane & E95-2 & 25.21 & $-9,701.0$ & $9.190 \times 10^{5}$ \\
Ethanol - 5\% iso-Pentane & E95-3 & 25.68 & $-10,110.0$ & $1.012 \times 10^{6}$ \\
Ethanol- 5\% C $/ C_{6}$ Isomerate & E95-4 & 28.55 & $-11,760.0$ & $1.237 \times 10^{6}$ \\
Ethanol - 5\% Diethyl Ether & E95-5 & 24.45 & $-9,099.0$ & $7.708 \times 10^{5}$ \\
Ethanol - 5\% UNLG & E95-6 & 26.57 & $-10,600.0$ & $1.041 \times 10^{6}$ \\
\hline
\end{tabular}

Curvature is caused by changes in the heat of vaporization with temperature and the effect of temperature on the solubility of the additive in ethanol. At lower temperatures, the nonpolar hydrocarbon additives become less miscible in ethanol so their vapor pressure dependence on concentration becomes more nonideal. Nonideal solutions have higher vapor pressures because the components act more independently to produce the observed vapor pressure. All ethanol-hydrocarbon solutions are nonideal, so lowering the temperature tends enhance that effect (make the solutions more nonideal). In contrast, the E95-5 and E85-5 blends of ethanol and diethyl ether have much lower vapor pressures than the ethanol-hydrocarbon blends because diethyl ether forms a nearly ideal solution with ethanol. 
However, a more detailed analysis of the data involving parameters such as equivalence ratio, fuel-air ratio, and measured flammability limits was desired. The vapor pressure temperature correlations represented by Equation 1 are used with literature data on flammability limits to predict the upper temperature limits of flammability given in the next section.

\section{Flammability Limit Data}

\section{Apparatus}

The apparatus used in this study was similar to those used by Fanick et al. (1990) and Lawson et: al. (1987) to measure flammability limits of fuel vapors. The flask dimensions were sufficient to preclude wall quenching effects on the flammability limits (Coward and Jones 1952). The electrodes for ignition and the thermocouples for measuring fuel temperature were mounted in rubber stoppers that were placed in ports of the round bottom flask. The igniter electrodes consisted of two $10-\mathrm{cm}$ lengths of 14-gauge copper wire mounted in parallel 12.7-mm apart in the stopper. The copper electrodes were sharpened to a point and bent at the ends to form a $2.5-\mathrm{mm}$ spark gap at the center of the flask. The electrodes were insulated with a polyethylene sheath up to where they were bent to form the spark gap. An automotive spark coil capable of producing a continuous $400-\mathrm{Hz}$ oscillating arc discharge was used to ignite the fuel vapors.

In fuel tanks, one ignition source of concern is a spark created by a triboelectric source charge accumulation in the fuel. Another source is a person charged with static electricity standing next to an open fuel tank. van Dolah et al. (1963) gave an interesting example; if an average-sized man with a capacitance of $300 \mathrm{pF}$ builds up a charge of $10,000 \mathrm{~V}$, a discharge with an energy of $15 \mathrm{~mJ}$ could be initiated. From this standpoint, the automotive spark coil igniter, which produced a highly visible arc between the electrodes, was assumed to be an overwhelming ignition source.

\section{Procedure}

The combustion vessel was filled with $25 \mathrm{~mL}$ of test fuel. It was agitated to wet the walls of the flask so the fuel would evaporate and mix with the air. The flask was immersed in a constant temperature isopropanol/water bath controlled to within $0.5^{\circ} \mathrm{C}$. It required about 30 minutes for the liquid fuel and bath temperatures to equilibrate. An attempt was made to ignite the fuel-air mixture about 20 minutes after the liquid fuel and bath temperatures reached equilibrium. The temperature limits of flammability were determined by trial and error.

At the start of testing, a presumed bath temperature was chosen. If ignition occurred at the chosen temperature, it would be characterized as weak, medium, or strong, depending on the aural (visual) intensity of the explosion. If the explosion was weak, the conditions were very close to the temperature limit of flammability. Therefore, in the next test the bath temperature would be raised just a few degrees. If no ignition occurred, the temperature limit was within a few degrees of the bath temperature in the last test. Once the temperature limit of flammability was bracketed to within a few degrees, tests were performed in $1^{\circ} \mathrm{C}$ increments to achieve accuracy to within $1^{\circ} \mathrm{C}$.

\section{Results}

Rich and lean flammability limits were measured, and are presented in Table 2. Figure 4 shows the flammability results from Table 6 plotted versus the RVP, which is the vapor pressure measured at $37.7^{\circ} \mathrm{C}$ $\left(100^{\circ} \mathrm{F}\right)$, from Table 4 . The flammability limits correlate with the RVP, except those data that are tagged with labels. The labels in Figure 4 correspond with those defined in Table 4. The flammability limits may be predicted from the Reid vapor pressures except for the mixtures with n-butane, diethyl ether, and neat ethanol. 


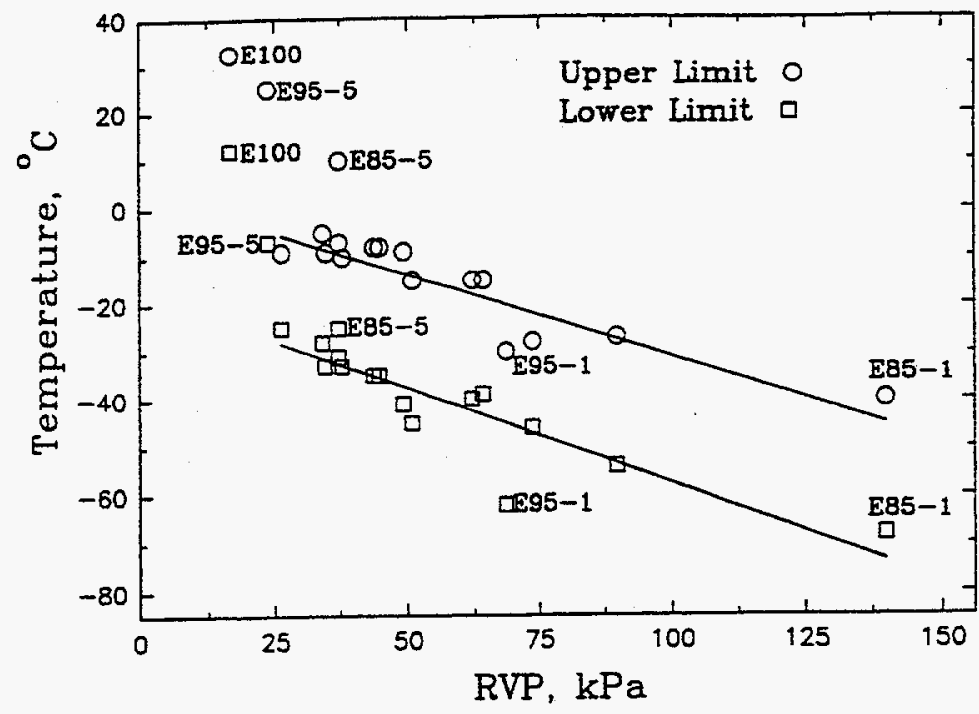

Figure 4. Temperature limits of flammability of ethanol blends containing $5 \%$ and $15 \%$ fuel additive

The relationship between fuel vapor pressure and flammability limits was investigated further to determine how the flammability limits may be accurately predicted from the vapor pressures. This is important in estimating both engine cold startability and fuel tank flammability. $\mathrm{N}$-butane shows a different flammability versus vapor pressure than the other mixtures because it forms a less ideal solution with ethanol; i.e., it does not follow Raoult's law for vapor pressures of mixtures. In contrast, the diethyl ether and ethanol form a relatively ideal mixture, which explains why ether blends do not show the same correlation of flammability limits versus RVP as the other blends. For the ethanol blends, much of the flammability is due to the hydrocarbon fractions.

For neat ethanol, only the ethanol vapors are available for combustion. Because of the different stoichiometry for ethanol combustion, more fuel vapor is required, which increases the temperature limit for flammable mixtures above that of the ethanol blends. The E-100 and blends that contain n-butane and diethyl ether presumably deviate from the general dependence of temperature limit versus RVP because of differences in stoichiometry. As an example, the air-fuel ratio for stoichiometric combustion of gasoline is about 14.6, but ethanol is 9.01 . The lean flammability limits for both materials are roughly at an equivalence ratio of 0.5 , but this is an air-fuel ratio of about 29 for gasoline/air and 18 for ethanol/air mixtures.

Table 6. Ethanol/Ethanol-Blends Flammability Test Results

\begin{tabular}{|ccc|}
\hline Sample & \multicolumn{2}{c|}{ Flammability Limits } \\
\hline & Upper ${ }^{\circ} \mathrm{C}$ (Rich) & Lower ${ }^{\circ} \mathrm{C}$ (Lean) \\
E80 & -15 & -45 \\
UNLG & 33 & 12 \\
& -27 & -54 \\
$85 \% \mathrm{ETOH}+15 \%$ n-Butane & & -69 \\
$85 \% \mathrm{ETOH}+15 \%$ n-Pentane & -40 & -40 \\
$85 \% \mathrm{ETOH}+15 \%$ Iso-Pentane & -15 & -46 \\
$85 \% \mathrm{ETOH}+15 \%$ Isomerate & -20 & -39 \\
\hline
\end{tabular}


Table 6. Ethanol/Ethanol-Blends Flammability Test Limits (concluded)

\begin{tabular}{|ccc|}
\hline Sample & \multicolumn{2}{c|}{ Flammability Limits } \\
\hline $85 \% \mathrm{ETOH}+15 \%$ Diethyl Ether & Upper ${ }^{\circ} \mathrm{C}$ (Rich) & Lower ${ }^{\circ} \mathrm{C}$ (Lean) \\
$85 \% \mathrm{ETOH}+15 \%$ UNLG & -10 & -25 \\
$95 \% \mathrm{ETOH}+5 \%$ n-Butane & -8 & -35 \\
$95 \% \mathrm{ETOH}+5 \%$ n-Pentane & -30 & -62 \\
$95 \% \mathrm{ETOH}+5 \%$ Iso-Pentane & -5 & -28 \\
$95 \% \mathrm{ETOH}+5 \%$ Isomerate & -10 & -33 \\
$95 \% \mathrm{ETOH}+5 \%$ Diethyl Ether & -9 & -33 \\
$95 \% \mathrm{ETOH}+5 \%$ UNLG & 25 & -7 \\
\hline
\end{tabular}

To account for variations in fuel composition, a simple computer model was written to use the vapor pressure measurements of the blends to estimate the molar ratios of ethanol and the additive, and then compute the equivalence ratio for the blends, accounting for the different fuel-air ratios required for the components. A computer code was written to calculate the upper and lower temperature limits of flammability from the vapor pressure and flammability limit data.

The calculations were performed by assuming that the partial pressure of ethanol, $P_{E}$, in the fuel blend is equal to,

$$
P_{E}=X_{E} P_{N}
$$

where $X_{E}$ is the mole fraction of ethanol in the liquid phase, and $P_{N}$ is the vapor pressure of neat ethanol. The partial pressure, $\mathrm{P}_{\mathrm{A}}$, of the fuel additive, such as butane and pentane, was determined as,

$$
P_{A}=P_{F B}-P_{E}
$$

where $P_{F B}$ is the vapor pressure of the fuel blend. The mole percent of ethanol vapor, $C_{E}$, and additive vapor, $\mathrm{C}_{\mathrm{A}}$, were expressed as,

$$
C_{E}=100 \frac{P_{E}}{P_{t}}
$$

and,

$$
C_{A}=100 \frac{P_{A}}{P_{t}}
$$

where $P_{t}$ is the total pressure, e.g., the atmospheric pressure. 
Flammability limit data for neat ethanol and the pure components, $n$-butane, n-pentane, I-pentane, and diethyl ether were obtained from the literature (Hodgman 1957). The flammability limits of the vapors from unleaded gasoline were weighted about 70 percent butane and 30 percent pentane. The vapors from the isomerate were weighted about 70 percent pentane and 30 percent hexane. More accurate vapor compositions could have been determined by speciating the vapor space, but they were not.

Various approaches were used in combining the flammability limits of the components to arrive at the flammability limit of the ethanol-additive mixture. The following method of combining flammability limits was used. First, Equation 6 was used to calculate the stoichiometric air-fuel ratios, $\mathrm{AFR}_{\mathrm{ST}}$, of the components.

$$
A F R_{S T}=4.76(x+y / 4-z / 2)
$$

The variables $\mathrm{x}, \mathrm{y}$, and $\mathrm{z}$ are the numbers of carbon, hydrogen and oxygen atoms respectively. The factors $\mathrm{F}_{\mathrm{A}}$ and $F_{E}$ were calculated via,

$$
F_{E}=\frac{P_{E} A F R(E)_{S T}}{P_{E} A F R(E)_{S T}+P_{A} A F R(A)_{S T}}
$$

and,

$$
F_{A}=1-F_{E}
$$

where AFR(E) $)_{S T}$ and AFR(A) $)_{S T}$ are the stoichiometric air-fuel ratios for ethanol and the additive. The flammability limit of the mixture, $\mathrm{L}_{\mathrm{M}}$, is then expressed as,

$$
L_{M}=F_{E} L_{E}+F_{A} L_{A}
$$

where $L_{E}$ and $L_{A}$ are the respective flammability limits of ethanol and the additive.

Finally, the temperature limit of flammability is determined when Equation 10 is satisfied.

$$
L_{M}=C_{E}+C_{A}
$$

Table 7 shows the upper temperature limits of flammability that were calculated by an iterative technique involving Equations 1 through 10. The calculations were performed by making incremental changes in temperature until the temperature satisfied the conditions of Equation 10. 
Table 7. Comparison of Calculations with Measured Temperature Limits of Flammability

\begin{tabular}{|c|c|c|c|c|}
\hline \multirow[t]{2}{*}{ Fuel Blend } & \multicolumn{2}{|c|}{$\begin{array}{c}\text { Upper Temperature Limits } \\
\text { of Flammability } \\
\left({ }^{\circ} \mathrm{C}\right)\end{array}$} & \multicolumn{2}{|c|}{$\begin{array}{l}\text { Lower Temperature } \\
\text { Limits of Flammability } \\
\left({ }^{\circ} \mathrm{C}\right)\end{array}$} \\
\hline & Meas. & Calc. & Meas. & Calc. \\
\hline E100 & 33 & 36.5 & 12 & 13.5 \\
\hline UNLG & -27 & -26 & -54 & -53 \\
\hline EtOH $+15 \%$ n-Butane & -40 & -43.5 & -69 & -70 \\
\hline $\mathrm{EtOH}+15 \%$ n-Pentane & -15 & -16 & -40 & -56 \\
\hline EtOH $+15 \%$ Iso-Pentane & -20 & -20 & -46 & -56 \\
\hline $\mathrm{EtOH}+15 \%$ Isomerate & -15 & -17 & -39 & -51 \\
\hline EtOH $+15 \%$ Diethyl Ether & 10 & 12 & -25 & -29 \\
\hline $\mathrm{EtOH}+15 \%$ UNLG & -8 & -8 & -35 & -49 \\
\hline $\mathrm{EtOH}+5 \% \mathrm{n}$-Butane & -30 & -26 & -62 & -62 \\
\hline EtOH $+5 \%$ n-Pentane & -5 & 4 & -28 & -37 \\
\hline EtOH $+5 \%$ Iso-Pentane & -10 & -2 & -33 & -59 \\
\hline $\mathrm{EtOH}+5 \%$ Isomerate & -9 & 2 & -33 & -106 \\
\hline EtOH $+5 \%$ Diethyl Ether & 25 & 25 & -7 & -10 \\
\hline $\mathrm{EtOH}+5 \%$ ULG & -9 & 15 & -25 & -23 \\
\hline $\mathrm{EtOH}+20 \%$ ULG & -15 & -17 & -45 & Error* \\
\hline
\end{tabular}

* An error occurred in the iteration scheme for this fuel blend.

The results of the calculations were strongly dependent on the literature values of the flammability limits. For example, the flammability limits of ethanol given by Hodgman (1957) are 3.28 and 18.95 mole percent in air. When these values are used, the calculated lower and upper limits of flammability are $6^{\circ} \mathrm{C}$ and $41^{\circ} \mathrm{C}$, respectively. The calculated limits for neat ethanol in Table 7 are based on lower and upper flammability limits of 4.4 and 14.3 mole percent, respectively, measured in a combustion bomb (Naegeli and Weatherford 1989).

A similar problem arises in computing the temperature limits of the ethanol/diethyl ether blends. Hodgman (1957) gives flammability limits of 1.85 and 36.5 mole percent in air for diethyl ether. The lower limit of 1.85 seems reasonable, but the measured upper temperature limits indicate that the upper flammability limit of diethyl ether is much lower than the literature value. Rich limits in the literature are often too high because they include cool flame reactions that give rise to chemiluminescence when there is no heat release or pressure rise accompanying the ignition process. The calculated values in Table 6 for the ethanol/15 percent diethyl ether and ethanol/5 percent diethyl ether blends were determined assuming that the upper flammability limit of diethyl ether is 12.5 mole percent in air. This is substantially lower than the literature value of 36.5 mole percent. Hence, from the standpoint of fuel tank flammability, we recommend that the flammability limits of diethyl ether and probably several other oxygenates should be re-examined. 
There was good agreement between measured and calculated upper and lower temperature limits of UNLG, E-95, ethanol/15 percent $n$-butane and ethanol/5 percent $n$-butane blends. The agreement was good between measured and calculated upper limits, but poor between the lower limits of E-85, and the blends of ethanol with 15 percent n-pentane, iso-pentane, and isomerate. The agreement was poor in upper and lower temperature limits of the ethanol blends containing 5 percent $n$-pentane, iso-pentane and isomerate. For the upper temperature limit, the problem seems not to be in the flammability limits of the additives, $n$-pentane, isopentane and isomerate, because the agreement was good in the 15 percent blends. However, the calculated lower temperature limits were well below the measured limits for both the 5 percent and 15 percent blends of ethanol that contained n-pentane, iso-pentane and isomerate. Increasing the lower flammability limits of $\mathbf{n}$ pentane, iso-pentane, and isomerate by 30 percent made an improvement of only a few degrees in the calculated lower temperature limits. Because the literature values of the lower flammability limits are relatively accurate, the problem seems to be related to the accuracy of the vapor pressure expressions (see Equation 1).

Because of the curvature in the Clapeyron-Clausius plots of vapor pressure versus temperature, there is some question of the accuracy of the low temperature data. If there are inaccuracies in the database, extrapolations of vapor pressures to temperature beyond the range of the database could yield erroneous vapor pressure values.

\section{Corrosion and Wear Associated with Ethanol Fuels}

\section{Fuel Lubricity}

Fuel lubricity is important to fuel pump and fuel injector wear. It is measured in terms of a wear pattern produced as the result of rubbing two metal surfaces together in the presence of the fuel. Experience has shown that oxygenated fuels have lubricating properties similar to gasolines. However, alcohols absorb water, which degrades fuel lubricity.

Fuel lubricity was measured with a Ball on Cylinder Lubrication Evaluator (BOCLE). In the BOCLE test, a steel ball locked in a fixed position rides on a rotating steel cylinder that is immersed in the test fluid. The contact frictional load between the ball and cylinder is controlled by a weight applied to a lever that forces the ball against the cylinder. The wear rates are measured in terms of the diameter of the wear scar on the steel ball. The wear scar is elliptical, so its diameter is determined as the average of its width and length. Fuel lubricity is inversely proportional to the wear scar diameter.

In the standard BOCLE procedure, the test fluid is purged with room temperature air at a relative humidity of 10 percent. Purging with air is applicable to lubricating oils and middle distillate fuels, but is seldom used with volatile fuels such as gasoline, ethanol, and ethers. It causes the fuel to evaporate and cool, and in some instances, fuels such as alcohols extract a large amount of water from the air. Because water has a significant effect on wear in the BOCLE test, there was no air purging of the ethanol and gasoline blends examined in the present study.

The results shown in Table 8 are interesting in that the wear scar diameter for ethanol is less than that for UNLG gasoline. Intuitively, it would seem that gasoline, which contains relatively high molecular weight hydrocarbons, would be a better lubricant than ethanol. There are various theories why ethanol is a better lubricant. One explanation is that ethanol's relatively high polarity causes it to adhere to the metal surface and act as a protective cushion. 
Table 8. Fuel Lubricity Determined from Wear Tests with the Ball on Cylinder Lubrication Evaluator

\begin{tabular}{|cc|}
\hline Fuel Blend & Wear Scar Diameter, mm \\
\hline UNLG & 0.60 \\
Ethanol + 20\% UNLG & 0.59 \\
Ethanol + 15\% UNLG & 0.53 \\
Ethanol + 5\% UNLG & 0.52 \\
Neat Ethanol & 0.50 \\
Neat Methanol & 0.44 \\
\hline
\end{tabular}

An alternative theory assumes that ethanol has a higher resistance to oxidation than the hydrocarbons in gasoline. Tribologists conclude that very high lubricant temperatures are produced in the wear zone when aspirates on the metal surfaces make contact. The fuels almost always contain some dissolved oxygen, so the high temperatures cause the fuel to autoxidize. Corrosive substances such as peroxides and carboxylic acids may be among the oxidation products.

Wear rates usually decrease dramatically when dissolved oxygen is removed from the test fluid. If the test fluid is thoroughly purged with nitrogen to remove the dissolved oxygen before the test, and also purged with nitrogen throughout the test, the wear scar is greatly reduced.

Table 9 shows the results of experiments performed to determine the effect of removing oxygen on the lubricity of alcohols. The nitrogen and air used in the tests were preconditioned with 10 percent relative humidity at room temperature. The alcohols were absolute water free at the start of the test, but no doubt absorbed a significant amount of water during the test. Methanol and ethanol literally extract moisture from the air; the effect is much less with propanol, and relatively weak with butanol. The experiments "with air" and "with nitrogen" were performed in the same way so the effect of humidity on both tests was the same.

Table 9. Ball on Cylinder Lubrication Tests on Alcohols With and Without Oxygen

\begin{tabular}{|ccc|}
\hline Alcohol Fuel & \multicolumn{2}{c|}{ Type of Aeration } \\
\hline & With Air & With Nitrogen \\
Methanol & 0.53 & 0.51 \\
Ethanol & 0.83 & 0.47 \\
Propanol & 0.72 & 0.56 \\
Butanol & 0.66 & 0.50 \\
\hline
\end{tabular}

Oxygen had little or no effect on the lubricity of methanol. The effect of dissolved oxygen on the other alcohols, particularly ethanol, was substantial. Preliminary work has shown that methanol has a relatively high oxidation stability. Because ethanol is more akin to a hydrocarbon, it probably has a lower oxidative stability than methanol. Theoretically the oxidation products such as peroxides and carboxylic acids cause metal corrosion, which enhances the wear process.

In conclusion, the lubricity of neat ethanol compares favorably with gasoline, but contamination with water and dissolved oxygen exacerbates the wear in ethanol more so than in gasoline. 


\section{In-Cylinder Corrosion}

Several investigations (Owens, et al. 1980; Ryan, et al. 1981; Naegeli and Owens, 1984) have shown that the operation of spark-ignition engines on methanol can cause unusually high levels of wear during warm-up conditions and cold weather operation. Test results from engines have shown that the increased wear occurs principally in the upper cylinder bore and ring areas. Surface profiles and electron micrographs of the cylinder bore and ring surfaces show that corrosion plays an important role in the mechanism.

Laboratory-scale engine tests showed that the wear rate was strongly dependent on the temperature of the oil and coolant, increasing exponentially as the temperature was reduced. Figure 5 shows the effects of oil sump temperature and fuel composition on wear in a 2.3-liter four-cylinder engine. The wear rates with unleaded gasoline and anhydrous ethanol were essentially the same, indicating that the wear problem for ethanol is not nearly as acute as it is for methanol. However, when 11 percent water was added to ethanol, there was a significant increase in the wear rate as the engine temperature was lowered. Of course, even with the water present, the wear rate for ethanol was not nearly as high as that for anhydrous methanol. Figure 5 shows that the addition of 11 percent water to methanol causes close to a three-fold increase in the wear rate. These results show that the wear problem with ethanol is of negligible proportion compared to that of methanol.

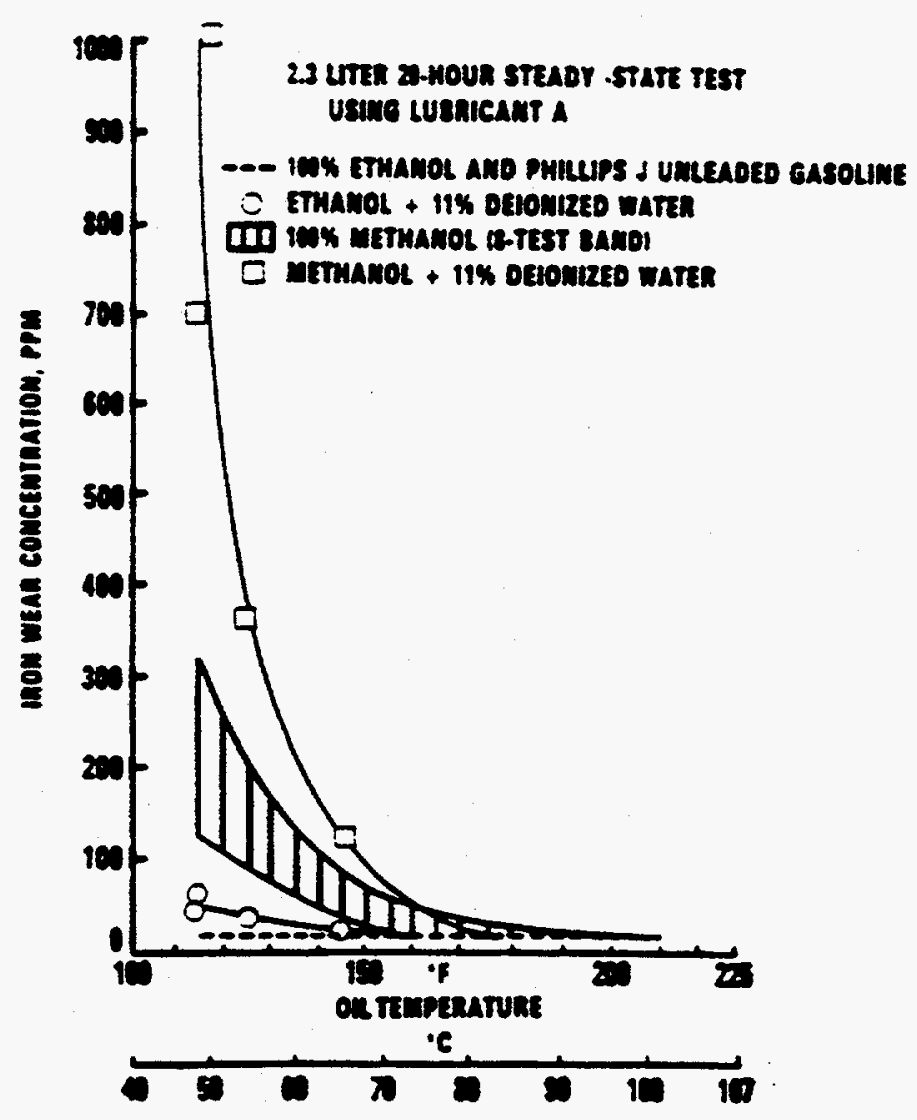

Figure 5. Effect of oil sump temperature on iron engine wear with various fuels 
The temperature dependence and the effect of water on the wear rate is explained by the theory that a liquid fuel layer forms on the cylinder wall when alcohol fuels are inducted into a cold engine. Compared to gasoline, methanol and ethanol have relatively high heats of vaporization and also higher fuel/air ratios for stoichiometric combustion, so when the engine is cold, very little of the fuel evaporates in the cylinder during the intake and compression strokes. For methanol the evaporative cooling is about twice as high as it is for ethanol, so at any one temperature, more liquid methanol is expected to accumulate on the cylinder wall. The theory of a liquid layer on the cylinder wall was supported by a simple model for the evaporation of fuel off a surface. Calculations with the model showed that the temperature dependence of the wear rate was similar to that of the evaporation rate.

In another study, Naegeli (1989) found that corrosive combustion residues were formed when shallow pools of alcohol fuels were burned in an apparatus designed to simulate the surface of a water-cooled cylinder wall. The combustion residues left on the surface consisted of water, alcohol, formaldehyde, acetaldehyde, formic acid, acetic acid, and methylene hydroxyperoxide. The amount of residue formed increased in volume as the surface temperature was lowered. As the coolant temperature was increased, there was a threshold temperature above which no combustion residue would form. The threshold temperature for methanol was about $10^{\circ} \mathrm{C}$ higher than that for ethanol, indicating that combustion residues are much more likely to form with methanol than with ethanol.

The corrosive components of the residues were formic acid, acetic acid, and methylene hydroxyperoxide. The methylene hydroxyperoxide was assumed to be formed in the liquid phase by the reaction of formaldehyde with hydrogen peroxide. Acetic acid was produced in relatively low concentrations. It was only found in the combustion residues formed by ethanol and isopropanol. Formic acid was the main cause of corrosion in both methanol and ethanol residues. However, laboratory experiments showed that methylene hydroxyperoxide greatly enhanced the rate of dissolution of iron metal by formic acid in aqueous solution. Based on initial rates of iron dissolution, the presence of methylene hydroxyperoxide increased the rate of corrosion by formic acid by an order of magnitude. Methanol residues contained about four times as much formic acid as those formed from ethanol, but the methylene hydroxyperoxide concentrations were about the same for both alcohols. Naegeli (1989) concluded that the corrosiveness of the methanol residue was about four times as great as that of ethanol residue.

In general, the engine tests showed that cylinder bore and ring wear in engines operating on anhydrous ethanol were comparable with that of engines operating on unleaded gasoline. In other words, the wear problems with ethanol are not expected to be any worse than those with unleaded gasoline if ethanol can be maintained in an anhydrous state. However, keeping ethanol dry is not a simple task. Ethanol combines with about 5 percent water to form an azeotropic mixture that cannot be separated through distillation. Removal of the water during production and preventing subsequent water adsorption during handling could add a significant cost to the fuel. It is clear that the presence of water will exacerbate the wear problem with ethanol, but it is not known with certainty that a water concentration of 5 percent is significant. In the present study the fuel is essentially anhydrous, so cylinder bore and ring wear are not expected to be a problem.

Several lubricant formulations have been developed to combat the wear problems with methanol. These lubricants are usually formulated with characteristics such as high base number and high surface adhesion. Because alcohol fuels accumulate on the cylinder wall when the engine temperature is low, there is a tendency to displace or wash the lubricant off the wall. In engines operating on methanol and ethanol, it is important that the lubricant adheres to the cylinder wall and maintains a protective film to prevent contact with corrosive combustion residues. 


\section{Oil Selection}

During this project, lubricants recommended for use in methanol-fueled vehicles were used during all testing and operation. Oil from Petrolube was selected for this project. 


\section{Task 2-Fuel Storage and Handling System Design}

\section{Objective}

The objective of this task was to evaluate material compatibility issues with ethanol and ethanol-blend fuels. This included compatibility of the fuel system with the ethanol or ethanol-blend fuels, and compatibility of the combustion system with the combustion products of ethanol. The concern about the combustion products is related to problems that have been observed when using methyl alcohol (methanol) as a fuel in spark-ignition engines.

\section{Fuel System Compatibility Issues}

Compatibility of fuel system materials with ethanol blends can be divided into two areas. First, the vehicle fuel system and its associated elastomers, plastics, and metals was considered. The second area includes all non-vehicle components, tanks, hoses, and fuel pumps. These areas are discussed below.

\section{Vehicle Fuel System}

The vehicle fuel system was reviewed and potential material compatibility problems were identified. The system can be broken down into several subsystems or components: fuel tank filler cap, fuel tank filler pipe, three fuel filters, fuel lines, fuel pump, fuel vapor valve, fuel pressure regulator, fuel injectors, and a flexiblefuel sensor. All of these items are methanol-compatible and appeared to be compatible with ethanol. These items and associated material are discussed below.

\section{Fuel Tank Filler Cap}

Plastic component with an elastomeric seal to maintain fuel tank pressure and control evaporative emissions.

\section{Fuel Tank Filler Tube}

Metal construction that is coated internally to prevent corrosion. No problems were noted when using the Ed-85 fuel blend.

\section{Fuel Filters}

There were three fuel filters in the system. There was an in-line filter downstream of the fuel pump, mounted to the underbody. There was an in-tank fuel filter made of nylon. Fuel was also filtered at the injector using a metal screen.

\section{Fuel Lines}

The fuel lines on the flexible-fuel vehicle were composed of nylon/stainless steel combination with steel pushconnect fittings. These fittings use special methanol-compatible o-rings. One o-ring was made of GFLT Viton and the second o-ring was made of fluorosilicone. 


\section{Fuel Tank}

The fuel tank was composed of high density polyethylene with a fluorinated interior surface. The fluorinated surface was resistant to methanol and ethanol. This fuel tank material is likely to be more permeable to fuel vapor than a metal tank or a multilayer coated-metal tank. Permeability is a major issue with regard to the enhanced evaporative emission standards enacted recently by the California Air Resources Board (CARB) and the U.S. Environmental Protection Agency. The fuel tank was connected to the fuel system using nitrile hoses. These hoses, while compatible with ethanol, may also be a source of evaporative emissions.

\section{Fuel Pump}

The fuel pump for the flexible-fuel vehicle was rated at $145 \mathrm{~L} / \mathrm{hr}(38 \mathrm{gal} / \mathrm{hr})$ at $39 \mathrm{psi}$. It had a nylon filter on the pickup in the fuel tank and a check valve of undetermined composition at the outlet. The check valve maintained fuel line pressure for a period of time following engine shutdown to assist in rapid engine starting. The pump is mounted to the fuel tank and this connection is sealed with a gasket material.

\section{Fuel Sending Unit}

The fuel sending unit was expected to be compatible with ethanol fuels, and no problems were observed.

\section{Fuel Vapor Valve}

The fuel vapor valve was expected to be compatible with ethanol fuels, and no problems were noted.

\section{Fuel Pressure Regulator}

The pressure regulator was a spring-loaded diaphragm-type regulator. The diaphragm material was a nitrilecoated nylon. The inlet of the regulator connects to the fuel supply line with an o-ring connection.

\section{Fuel Injectors}

There were multiple o-rings used in the fuel injector body and in the connection of the fuel lines to the injectors. These o-rings were primarily GFLT Viton. The majority of fuel-wetted components appeared to be stainless steel and posed no compatibility problem with ethanol fuels.

\section{Ethanol Fuel Distribution, Storage, and Dispensing}

At the kickoff meeting for this project between the National Renewable Energy Laboratory (NREL) project officer and Southwest Research Institute (SwRI) staff, it was decided that this part of the fuel infrastructure system would be excluded from the experimental part of the effort. However, it was recognized as being an important part of the successful use of ethanol, and warrants discussion of the various parts of the system with which ethanol must interface.

To most consumers, the storage, transportation, and distribution system for fuels is largely transparent. This contrasts with exploration and production which has drilling rigs and publicity about shortages and new discoveries, and fuel processing its very visible refineries. Our exposure to the distribution infrastructure is from the seemingly endless number of gasoline refueling stations. However, what we see as the "gas station" is the final component of a highly developed system that gets the product from the point of production to the marketplace. Therefore, if ethanol is to live up to its promise as an alternative fuel that can easily fit into the present liquid fuel system, each component of the system needs to be examined to determine potential weaknesses in its interaction with ethanol. 
The following is a brief description of links in the finished fuel transportation and distribution chain to provide a perspective for the point at which a dedicated ethanol system can be blended into the existing system. At this point, the discussion will not be comprehensive; this is intended only to provide a general overview.

\section{Refinery Storage}

Finished product is stored in large tanks usually having a steel/product interface and enclosed to prevent weathering. Venting can allow breathing to occur, although tank farms are being upgraded for vapor control and recovery. The product must be compatible with the associated piping and pumping equipment and tanks are not necessarily dedicated to a specific product. Insertion of ethanol into the system would probably not occur at this point unless final blending with a hydrocarbon component could most economically be achieved here. Personnel are trained for the specific job, safety, and quality.

From the refinery, fuel is transported to a bulk terminal near the final point of use. Several transportation systems may be employed, including pipeline, ship, barge, train tank car, and tanker truck. These systems are composed of a range of materials, and compartment space is not dedicated to a specific product. Personnel may range in capability and concern, but are generally trained for specific job requirements, safety, and quality.

\section{Bulk Terminal}

At the bulk terminal, the fuel is again stored in large, steel tanks. Because most bulk terminals are in the vicinity of large populated areas, tanks are configured with systems for vapor control. Dedicated product tanks are often used, although this may change depending on the season and product demand. Because systems are automated to reduce personnel requirements, products must be compatible with various sensors. Final blending with additives is usually accomplished at this point, and is also automated. Personnel range in skills and training. From this point, fuel may be transported to the bulk storage plant of an independent distributor or marketer, or, if in a large urban area, directly to the service station.

\section{Distributor}

The distributor system handles well over 50 percent of all the fuel sold in the United States. Transportation to the distributor bulk plant is usually by tank truck, although large distributors may be serviced by any of the other transportation systems as well. Final blending of additives into a fuel for specific customer needs (particularly true with diesel fuels) is accomplished at this point. Employee skill level and job/product knowledge are large variables. Transportation from the distributor to the service station is usually by transport truck (also from terminal to service station) although deliveries in rural areas may be made with sinaller tank vehicles (bobtails). Dedicated product compartments are not used due to cost of delivery and flexibility required.

\section{Service Station}

Although "service" is no longer available at the majority of the refueling points, this terminology continues to be used. Equipment found at the point of sale can range dramatically from sophisticated vapor recovery at the storage tank and dispensing point, utilizing storage tank materials and lines of fiberglass, to atmospheric vented drops into steel tanks connected to the dispensers with steel lines. In some of the older (1970s) installations, copper lines were used along with suction pumps for the dispenser. Dispensers range from single hose suction pumps to multi-product dispensers (MPDs) fed by fuel pumps in the underground tanks. Dispenser hoses are variations of rubber with a continuous wire for grounding and the nozzle is largely aluminum. In these systems, examples of most engineering materials, in some form, can be found. Tank/product housekeeping varies widely from station to station, as do contamination risks. Personnel that 
interface with these systems are the least well trained of any in the system because they include not only the employees of the station (often entry level positions), but also the consumer. Therefore, education requirements for special handling of a fuel should be kept to a minimum at this point.

In summary, the distribution system is not "high technology," but a fuel within its bounds can experience a wide variety of materials, co-mingling and contamination opportunities, and human error. Before inserting ethanol into this system, its point of entry and potential interfaces need to be more fully explored.

\section{Effect of Enhanced Evaporative Emissions}

Because of the new enhanced evaporative emissions regulations, many fuel line components used in current flexible-fuel vehicles (FFVs), such as the 1993 Ford Taurus FFVs purchased for this project, will not be suitable in future vehicles. For example, fuel lines and elastomers in o-rings in current FFVs have high enough permeability that they will not pass the enhanced evaporative emissions test, according to Ford engineers. Therefore, durability testing with these components, as originally proposed, was no longer suitable. The new materials that will pass enhanced evaporative emissions standards were either still being developed or were proprietary, and were not available for testing. This section summarizes some areas where new materials are required.

Ford staff members were consulted about materials currently used in the Taurus FFV and material changes Ford is making to meet the enhanced evaporative emission standards. Most current materials are unsuitable for the more stringent requirements of the enhanced evaporative standard, and Ford is replacing them with more suitable materials. Several areas are discussed below.

The current fuel tank is a high-density polyethylene with a fluorinated interior surface. This tank will not meet the new standards, and future vehicles will be fitted with a metal tank that may be coated with a plastic or polymer.

Flexible fuel lines used to connect the fuel tank to the fuel lines are a potential problem for evaporative emissions. To be crash worthy, these lines must be flexible and have 150 percent elongation. Many materials that have the flexibility are permeable and sources of evaporative emissions.

Fuel line connectors are sealed using Viton o-rings with a high fluorine content. These o-rings have permeability problems. Ford was investigating several materials to replace viton in the fuel system. At this time these materials are proprietary.

O-rings and seals currently in the fuel system were acquired for compatibility testing. Data for elastomer swell for many of the materials were found, and were included in the design report (Bourn et al. 1994).

The enhanced evaporative standard is apparently forcing the use of new materials. Therefore, the value of testing the current materials is unclear. Two components that often give trouble in FFVs are the fuel pumps and the fuel injectors. Although occasional problems have been reported in earlier FFVs when the vehicles are operated on methanol (for which the fuel system was designed), very few problems have been reported with ethanol.

\section{Fuel Injector Wear Testing}

For the above reasons, the focus of the durability testing for this task shifted from overall fuel system durability testing to testing fuel injectors and fuel pumps. The interest in testing the fuel pumps was strictly durability, but the interest in testing the fuel injectors was both fuel leakage and injector performance degradation. There is concern about leakage past the fuel injector seats in gasoline-fueled engines when the engine is turned off 
and the fuel line remains pressurized. The line must remain pressurized to avoid vapor lock (fuel boiling in the line during heat soak-back). Any fuel leaking past the valve seat collects in the intake port and manifold, and introduces a large hydrocarbon spike on the next start-up. This cannot be corrected with fueling strategy, because the amount of leakage is unknown and the engine must be fueled sufficiently to start on the first cylinders to receive fuel.

Researchers must determine whether the ethanol fuel injectors begin to leak more after some usage, and whether they are better or worse than gasoline injectors in their leakage and wear characteristics. A test plan, based on SAE Procedure J1832, was developed in Phase 2 for these tests. The testing was conducted during Phase 3. The SAE procedure provides some guidelines for performing the injector leak rate test, but it also leaves significant room for variations in test procedures between different laboratories.

Several industry sources have suggested that alcohol fuels can affect the durability and performance of fuel injectors. In particular, injectors have been subject to erosion and wear of the nozzle seat and orifices resulting in variation in fuel flow and injector leakage.

SAE Standard J1832 specifies test procedures for evaluating gasoline fuel injectors. It covers all aspects of the fuel injectors, including spray distribution and coil dynamics, but only the static flow rate, the dynamic flow, and the seat leakage rate are typically of interest for durability experiments. The static flow rate is the maximum flow of the injector, and is achieved when the injector is energized in the fully open position. The dynamic flow is the measured fuel delivered per pulse of the injector when energized at $2.5-\mathrm{ms}$ pulse width (PW) and a 10-ms period.

Field and engine tests have shown problems using some injector designs. For that reason, durability tests were conducted with six Nippon Denso injectors used as original equipment in the 1993 Ford FFVs. The fuel injectors were identified as injectors for a 1993 Ford FFV, injector no. F3DE-A2C, F3DZ-9F593-AFFV, CM4753, 2561-272, made by Nippon Denso for Ford. Evaluation of the fuel injector durability was performed in accordance with SAE J1832. The performance criteria to evaluate the injector performance are the nozzle flow rate and the seat leakage. A schematic of the durability test rig is shown in Figure 6. A Ford fuel rail was used to mount six injectors on a 5-gal fuel container. A standard fuel pump used in the FFV was used to recirculate the fuel and to supply the fuel rail with $270 \mathrm{kPa}$ fuel pressure. A heater and heat exchanger were used to control the temperature of the test fuel. An injector driver box was used to energize the injectors.

The seat leakage test was performed by using the following procedure. The injectors were cleaned with heptane by supplying the injectors with heptane at $270 \mathrm{kPa}(39 \mathrm{psig}$ ) and running the injectors for 10,000 injections at a pulse width of $5 \mathrm{~ms}$ and a period of $10 \mathrm{~ms}$. The injectors were then dried with nitrogen in a similar manner for 6000 injections with the tip pointed down and 6000 injections with the tip pointed up. The seat leakage tests were then tested by placing the injector in the apparatus shown schematically in Figure 7. Nitrogen is supplied to the nozzle at $270 \mathrm{kPa}$ and any leakage is contained in the graduated cylinder filled with mineral oil. The leakage is recorded for a 5-minute period.

The static and dynamic flow rates were determined gravimetrically using injector calibration fluid and spraying into a container of known weight. For the static flow rate the injector was energized continuously for a period of $30 \mathrm{~s}$. After $30 \mathrm{~s}$, the container was weighed to determine the mass of test fluid injected.

The dynamic flow rate measurement was also gravimetric using injector calibration fluid. The injector was supplied with $270 \mathrm{kPa}$ fluid pressure and was energized intermittently using a pulse width of $5 \mathrm{~ms}$ and a period of $10 \mathrm{~ms}$ for a duration of 1000 injections. The injected fluid was collected in a container and weighed to determine the mass injected. 


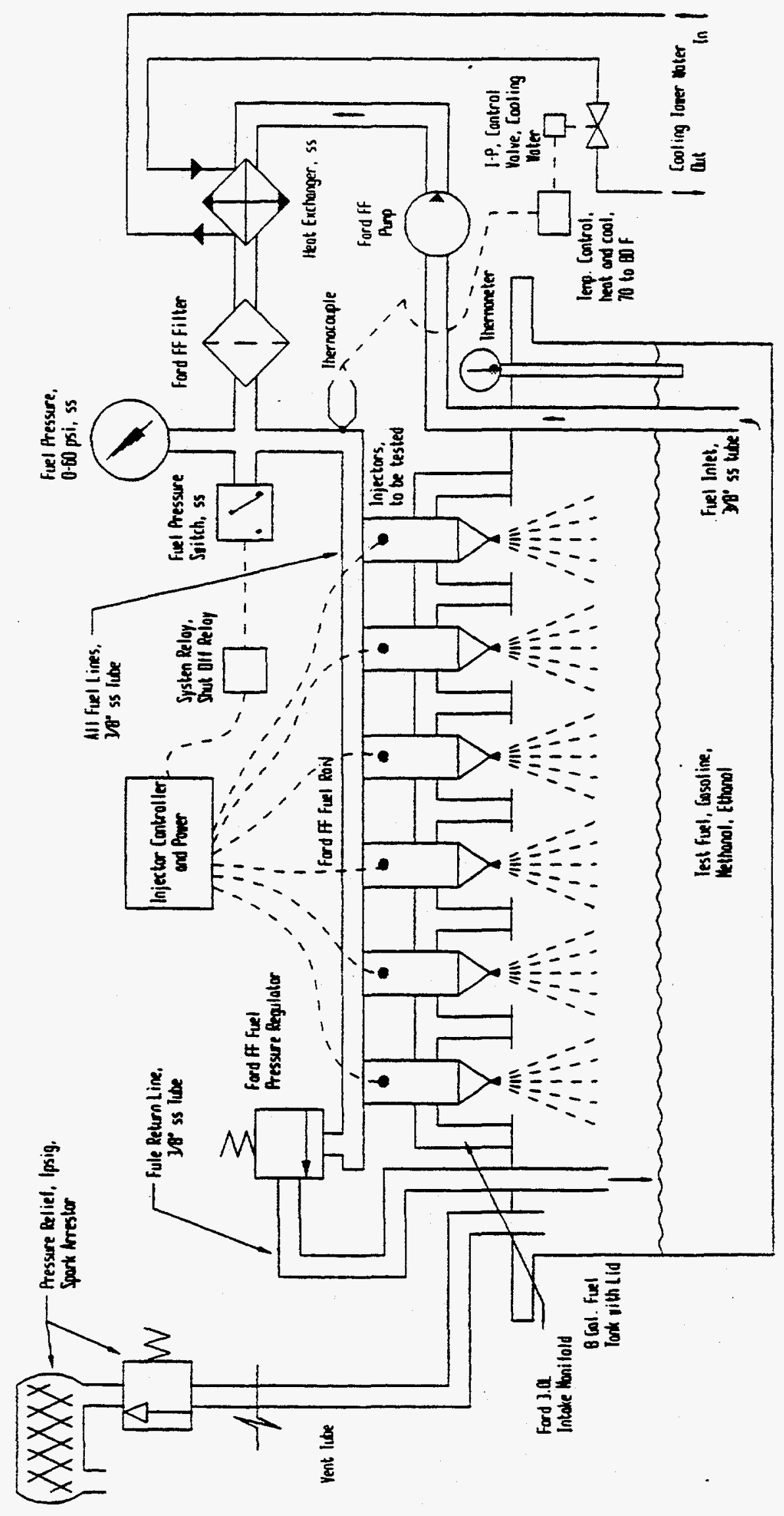

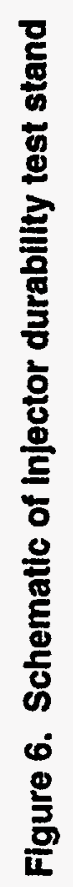




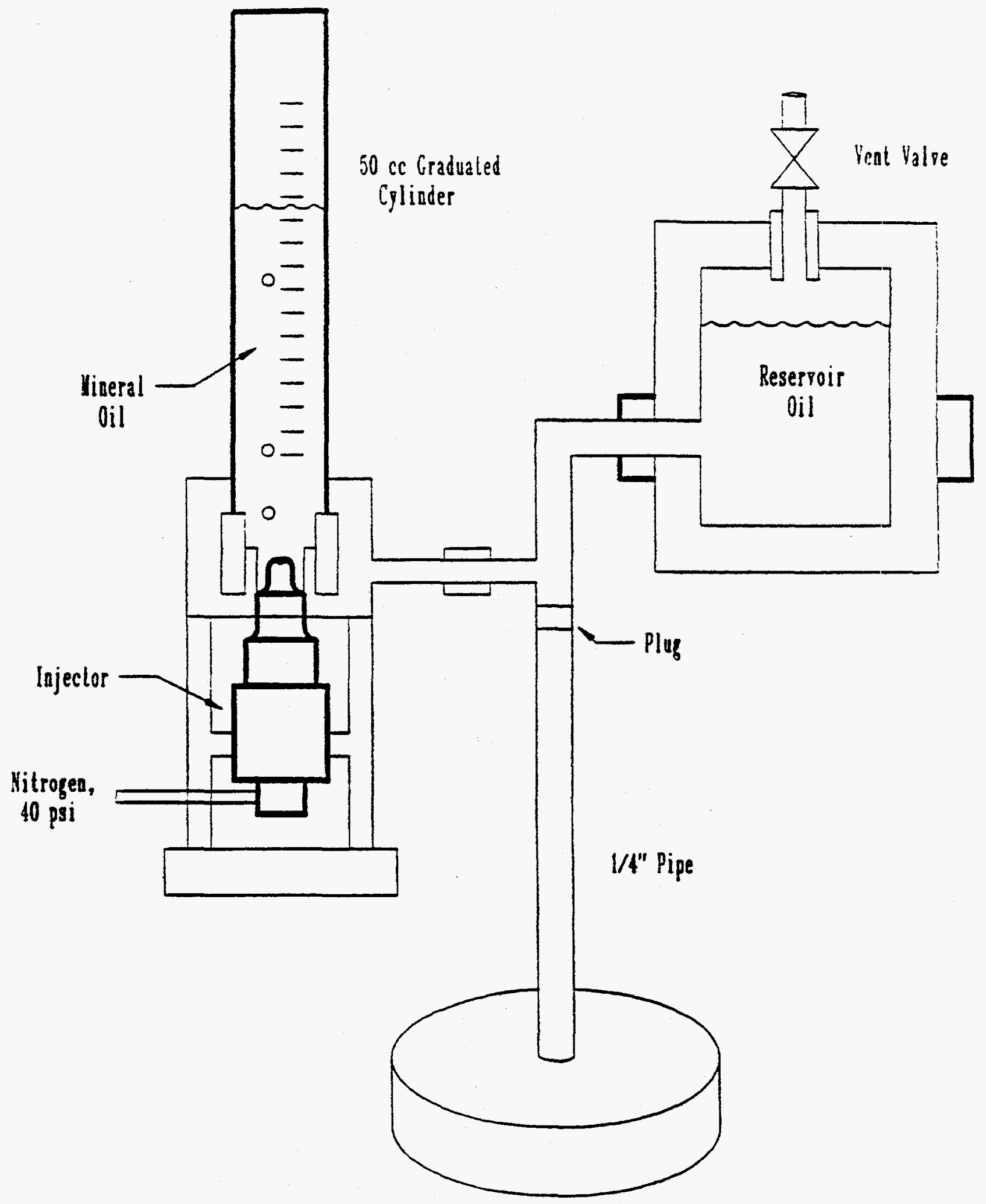

Figure 7. Seat leakage test apparatus 
In all, 1124 hours were accumulated on the injectors, representing approximately 800 million injections. The results for the static and dynamic flow rates are shown in Figure 8 as a function of test time. The plot shows the average of the six test injectors and a control injector with a error bar representing $+/$ - one standard deviation.

For the static flow rate test, there was a shift in the measured values at the start of the testing (time 0 ) and the measured values after testing had begun (time $>0$ ). This shift is attributed to a modification of the test procedures. The initial test was performed with a hand held stop watch; the remaining tests were performed with an automatic timer. The procedure requires the injectors to be flowed for a period of $30 \mathrm{~s}$. A 1-s difference between the two timing methods would result in a 3 percent difference in fuel mass. The shift observed in the measured values was approximately 3 percent. As shown, with the exception of the initial shift in static flow, there did not appear to be major changes in either the dynamic or the static flow of the injectors.

The seat leakage was also measured for all of the injectors throughout the test. The initial test indicated that two out of the six test injectors and the one control injector had measurable seat leakage levels. One injector had a seat leakage value of $1.0 \mathrm{cc} / \mathrm{min}$ and a second injector had a value of $0.5 \mathrm{cc} / \mathrm{min}$. Both of these injectors were below the acceptable limit of $1.5 \mathrm{cc} / \mathrm{min}$. The remaining injectors had no measurable leakage. It was interesting to note that after 53.8 hours of testing (approximately 38 million injections), that all injectors had a negligible level of seat leakage indicating that a small amount of running improved the sealing capability of the injectors. None of the injectors developed seat leakage during the duration of the test.

Thus, although fuel injector wear and leakage has been a significant problem with the methanol-fueled vehicles in the past, the improved injector design and/or the use of ethanol fuels has resulted in no injector wear and no injector leakage. The E100 used for these tests was very low in water content. It may be that water is a crucial contaminant of the alcohol fuels that leads to wear. Discussions with others involved in testing ethanol injectors for wear have indicated that elevated fuel temperatures may also be critical in the alcohol wear problem. For the tests reported here, SAE J1832 recommendations were used to set the fuel temperature to $20^{\circ} \mathrm{C} \pm 1{ }^{\circ} \mathrm{C}$. 


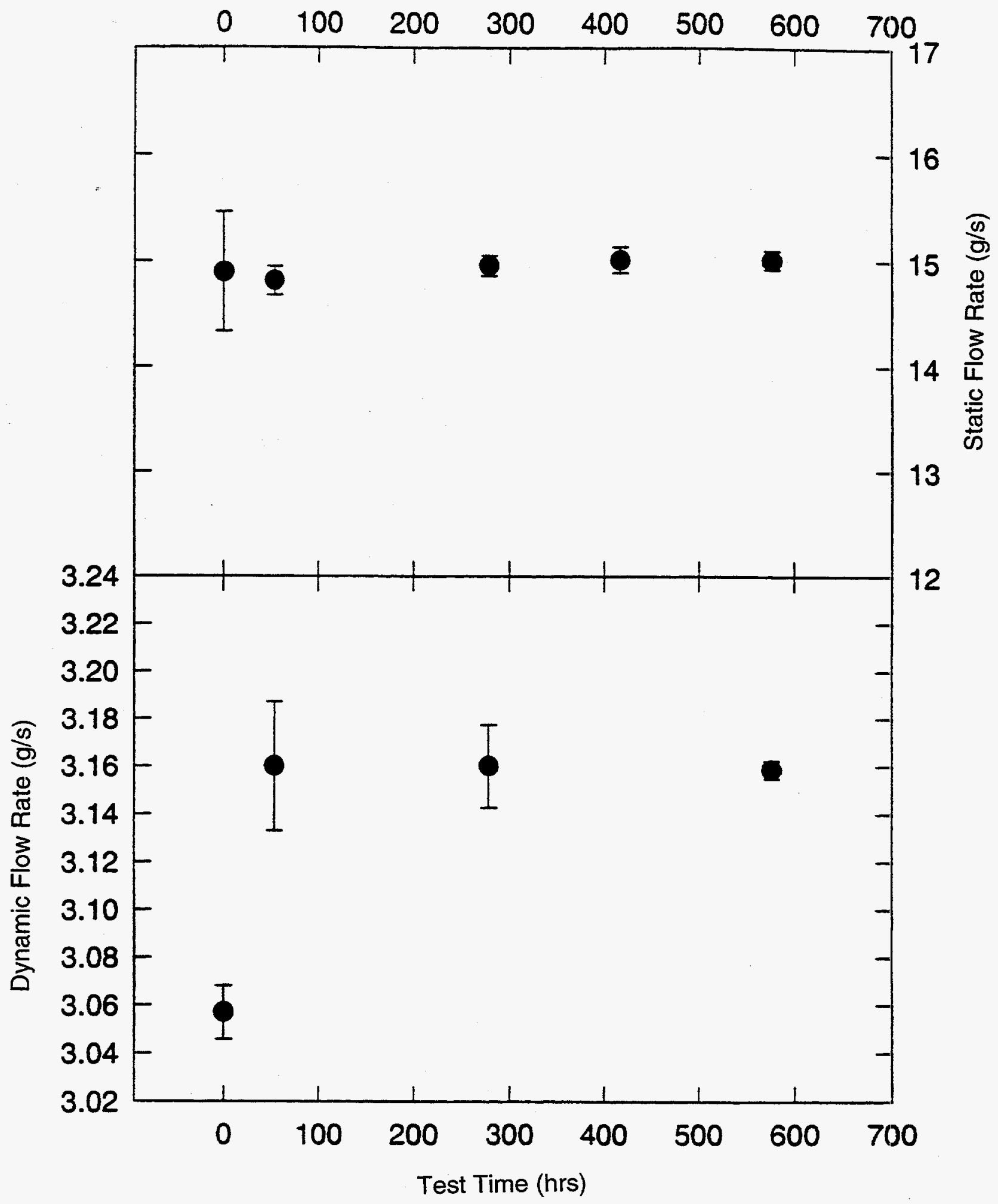

Figure 8. Fuel injector durability test results, E-100 (neat ethanol) static and dynamic flow rates versus test time 


\section{Task 3-Engine System Assembly and Testing \\ and \\ Task 5-Fuel/Engine/Vehicle System Integration \\ and \\ Task 6-Integrated Fuel/Engine System Optimization}

\section{Objectives}

During Phases 3 and 4 of this project, Task 3 for engine modifications, Task 5 for system integration, and Task 6 for the integration of the fuel/engine and system optimization overlapped heavily. For that reason, the results of these three tasks are reported in this one section. There were several objectives of these three tasks, but basically they were all directed at modifying engine hardware and then calibrating the engine for good performance and low emissions to meet ultra-low emission vehicle (ULEV) emissions standards. These objectives included: (a) improvements in the air-assist injectors to improve air-fuel ratio control under steadystate conditions; (b) replace the original equipment manufacturer (OEM) engine controller (Ford EEC IV) with a SwRI Rapid Prototyping Engine Control System (RPECS) so provide flexibility to change control algorithms; (c) develop a cranking and start-up strategy that would provide rapid starts at any temperature, and in doing so, minimize hydrocarbon emissions associated with misfires; (d) implement model-based control in the RPECS to compute air and fuel flow into the cylinders for optimum air-fuel ratio control under steady-state and transient conditions; (e) develop various other engine control strategies to take care of closed-loop engine control and specialized parts of the cycle; and (f) develop an rapid exhaust port oxidation system and control algorithms to obtain rapid catalyst light-off with a minimum of added equipment. Details of how these objectives were met are provided below. Emissions test results are provided under Task 4.

\section{Introduction}

Two OEM vehicles were obtained for this project, one for testing advanced aftertreatment devices and one for the demonstrator vehicle to be used to meet ULEV standards. Both vehicles were purchased as nominally identical 1993 Ford Taurus FFVs. One vehicle was used exclusively to test advanced aftertreatment devices but was otherwise configured as an OEM vehicle. The second vehicle had major engine and control system modifications and was developed as the demonstrator vehicle. Two vehicles were used so that testing of aftertreatment systems and engine modifications could be conducted in parallel. The advanced aftertreatment tests are described in the Task 4 section of this report. The modifications to the engine and controls are described in this section.

Modifications to the vehicle were made for the following purposes. First, because the vehicle was to be a dedicated ethanol-fueled vehicle, the engine was modified to take advantage of the high octane number of ethanol fuel. Second, modifications were made to the fuel injection system and the hardware and software systems to improve the cranking and cold-engine performance, and to more rapidly heat the exhaust gas catalyst. Finally, changes were made to improve air:fuel ratio control in terms of both speed and accuracy and exhaust gas recirculation (EGR) control during warmed up performance.

Specific modifications to the vehicle included the following:

(1) Increased the compression ratio from about 9.27:1 to 11.0:1 to take advantage of the high octane number of the ethanol and to improve the thermodynamic cycle efficiency of the engine 
(2) Changed fuel injectors from standard pintle injectors to fine-spray air-assist injectors to provide more rapid starts and better cold engine performance with the ethanol fuel

(3) Replaced the standard Ford ignition timing device with an optical shaft encoder from a GM LT-1 engine, that included four distinct low-resolution timing marks in place of the normal one for faster engine crankshaft synchronization with the engine control system

(4) Replaced the standard OEM Ford EEC controller with an SwRI RPECS with cylinder-event based logic for cranking and startup, with model-based air flow and a MAP observer for accurate estimates of air flow into the engine, and with model-based fuel flow to account for intake port wall wetting

(5) Replaced the OEM idle air control (IAC) valve with a General Motor (GM) EGR valve with pintle position feedback to provide more accurate control of the IAC valve to avoid misfires on decelerations and better control during idle

(6) Replaced the OEM EGR valve with a GM EGR valve with pintle position feedback for more accurate control of the EGR flow rate

(7) Added a rapid exhaust port oxidation system, consisting of operating the engine rich when cold and adding air at the exhaust ports to oxidize unburned fuel and add heat to the catalysts for rapid activation

Each of these modifications is discussed below in the order listed above. Other information is also provided in two SAE papers included as Appendices, Appendix A, "Model-Based Control and Cylinder-Event-Based Logic for an Ultra-Low Emissions Vehicle" and Appendix B, "Development of an Ethanol-Fueled Ultra-Low Emissions Vehicle."

\section{Increase in Compression Ratio}

The compression ratio of the Ford 3.0-liter Vulcan engine was increased from about 9.27 to 11.0 to take advantage of the high octane number of the Ed-85 $(\sim 102(\mathrm{R}+\mathrm{M}) / 2)$ fuel and to improve the efficiency of the engine. Using SwRI's ALAMO_ENGINE code, the compression ratio increase was calculated to improve the efficiency by about 5.3 percent. The efficiency gain would be best exploited by taking advantage of the increase in maximum power with the higher compression ratio, and reducing the displacement of the engine in the same amount. However, reducing the engine size was not practical.

The higher compression ratio improved efficiency, but also increased emissions. Therefore, it made ULEV emissions more difficult to achieve. This increase in compression ratio was predicted to increase the hydrocarbon emissions by about 26 percent to 41 percent (Russ, et al., 1995; Cook, et al., 1994; Hamrin and Heywood, 1995), and the $\mathrm{NO}_{\mathrm{x}}$ emissions about 11 percent (from calculations using SwRI's ALAMO_ENGINE computer model).

The high octane number and latent heat of evaporation for ethanol permits a higher knock-free compression ratio than that of gasoline. Compression ratios listed in the literature for dedicated alcohol (ethanol and methanol) engines in automotive applications range from standard gasoline to 13:1 with an average of 11.01:1. In determining the compression ratio for a ULEV engine, the potential increase in $\mathrm{NO}_{\mathrm{x}}$ and hydrocarbon emissions are more of a limiting factor than detonation. 
Increasing the compression ratio can be achieved by reducing the cylinder volume at top dead center (TDC) by installing only a domed piston, reducing the combustion chamber volume by machining the cylinder block and head, or a combination of both. The installation of a domed piston is a simple and cost-effective means of increasing the compression ratio, but is undesirable as the dome will cause a disruption in the flame propagation and increase the surface-area-to-volume ratio of the combustion volume. A domed piston configuration, compared to a flat-face piston, will increase the hydrocarbon-rich quench layer on the piston face and quench volume between the cylinder wall, piston crown, and first compression ring.

J.B. Heywood (1972) in a study of hydrocarbon mass flowrate states that 50 percent of the hydrocarbons in the exhaust escape near the end of the exhaust process due to the exit of a hydrocarbon-rich vortex, and 40 percent escape early in the exhaust process because of the exit of a head quench layer. Changes in the combustion chamber shape and volume may affect the head quench layer.

The original 3.0-liter piston had a flat face and will not inhibit the flame kernel convection, which is dominated by the tumble charge motion induced by the squish area of the combustion chamber (Hinze and Cheng, 1993). The velocity of the tumble charge will be increased with a reduced piston-to-cylinder-head clearance. Removing the volume between the piston face and cylinder block deck also reduces the quench volume and surface-area-to-volume ratio. The piston face quench layer and surface area is less on a flat-face piston compared to a domed piston design.

Reducing the volume of the cylinder head combustion chamber can be achieved by milling the gasket surface of the head. The thickness to be removed for a specific volume reduction is governed by the geometry of the combustion chamber.

Figure 9 shows the dimensions of the Ford 3.0-liter reciprocating components and combustion chamber. Table 10 shows the calculated new dimensions for increased compression ratios. The piston face-to-block deck clearance was $0.493 \mathrm{~mm}(0.0194 \mathrm{in}$.), which was reduced by milling the block surface, achieving a zero deck height and removing $3.07 \mathrm{cc}(0.187 \mathrm{ci})$ from the clearance volume. The original cylinder head combustion chamber volume was measured to be $49.6 \mathrm{cc}$ ( $3.03 \mathrm{ci})$ and Table 10 gives compression ratios corresponding to volume removed from the chamber. Calculations were performed for reducing the clearance volume by machining the cylinder head and block gasket surfaces the maximum safe amount. Valve-tocylinder block interference will occur if the head is machined to too great an extent and the potential for cylinder head failure will exist. The calculations are approximate as the volumes of reliefs cut into the cylinder bore to eliminate shrouding the valves were not accounted for.

Table 10. Ford 3.0-Liter Flexible-Fuel Vehicle Cylinder Modifications

\begin{tabular}{|l|c|l|c|}
\hline \multicolumn{2}{|c|}{ Original Dimensions } & \multicolumn{2}{c|}{ Modified Dimensions } \\
\hline Combustion Chamber Volume & $48.56 \mathrm{cc}$ & Mill Head $0.71 \mathrm{~mm}(0.028 \mathrm{in})$. & $45.06 \mathrm{cc}$ \\
\hline Head Gasket Volume & $7.69 \mathrm{cc}$ & & $7.69 \mathrm{cc}$ \\
\hline Piston-to-Deck Volume & $3.07 \mathrm{cc}$ & Mill Block $0.49 \mathrm{~mm}(0.019 \mathrm{in})$. & $0 \mathrm{cc}$ \\
\hline Ring Crevice Volume & $0.58 \mathrm{cc}$ & & $0.58 \mathrm{cc}$ \\
\hline Valve Relief Volume & $0.34 \mathrm{cc}$ & & $0.34 \mathrm{cc}$ \\
\hline Piston Dome Volume & $0 \mathrm{cc}$ & $1.01 \mathrm{~mm}(0.040 \mathrm{in}$.$) height$ & $-4.0 \mathrm{cc}$ \\
\hline $\begin{array}{l}\text { Clearance Volume } \\
\text { Swept Volume }\end{array}$ & $\begin{array}{c}60.24 \mathrm{cc} \\
498.13 \mathrm{cc}\end{array}$ & & $47.42 \mathrm{cc}$ \\
\hline
\end{tabular}


A maximum compression ratio of approximately $10.4: 1$ was achieved by the machining procedures alone. The target compression ratio of 11:1 was achieved by the addition of pistons with a small dome volume of $4.0 \mathrm{cc}$ $(0.244 \mathrm{ci})$. The combination of cylinder head and block machining and pistons with a very small dome allowed for the desired compression ratio for increased engine efficiency while minimizing the quench volume.

\section{Air-Assist Injectors}

The main purpose of the air-assist injectors was to improve start-up and transient performance by improving fuel transport from the injectors to the cylinders. The air-assist injectors produce smaller drops than the OEM pintle injectors. This improves fuel transport in two ways. First, because evaporation rates scale as the square of the drop sizes, reducing drop sizes by, for example, a factor of two increases evaporation rates by about a factor of four. Second, the smaller drops tend to follow the air stream through the port, past the intake valves, and into the cylinder. If the drops are small enough, they will evaporate during the compression stroke of the engine. This reduces intake manifold wall wetting, and reduced wall wetting improves engine performance during cranking and engine transients in speed and load, especially when the port walls and intake valves are cold. The air-assist injectors were made by adding a fuel-air mixing cap onto the OEM pintle injectors that were designed to handle alcohol fuels. The design of the first-generation caps is shown in Figure 10. The combination of the cap and the pintle injector is shown in Figure 11. Good cranking and transient performance were observed with the first-generation air-assist injectors. 


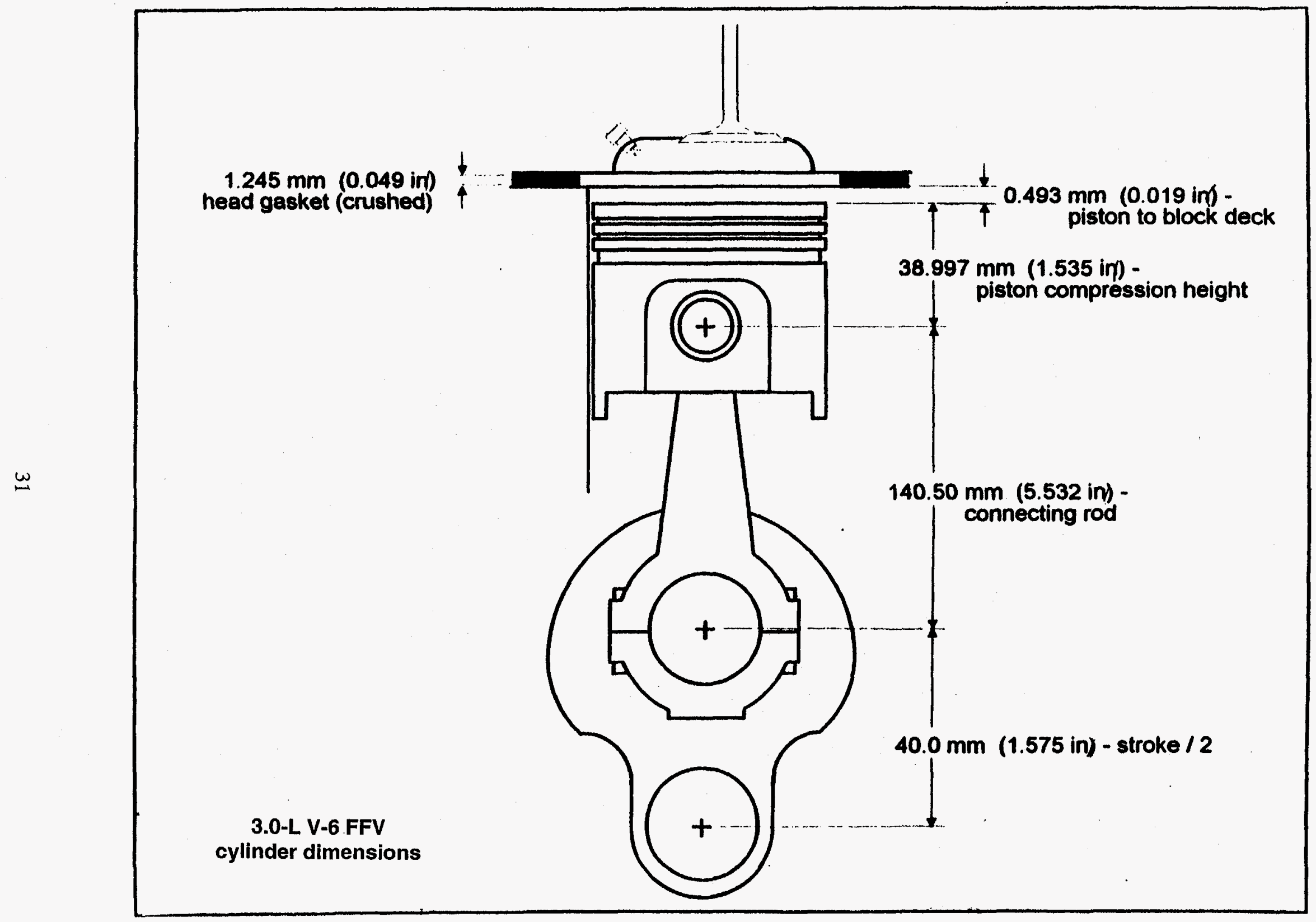

Figure 9. Piston and combustion chamber for Ford Taurus 3.0-liter V-6 


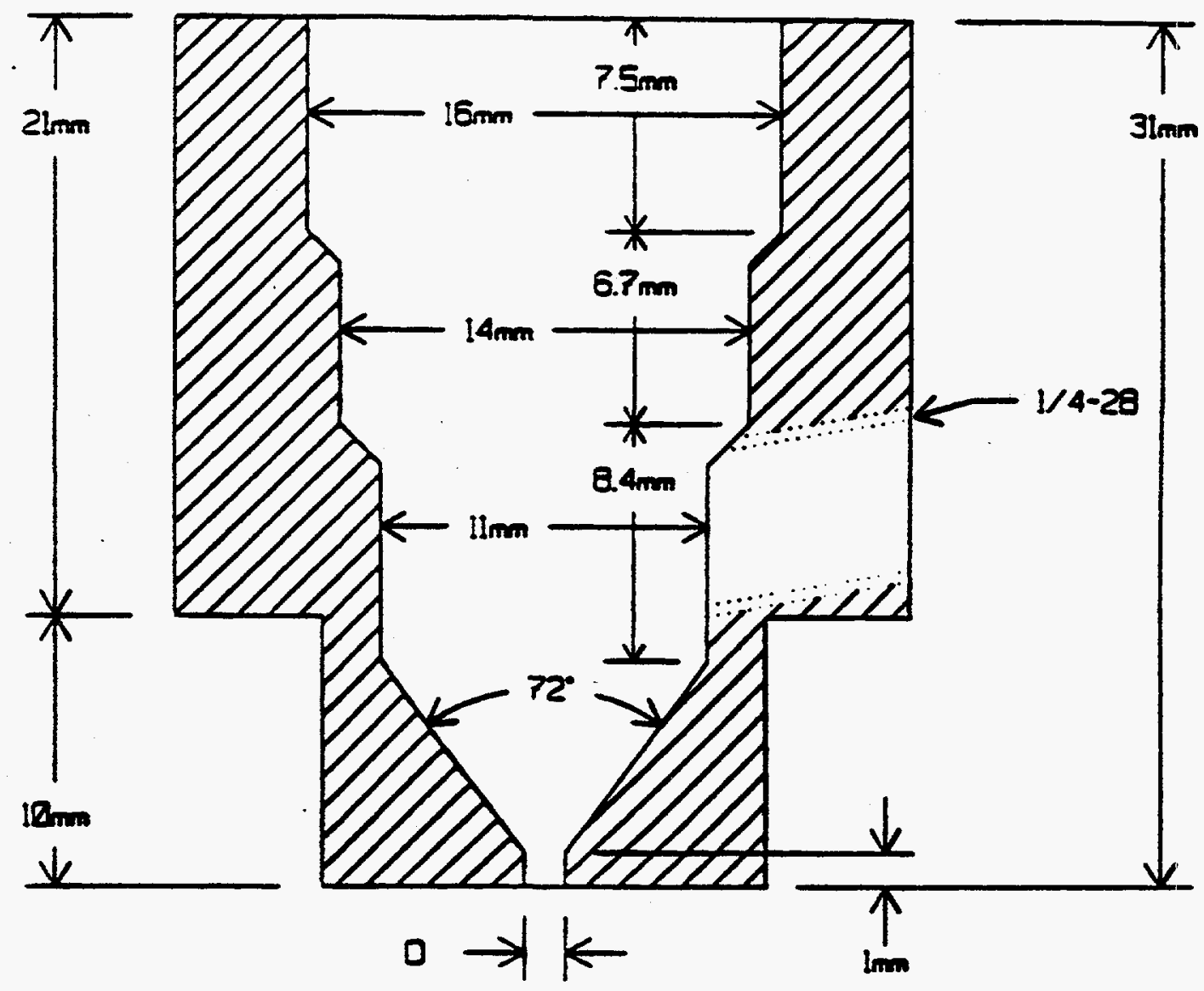

3 INUECTOR CAPS:

$\square=1.0 \mathrm{~mm}$
$\square=1.41 \mathrm{~mm}$
$\square=2.0 \mathrm{~mm}$

Figure 10. SwRI internal mix, air-assist injector caps 


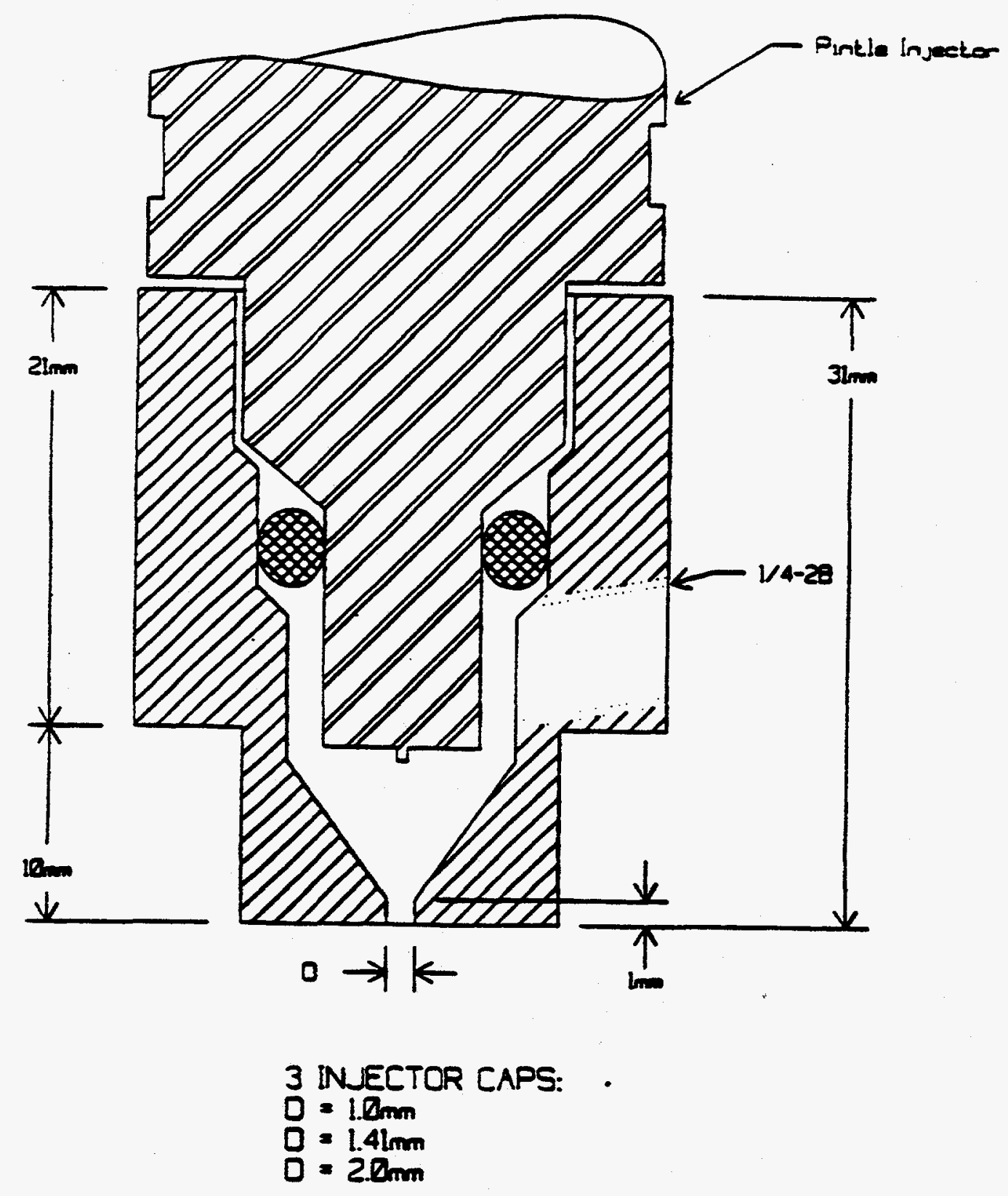

Figure 11. SwRI internal mix, air-assist injector cap mounted on conventional pintle injector

However, the performance of the first-generation air-assist injectors at steady-state conditions was found to be unacceptable in terms of maintaining a very stable air-fuel ratio. The air-fuel ratio measured by a heated exhaust gas oxygen (HEGO) sensor showed relatively high-frequency variations that were significantly larger for the first-generation air-assist injectors than for the OEM pintle injectors. As a result, the air-assist injector caps were redesigned as second-generation caps to reduce the air-fuel mixing volume and the residence time, while maintaining a single $1-\mathrm{mm}$ exit hole diameter. 
The performance of the OEM pintle injectors, the first generation air-assist injectors, and the redesigned or second-generation, air-assist injectors are compared in Figure 12 for the OEM injectors, in Figure 13 for the first-generation air-assist injectors, and in Figure 14 for the redesigned, second-generation, air-assist injectors. The engine conditions were the same for all these tests, $32^{\circ} \mathrm{C}$ coolant temperature, $1500 \mathrm{rpm}$, and $30 \mathrm{kPa}$ intake manifold pressure. The engine was operated open loop with no load and constant commanded fuel injection pulse width. The air-fuel (A/F) ratio control for the first-generation air-assist injectors showed high variability at this and most other conditions. The redesigned air-assist injector performed better than the firstgeneration air-assist injectors and better than the OEM pintle injectors at the $32^{\circ} \mathrm{C}$ condition in terms of stable air-fuel ratio control. At warmed up engine conditions, the air-fuel ratio control was better for all the injectors than at the cold coolant conditions, but the second-generation air-assist injectors still provided the most stable control.

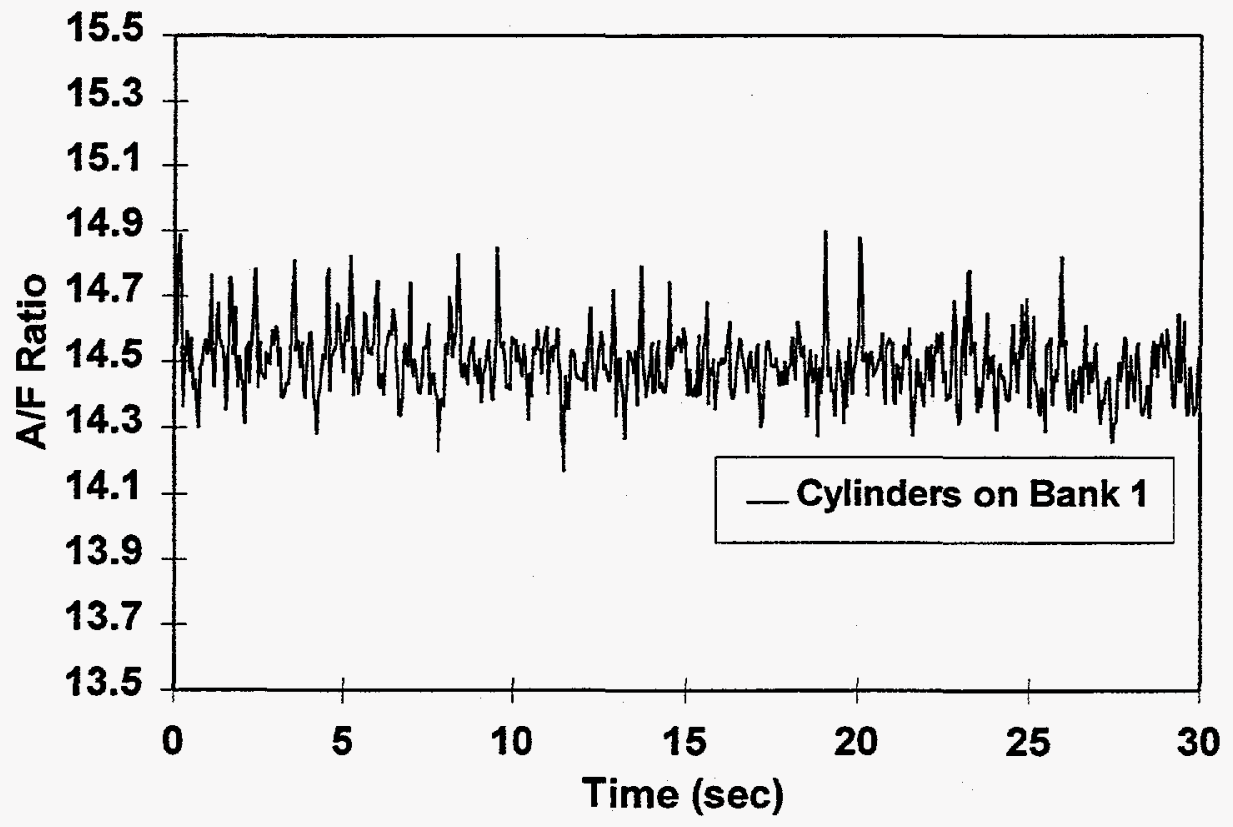

Figure 12. Measured air-fuel ratio for OEM pintle injectors at $32^{\circ} \mathrm{C}$ coolant temperature, $1500 \mathrm{rpm}, 0.3$ bar condition 


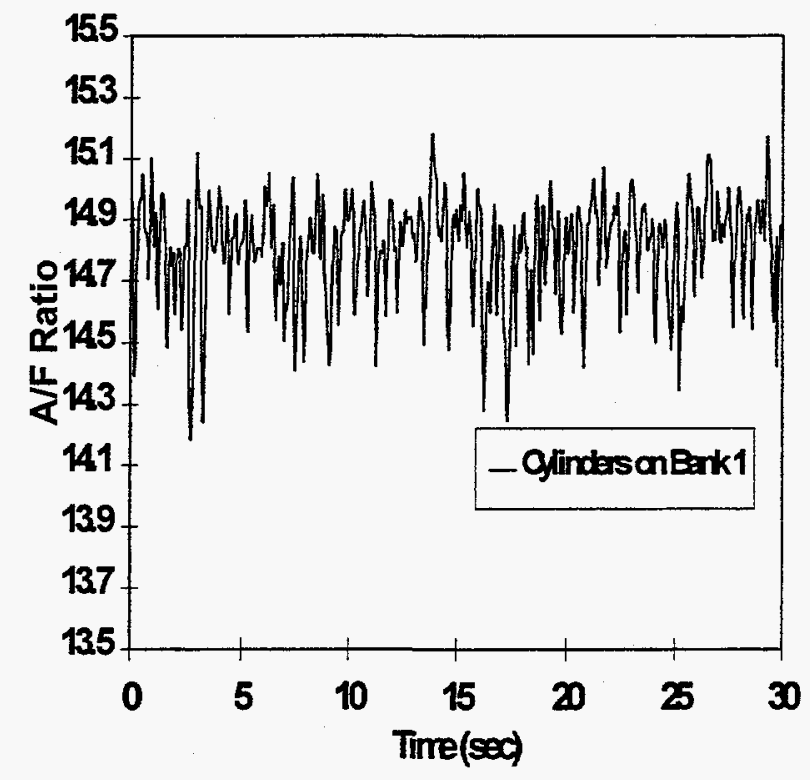

Figure 13. Measured air-fuel ratio for first-generation air-assist injectors at $32^{\circ} \mathrm{C}$ coolant temperature, $1500 \mathrm{rpm}, 0.3$ bar condition

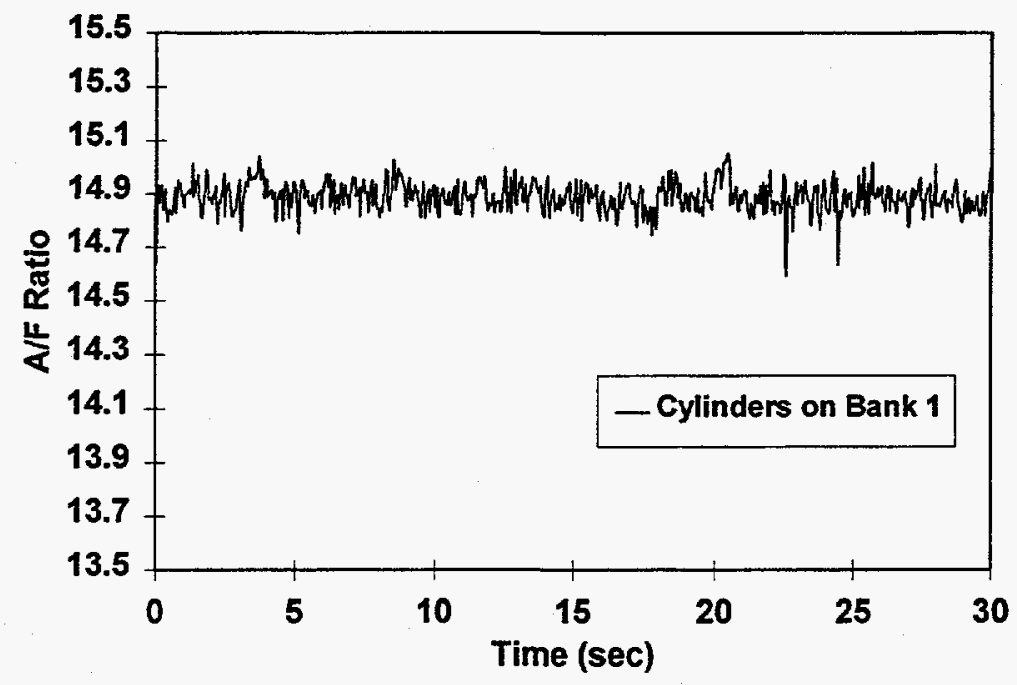

Figure 14. Measured air-fuel ratio for second-generation air-assist injectors at $32^{\circ} \mathrm{C}$ coolant temperature, $1500 \mathrm{rpm}, 0.3$ bar condition

The second-generation air-assist injectors provided very good atomization quality, as shown in Figure 15 . The atomizing air pressure is the pressure differential across the fuel-air mixing cap. In the engine, the pumps provide a pressure of $70 \mathrm{kPa}$ gage, so the differential air pressure varies from about $70 \mathrm{kPa}$ during cranking to about $120 \mathrm{kPa}$ during idle with a manifold air pressure of $50 \mathrm{kPa}$. At idle, a pulse width of about $4 \mathrm{~ms}$ is used, so the average drop size as represented by the Sauter mean diameter (SMD) is about $18 \mu \mathrm{m}$, while at 
wide open throttle the manifold pressure increases to about $100 \mathrm{kPa}$ and the pulse width to about $10 \mathrm{~ms}$, and the SMD increases to about $25 \mu \mathrm{m}$. The SMD is that drop size of an idealized monodispersed spray that represents the surface area to volume ratio of the actual polydisperse spray. The surface area to volume ratio roughly determines the evaporation rate of the spray. The OEM pintle injector has average drop sizes represented by the SMD of about $120 \mu \mathrm{m}$.

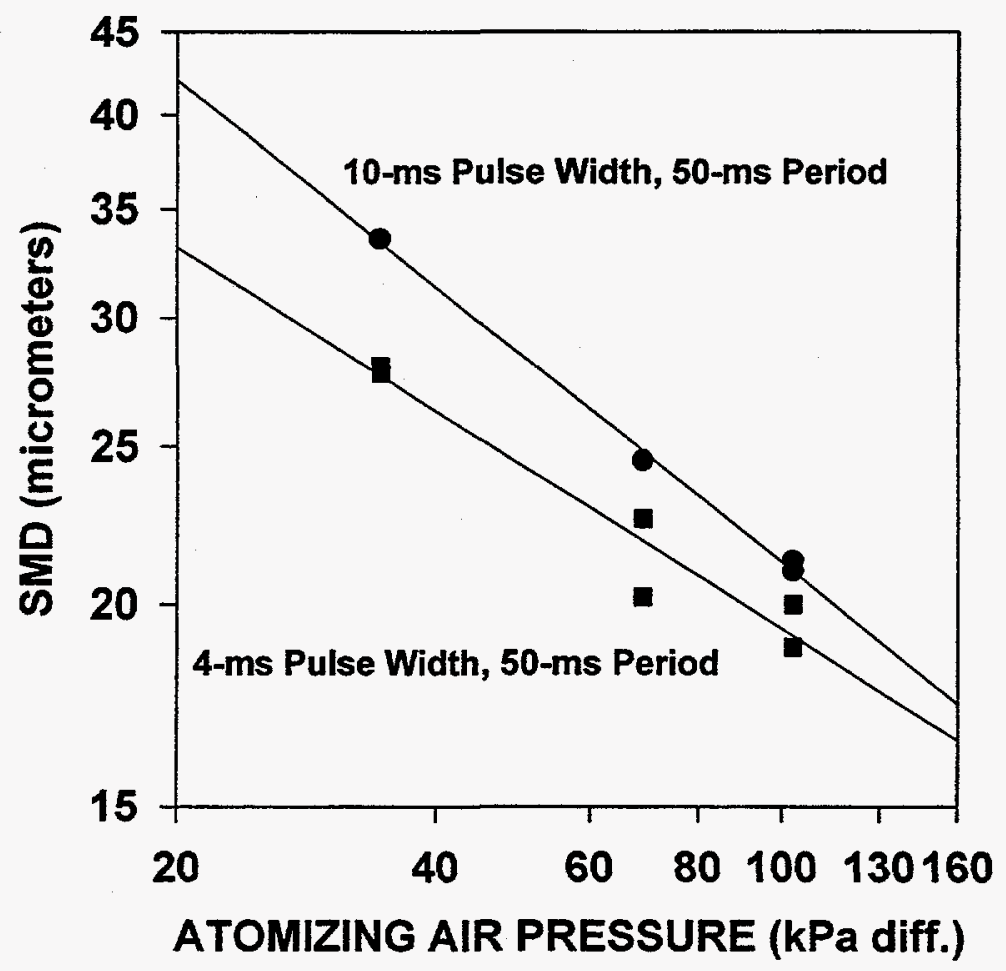

Figure 15. Effect of differential air pressure and pulse width on average drop sizes as measured by the SMD from second-generation air-assist injectors spraying ethanol (E-100)

The finer spray produced by the air-assist injectors results in faster evaporation of the fuel. For example, at a cranking condition at $25^{\circ} \mathrm{C}$, the SwRI TESS ${ }^{\mathrm{TM}}$ code was used to estimate that for the OEM injector spray with an SMD of $120 \mu \mathrm{m}$ and a Rosin Rammler $\mathrm{N}$ parameter of 1.9 , the evaporation of an E-100 spray in traveling from the injector tip to the intake valve about $120 \mathrm{~mm}$ away would be about 4.1 percent. For the airassist injectors with an SMD of about $25 \mu \mathrm{m}$ and a Rosin-Rammler $\mathrm{N}$ parameter of 1.6, the computed evaporation would be about 21 percent. Further, about 20 percent of the remaining liquid spray is predicted to follow the air stream into the combustion chamber during idle conditions for the air-assist spray, while essentially none of the liquid spray from the OEM injector follows the air stream into the cylinder.

In summary, the first-generation, air-assist injectors showed very good atomization quality, but unacceptable air-fuel ratio control at steady-state conditions compared with the OEM pintle injectors. However, the secondgeneration (or redesigned) air-assist injectors with a much smaller mixing chamber showed better air-fuel ratio control at steady-state conditions than the OEM injectors. In addition, the second-generation, air-assist 
injectors provided good atomization quality and very good start-up and transient performance, although backto-back engine performance comparisons with the OEM pintle injectors were not made. The fuel transport into the cylinders for the air-assist injectors was predicted to be much higher than for the OEM injectors under cold operating conditions.

\section{GM Shaft Encoder for Rapid Synchronization}

Many current production vehicles would fail the ULEV hydrocarbon emissions standards during the cranking portion of the U.S. FTP, before the engine ever started. Most vehicles in production do not synchronize spark and fuel injection until two or more engine revolutions. Before that time, fueling and spark timing is somewhat random relative to valve and piston movements. Therefore, only some cylinders of an engine are firing, while others are misfiring and producing large amounts of hydrocarbons. This is unacceptable for a ULEV. It would seem that an easy solution would be to wait to inject fuel until the controller is synchronized, but there is enough fuel in the cylinders and intake system at shutdown that very high hydrocarbon emissions result from this approach.

The first part of the approach adopted for clean starts in this project was to synchronize the engine controller with the engine hardware in $1 / 2$ or less rotations of the crankshaft. This was accomplished by replacing the standard synchronization system with a GM optical encoder used on the LT-1 engine (Kulkarni, 1992), and mounted in the distributor location on top of the 3.0-liter V-6 engine. This encoder has four, equally spaced, distinct marks, as well as 360 regularly spaced encoder marks used for higher-resolution position information. The four distinct encoder marks allow a unique indication of engine position within $1 / 4$ or less revolutions of the camshaft, or $1 / 2$ revolution or less of the crankshaft. Once one of these distinct marks passes the lightemitting diode (LED) and detector, the control system is synchronized in about $5 \mathrm{~ms}$ ( $7.5 \mathrm{crank}$ angle degrees, or $\mathrm{CAD}$, at $250 \mathrm{rpm}$ cranking speed).

The encoder is connected to a Silicon Systems F67-F687 engine controller chip that keeps track of the engine position. The higher level control is done on the Pentium PC, but the F67-F687 can compute desired spark and fuel injection in time based on desired timings in crank angle degrees (CAD). This system allows rapid synchronization to begin the start-up process. No fuel or spark occurs until the engine controller is synchronized, but this occurs very rapidly. The first cylinder that has time to receive a full amount of fuel injection then receives the first fuel pulse. Further details on how the encoder and engine controller are interfaced are provided below.

\section{Rapid Prototyping Electronic Control System (RPECS)}

Ford, like all other OEMs, does not provide any support for adapting their engine controller for changes in engine hardware or for trying new control algorithms. Therefore, with the installation of the air-assist injectors, the rapid synchronization start-up system, the exhaust gas ignition system, and other changes, it was not possible to use the standard Ford electronic engine controller (EEC) for control of the engine. Therefore, it was necessary to install an SwRI-developed, PC-based engine controller (the RPECS) that could be programmed to handle all hardware changes and all engine control strategies

The hardware for the RPECS engine controller was constructed as planned and as described by Bourn et al. (1994). This is basically a PC-based engine controller that uses the PC for higher-level logic development that is programmed in C-code, and for input and output from the engine controller. However, many lower level, engine specific tasks are off-loaded to a Silicon Systems 67F687 engine controller chip.

The engine test cell version of this controller is shown in Figure 16. The key to this setup is the real-time operating system extensions together with the custom boards. The custom boards off-load the most timecritical engine control operations, such as injector and ignition timing. Because of this reduction in the PC's 
timing requirements, all control codes may be written in the high-level language $C$. In this way, new control strategies may be very efficiently and quickly implemented and tested.

The high-level engine control software was developed from a "clean sheet of paper,"and included model-based control for air and fuel flow, and cylinder-event-based logic used for cranking and startup for about the first $17 \mathrm{~s}$ of engine operation. The development of these control algorithms required a significant effort, and the algorithms and engine results are described in detail in Appendix $A$ of this report under Federal Test Procedure (FTP)-type conditions. The low-temperature cold start performance is described below. Basically these control algorithms can be described as follows.

\section{Prime Pulse System}

When the key is first turned to the start position, cranking is delayed until the air-assist pumps reach operating pressure and the prime fueling pulses are delivered from each of the six injectors. The total amount of fuel to be delivered is determined from a 1-dimensional table of coolant temperature at time of cranking. The prime pulses are intermittent with a duration of $4.5-\mathrm{ms}$, and a delay between pulses of 5.5-ms. This strategy is used to provide a finer spray than would be obtained if the injectors were fired continuously, as shown in Figure 15. Once the prime pulses are completed, the cranking motor is enabled. 


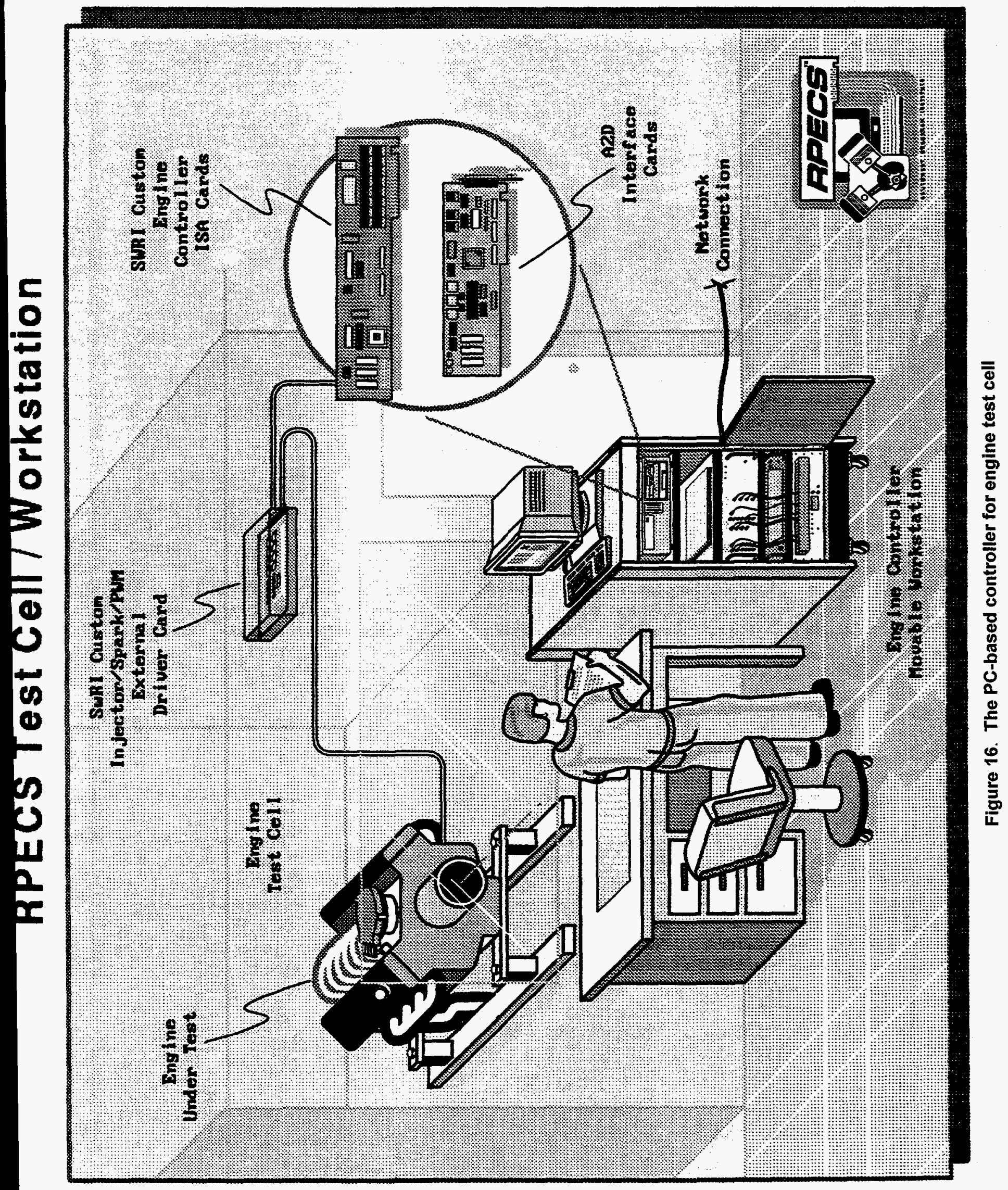




\section{Cylinder-Event-Based Logic and Starting Performance}

During cranking and start-up, cylinder-event-based logic was used to identify the first cylinder available for a full charge of fueling before the intake valve closing, and each of the following cylinders available for fueling. The amount of fuel to be injected, the timing of the fuel injection pulse, and the timing of the spark could be customized on a cylinder event basis. The calibration was accomplished by using three 2-dimensional tables of the dependent variable (fuel amount, fuel-injection timing, or spark timing) versus coolant temperature at the start of cranking, and the cylinder event number. The amount of fuel to be injected was expressed as a multiplier times the amount of fuel already computed that would be required for a stoichiometric mixture of fuel in-cylinder if all the fuel-injected fuel were vaporized in-cylinder. As the engine warmed up, the multiplier approached 1.0, or stoichiometric operation. However, the amount of fuel injected was still further modified for the rapid exhaust port oxidation system, as explained later and in Appendix A. This logic was used for about the first $17 \mathrm{~s}$ of engine operation, or until the throttle was opened. As shown in Appendix A, this resulted in very clean, relatively misfire-free starts under FTP type starts at approximately $25^{\circ} \mathrm{C}$ air and coolant temperatures.

Low-temperature cold-starting is an important issue in ethanol-fueled vehicles because of the low volatility of ethanol compared to gasoline. Using the rapid synchronization and cylinder-event-based logic combined with the prime pulse allowed very rapid starts over a wide range of temperatures. Hydrocarbon measurements were taken only at starts in the FTP range of $20^{\circ} \mathrm{C}$ to $30^{\circ} \mathrm{C}\left(68^{\circ} \mathrm{F}\right.$ to $\left.86^{\circ} \mathrm{F}\right)$, and it was verified that hydrocarbon emissions during the cranking period correlate very well with the number of misfires observed during cranking. Misfire information was obtained by instrumenting the engine with spark-plug cylinder-pressure transducers connected to a DSP, Inc., Combustion Analyzer. Hydrocarbon emissions were measured with a Cambustion fast-flame ionization detector (FID). For most of the low-temperature starts, hydrocarbon emissions were not recorded, but it was assumed that a low misfire rate would correspond directly with low hydrocarbon emissions.

Starting calibrations were developed for the temperature range from $100^{\circ} \mathrm{C}\left(212^{\circ} \mathrm{F}\right)$ down to $-18^{\circ} \mathrm{C}\left(0^{\circ} \mathrm{F}\right)$. Cold-starts at FTP test temperatures of about $25^{\circ} \mathrm{C}\left(77^{\circ} \mathrm{F}\right)$ are discussed in Appendices A and B. These starts were typically accomplished with very few misfires, and very low hydrocarbon emissions.

As the temperature was lowered, the engine continued to start well, although the number of misfires increased as expected for low-temperature starts. All of these low-temperature starts were obtained using a single long prime pulse, rather than the intermittent prime pulse system described above. It is expected that the good performance achieved with low-temperature cold starts would be further improved with the new prime pulse strategy, but this was not verified by tests. At $16^{\circ} \mathrm{C}\left(60^{\circ} \mathrm{F}\right)$, the start-up results shown in Figure 17 were obtained. The top panel of Figure 17 shows the indicated mean effective pressures (IMEP), the second panel shows, on a much expanded scale, the actual cylinder pressure traces for the first few cycles, and the bottom panel shows the engine speed in rpm (dashed line), the manifold absolute air pressure in bars (solid line), and the wide range exhaust gas oxygen sensor (dotted line) in volts, where $3 \mathrm{~V}$ is stoichiometric, higher than $3 \mathrm{~V}$ is lean, and lower than $3 \mathrm{~V}$ is rich. The engine started with no misfires over the first 16 engine cycles, and then some misfires were observed when the manifold absolute pressure (MAP) dropped to about 0.24 bar, a pressure where the volumetric pumping efficiency of the engine is quite low, and the in-cylinder residual gases (burned gases from previous cycle) are quite high, so there is insufficient fresh air for good combustion. For this start, the IAC valve was used to set the air flow rate into the engine, and problems with the IAC are evident in Figure 17. The speed oscillates to about $1800 \mathrm{rpm}$, and the MAP gets so low during the speed oscillations, about 0.24 bar, that the engine misfires. The IAC control problem was experienced during conditions other than start-up and, as a result, SwRI replaced the OEM IAC valve with a GM EGR valve with pintle position feedback. 


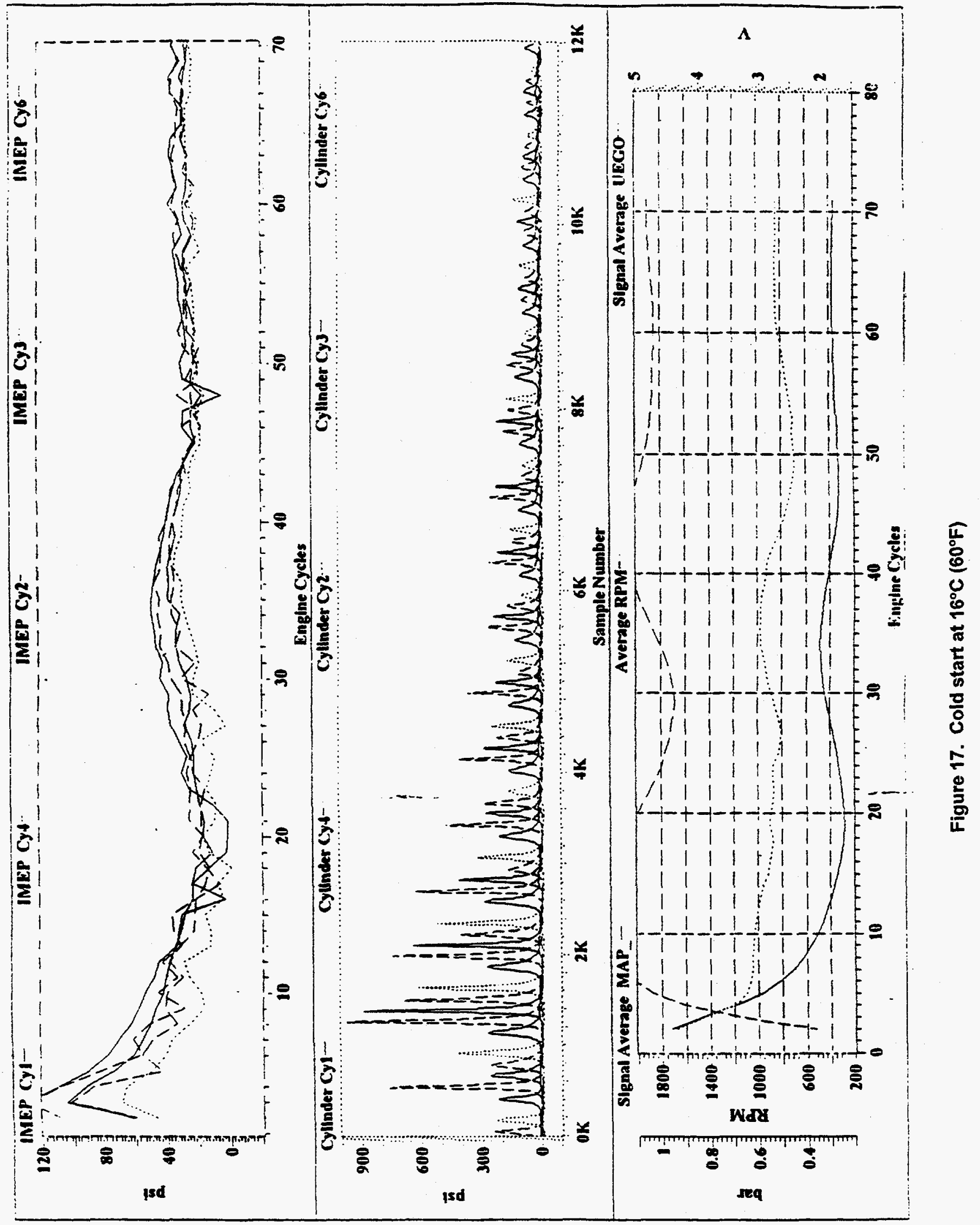




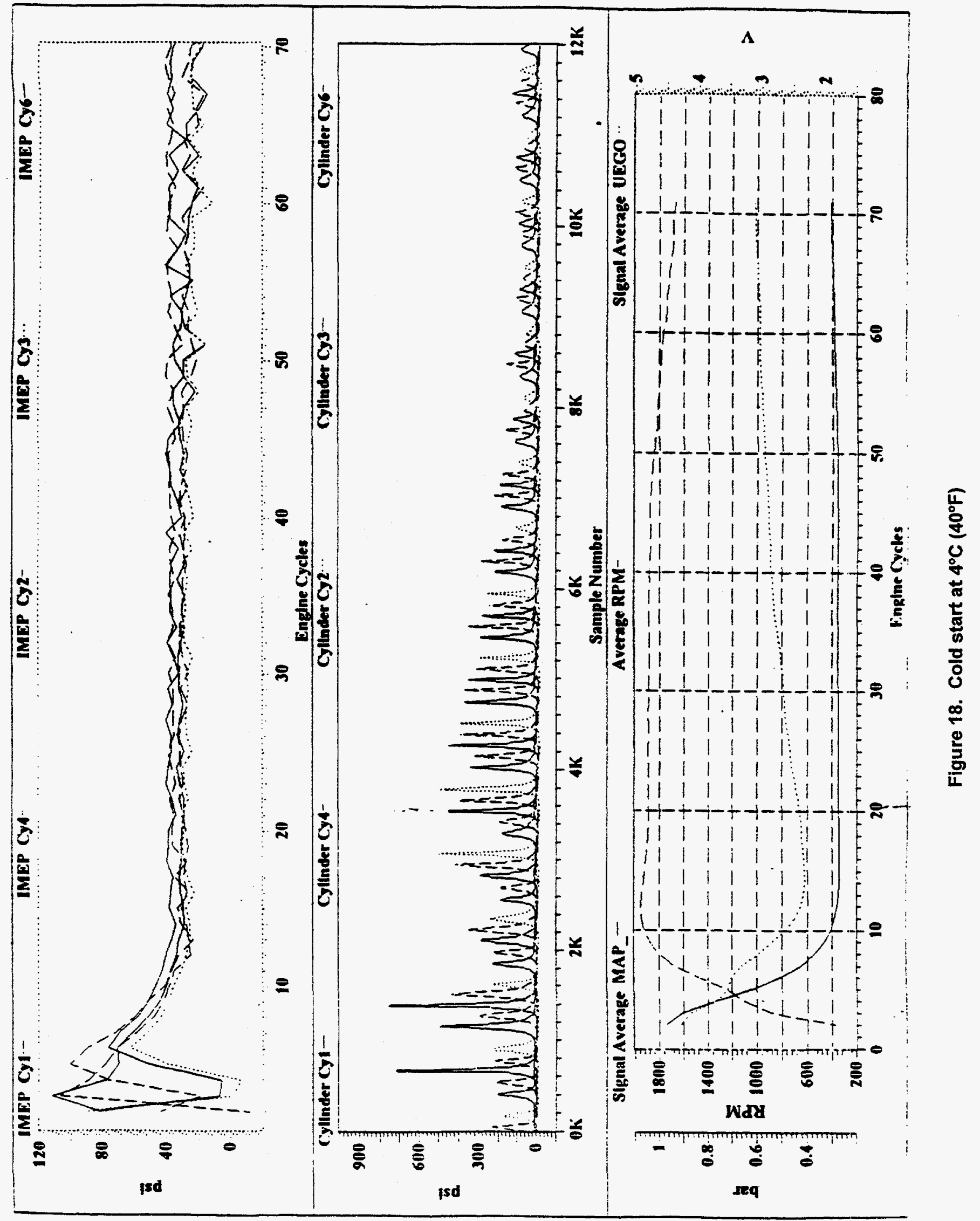


At $4^{\circ} \mathrm{C}\left(40^{\circ} \mathrm{F}\right)$, the start-up results obtained are shown in Figure 18. At this condition, there were more misfires during the first 3-cylinder events than at warmer temperatures, but notice that the engine speed still increases quickly to $1800 \mathrm{rpm}$ in about $5 \mathrm{~s}$ after the beginning of cranking. Start-up results at $-7^{\circ} \mathrm{C}\left(20^{\circ} \mathrm{F}\right)$ are shown in Figure 19. As the air temperature was lowered, it was necessary to open the throttle or IAC to progressively greater amounts so that the engine could overcome the greater loads due to more viscous oil. For this start-up the throttle position was opened enough so the start-up speed exceeded $2000 \mathrm{rpm}$. This may be a higher speed than desirable, but note the very strong start with no misfires in spite of the low temperature. Figure 20 shows a start-up at $-14^{\circ} \mathrm{C}\left(6^{\circ} \mathrm{F}\right)$. At this temperature, the start-up was strong, but there were misfires on some cylinders during the first eight cycles, and then no misfires after that. The $-14^{\circ} \mathrm{C}$ temperature was the lower limit of the cold box at the time these tests were conducted.

Thus, the modifications to the engine and the strategy used in the control system were shown to provide very rapid, clean starts in the temperature range for FTP starts of $20^{\circ} \mathrm{C}$ to $30^{\circ} \mathrm{C}\left(68^{\circ} \mathrm{F}\right.$ to $\left.86^{\circ} \mathrm{F}\right)$. In addition, strong, rapid starts at low temperatures as low as $-14^{\circ} \mathrm{C}$ with Ed-85 fuel have been demonstrated.

\section{Model-Based Open-Loop Control Algorithms}

Models of both air flow past the throttle plate, IAC valve, EGR valve, pollution control valve (PCV), and airassist injector were used to estimate air flow into the intake manifold. Air flow out of the intake manifold and into the cylinders was modeled using speed-density calculations, i.e., the mass of air per unit time equal speed $(x)$ air density in intake manifold $(x)$ volumetric efficiency $(x)$ engine displacement. From the air-mass flow rate into and out of the intake manifold, the air pressure in the intake manifold was calculated every $5 \mathrm{~ms}$. This calculated value was trimmed in the low-frequency domain by the measured MAP sensor, improving the accuracy of the calculated value, but retaining the very fast frequency response. Details are provided in Appendix A.

The fuel flow from the injector into the cylinder was based on the tau-epsilon $(\tau-\epsilon)$ model, where $\epsilon$ is the fraction of the injected fuel that goes into the cylinder before the first intake valve closing following the end of injection, and $\tau$ is the time constant of the remaining fuel in the intake manifold. Actually a dual $\tau-\epsilon$ model was used, one with a fast time constant, $\tau$ of about $0.5 \mathrm{~s}$, and the other with a slower time constant with $\tau$ of about $7 \mathrm{~s}$. The slow time constant model was only used for about the first $100 \mathrm{~s}$ or so of engine operation, while the fast time-constant model was used for all times. Both sets of $\tau-\epsilon$ were calibrated as a function of speed and load, with further modifiers for each of the four variables as a function of coolant temperature at the start of cranking and mass of fuel burned from the start of cranking. The excellent open-loop fuel control achieved with the model-based air and fuel flows is documented in Appendix A. 


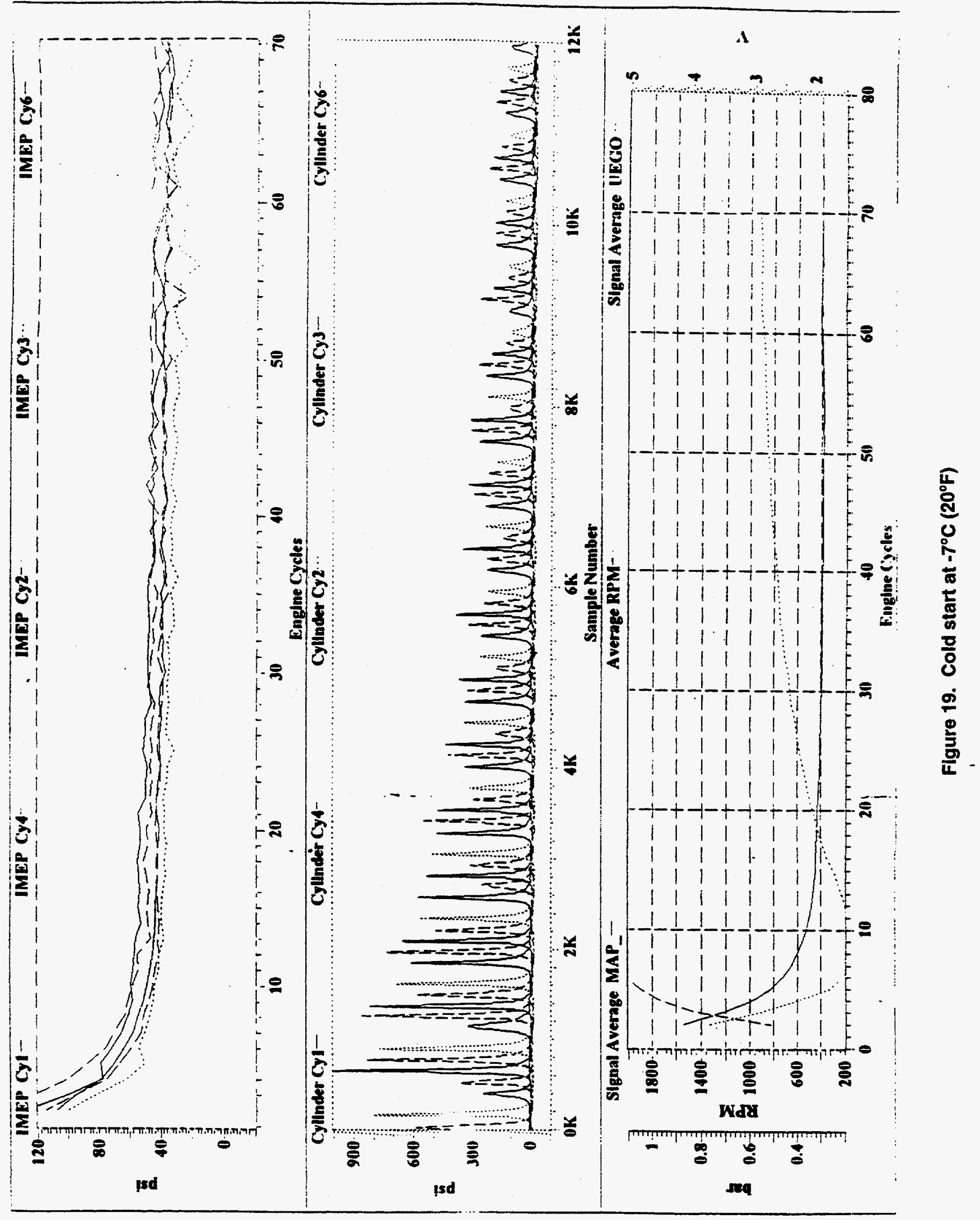




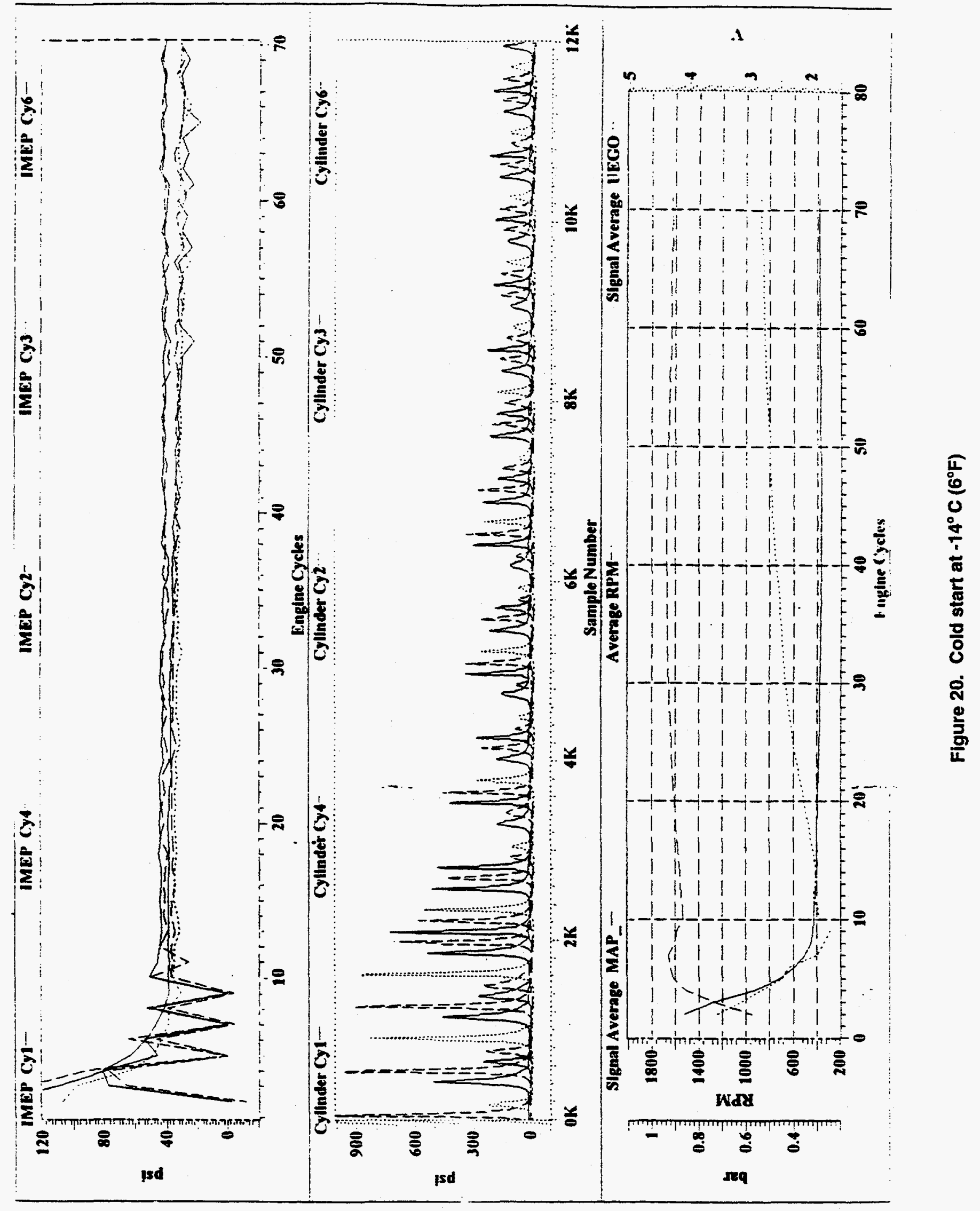




\section{Closed-Loop Control of Air-Fuel Ratio}

Beyond good fuel control during throttle transients, the low emissions vehicle controller must provide the catalyst an exhaust feed gas that alternates rich and lean in a switching fashion or maintains the air-fuel ratio very close to stoichiometric. The catalyst efficiency for a particular species is depends on the A/F ratio switching point, amplitude, and frequency for the closed-loop controller. Dual, switching, HEGO sensors installed upstream of the catalysts provided the exhaust gas feedback. A model of the air and fuel transport was used to estimate transit times from the fuel injectors to the HEGO sensors to obtain the fastest switching frequency possible while maintaining control stability. The algorithm includes jump-back logic. Jump-back increases the frequency of the switching rate. The rate of fuel ramp-up or ramp-down following the jump-back is computed based on the desired biasing, switching amplitude, and computed transit time for fuel. Biasing of the switching point is obtained by using different fueling ramp-up and ramp-down rates. Biasing can be up to 1 percent rich or lean of stoichiometric. Biasing lean of stoichiometric reduces $\mathrm{CO}$ at the expense of $\mathrm{NO}_{\mathrm{x}}$, and biasing rich of stoichiometric reduces $\mathrm{NO}_{\mathrm{x}}$ at the expense of $\mathrm{CO}$. Desired biasing was set as a function of engine speed and manifold pressure, always to the rich side of stoichiometric. Desired switching amplitude was set as a function of engine speed.

Adaptive feedback was used to improve the estimation of steady-state fueling requirements. The adaptive feedback was a function of engine speed and manifold pressure. The adaptive update was driven by a standard steepest-descent adaptive update algorithm.

\section{Replacement of OEM IAC and EGR Valves with GM EGR Valves with Pintle Position Sensors}

The OEM IAC valve was replaced with a GM EGR valve with pintle position feedback to provide more accurate control of the IAC valve to avoid misfires on decelerations and better control during idle. The IAC valve position for both the OEM valve and the replacement valve were a function of not only the pulse-width modulated (PWM) signal to the valve, but also the pressure drop across the valve and the previous history of the valve (hysteresis). However, with the pintle position sensor, a feedback control was added based on the measured valve position.

The OEM EGR valve was replaced with a GM EGR valve with pintle position feedback for more accurate control of the EGR flow rate. Again the pintle position was measured and used in a feedback loop. On the OEM EGR system, Ford includes a sensor to measure the EGR flow rate based on the pressure change through a nozzle in the EGR flow loop. This flow rate measurement was also used as another option for closed loop control of the EGR flow rate. The best control was usually obtained from this second method.

\section{Rapid Exhaust Port Oxidation System}

The rapid exhaust port oxidation (REPO) system is a method for rapidly heating the exhaust catalysts up to full catalytic activity temperature, corresponding to about $400^{\circ} \mathrm{C}$ front-face temperature, within about $17 \mathrm{~s}$ from the initiation of a cold-start on a FTP emissions cycle. The REPO accomplishes this by establishing a relatively low-temperature flame in the exhaust manifold of the engine. The flame is low temperature because it is diluted with burned gases from the primary combustion in the engine cylinders. The fuel for the REPO is supplied by running the engine rich. The air was supplied by external air pumps. The two air pumps used on the vehicle were supplied by Bosch for application to the Mercedes Benz vehicle. For the REPO system, the position of the two catalysts was the same as that found in the OEM vehicles. The front faces of the two catalysts were approximately 500 and $610 \mathrm{~mm}$ downstream from the exhaust port. The catalysts reached 50 percent conversion efficiency in about $17 \mathrm{~s}$, as shown in Appendix B. This was a key technology for meeting the ULEV standards, as discussed in Figure 21 and Appendix B. 


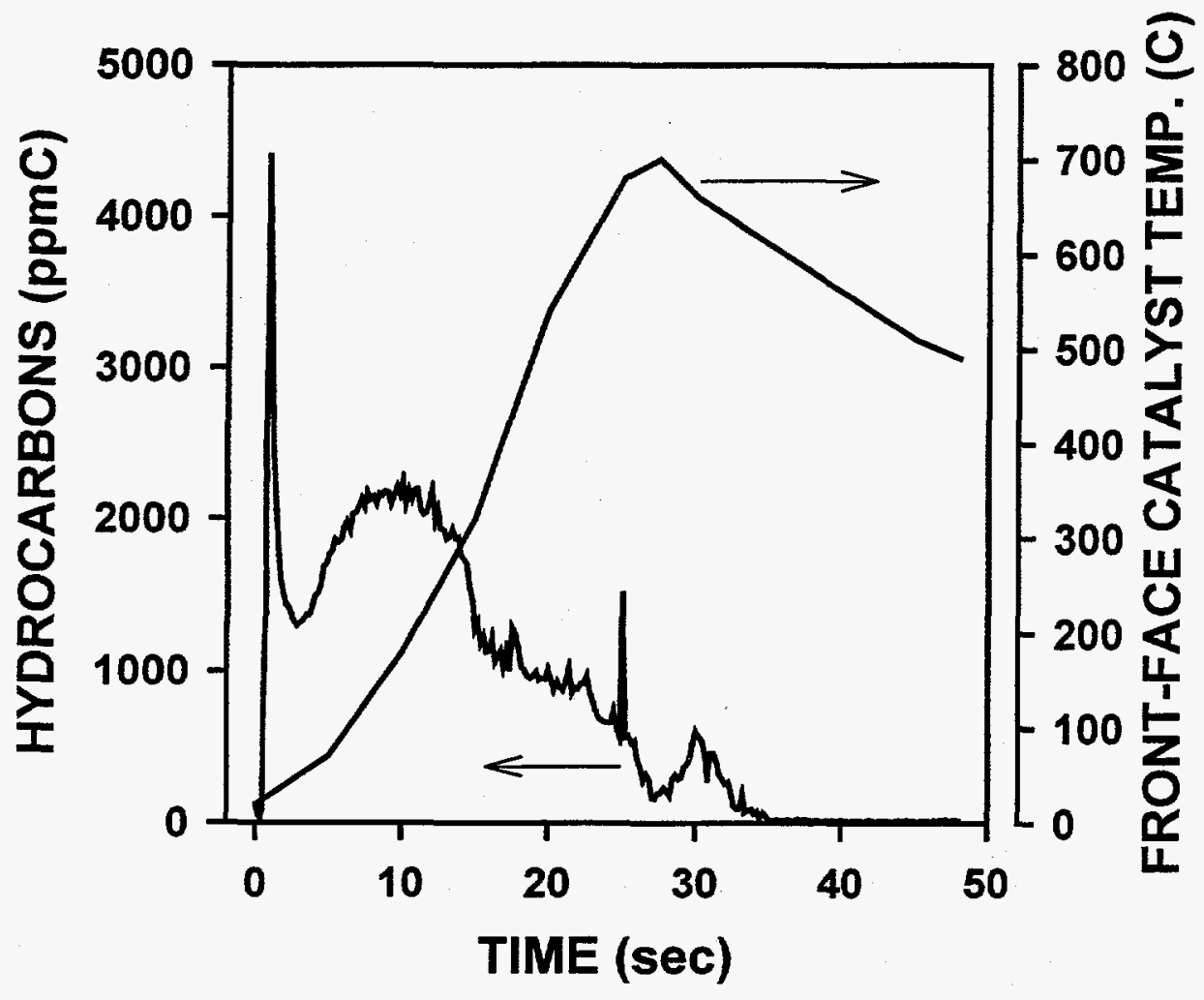

Figure 21. Catalyst front-face temperature and hydrocarbon emissions measured downstream of catalyst using clean-start engine modifications and the rapid exhaust port oxidation system 


\section{Task 4-Emissions Control System Development and Testing}

\section{Objectives}

The objective of this task was to evaluate various concepts for advanced aftertreatment technologies. These included an electrically heated catalyst (EHC), a hydrocarbon adsorber plus an EHC, and a combination adsorber/catalyst built into one package.

The following section details the exhaust emissions control efforts undertaken in this program, including:

- Baseline emissions tests

- Advanced aftertreatment system characteristics

- Modifications to vehicle for installation of aftertreatment systems

- Emissions results with electrically heated catalyst/reformulated main catalyst systems

- Hydrocarbon adsorber plus electrically heated catalyst plus reformulated main catalyst

- Hydrocarbon adsorber close-coupled with catalyst followed by reformulated main catalyst.

\section{Baseline Emissions Tests}

SwRI received two Ford Taurus FFVs in March 1994. One was designated for use in the emissions control system design task, and did not include any of the engine modifications discussed in the previous section. These vehicles were delivered with less than 20 miles on their respective odometers. For both vehicles, the oil was replaced with Petrolube oil specified for use with alcohol-fueled vehicles and purchased for this program, and new oil filters were installed. The fuel systems on both vehicles were drained, and the vehicles were fueled with Ed-85. The vehicles were then driven for 4,000 miles over a modified Automobile Manufacturers Association durability driving schedule before baseline emissions tests were conducted.

Duplicate tests were conducted on the aftertreatment-test vehicle both with and without a catalytic converter to establish baseline exhaust emissions levels. The vehicle was operated over the chassis dynamometer portion of the FTP for light-duty vehicles while operating on Ed-85. Results of these tests are presented in Table 11. 
Table 11. Baseline Federal Test Procedure Exhaust

Emissions From Ford Flexible-Fuel Vehicle 1

\begin{tabular}{|c|c|c|c|c|}
\hline $\begin{array}{c}\text { Exhaust } \\
\text { Constituents }\end{array}$ & $\begin{array}{l}\text { Without } \\
\text { Catalyst }\end{array}$ & $\begin{array}{c}\text { With } \\
\text { Catalyst }\end{array}$ & TLEV & ULEV \\
\hline $\mathrm{THC}^{\mathrm{a}}(\mathrm{g} / \mathrm{mi})$ & 2.75 & 0.21 & & \\
\hline $\mathrm{CO}(\mathrm{g} / \mathrm{mi})$ & 12.71 & 1.90 & 3.4 & 1.7 \\
\hline $\mathrm{NO}_{x}(\mathrm{~g} / \mathrm{mi})$ & 2.03 & 0.10 & 0.4 & 0.2 \\
\hline $\mathrm{CH}_{4}(\mathrm{~g} / \mathrm{mi})$ & 0.09 & 0.05 & 5 & \\
\hline $\mathrm{NMHC}^{\mathrm{b}}(\mathrm{g} / \mathrm{mi})$ & 0.83 & 0.06 & & \\
\hline Carbonyls ${ }^{\mathrm{c}}(\mathrm{g} / \mathrm{mi})$ & 0.41 & 0.02 & 2 & 8 \\
\hline Alcohols $^{d}(\mathrm{~g} / \mathrm{mi})$ & 1.43 & 0.09 & 2 & \\
\hline Estimated NMOG $(\mathrm{g} / \mathrm{mi})$ & 2.663 & 0.160 & 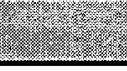 & 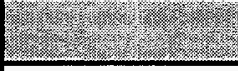 \\
\hline Est NMOG $\times$ RAF $^{\mathrm{f}}(\mathrm{g} / \mathrm{mi})$ & 1.784 & 0.107 & 0.125 & 0.040 \\
\hline Formaldehyde (mg/mi) & 122.80 & 1.54 & 15 & 8 \\
\hline Acetaldehyde (mg/mi) & 266.93 & 12.87 & $\sqrt{100}=$ & 20 \\
\hline \multicolumn{5}{|c|}{ 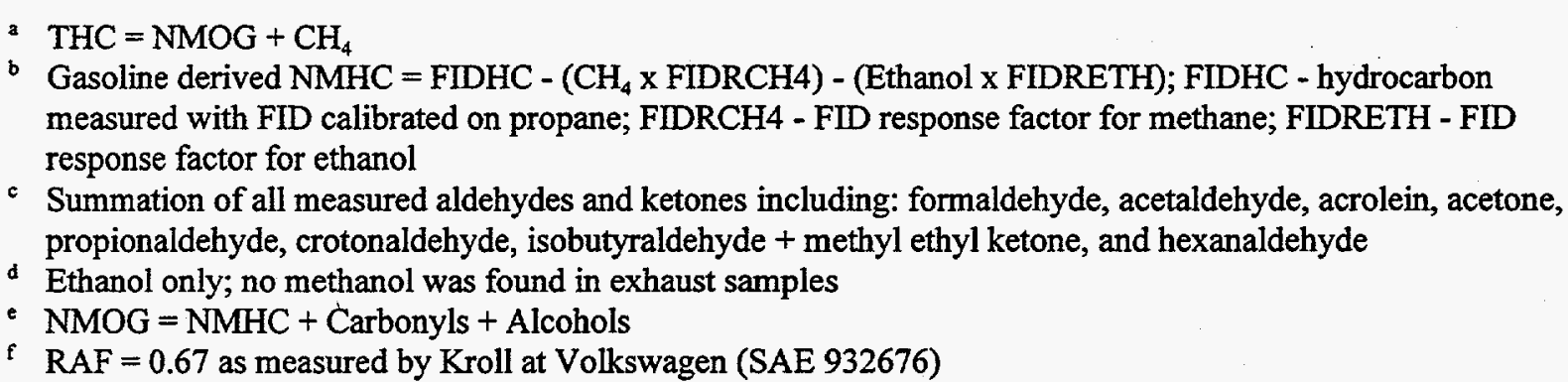 } \\
\hline
\end{tabular}

Exhaust samples were measured for $\mathrm{HC}, \mathrm{CO}, \mathrm{NO}_{x}, \mathrm{CH}_{4}$, aldehydes and ketones, and alcohols (only ethanol was detected). Nonmethane organic gases were estimated using nonmethane hydrocarbons (NMHCs) from the gasoline portion of the fuel as measured by a FID rather than by hydrocarbon speciation. Gasoline-derived NMHC was determined by measuring hydrocarbons with a FID calibrated on propane, then correcting the results for the removal of $\mathrm{CH}_{4}$ and ethanol.

These data show the unmodified vehicle meets transitional low-emission vehicle (TLEV) exhaust emissions standards, and that the vehicle catalyst is quite effective in reducing all exhaust constituents. These low emissions levels were obtained even though the vehicle was calibrated for low emissions on M85 or gasoline, but not on ethanol blends. To better demonstrate where improvements could be made in the efficiency of the catalyst, selected individually weighted emissions for each phase of the FTP are presented in Table 12. 
Table 12. Weighted Baseline Federal Test Procedure Exhaust Emissions For Ford Flexible-Fuel Vehicle With Catalyst

\begin{tabular}{|c|c|c|c|c|c|c|}
\hline \multirow[b]{2}{*}{$\begin{array}{l}\text { Exhaust } \\
\text { Emission }\end{array}$} & \multicolumn{4}{|c|}{$\begin{array}{c}\text { Individually Weighted Exhaust } \\
\text { Emissions (g/mi) }\end{array}$} & \multirow{2}{*}{$\begin{array}{c}\text { Total } \\
\text { Weighted } \\
\text { FTP } \\
\text { Emissions } \\
\text { (g/mi) }\end{array}$} & \multirow{2}{*}{$\begin{array}{c}\text { Bag 1A } \\
\text { Percentage } \\
\text { of Total } \\
\text { NMOG } \\
\text { Emissions }\end{array}$} \\
\hline & $\begin{array}{c}\text { Bag 1A } \\
(0-140 \\
\text { sec }) \\
\end{array}$ & $\begin{array}{c}\text { Bag 1B } \\
(141-505 \\
\text { sec) } \\
\end{array}$ & Bag 2 & Bag 3 & & \\
\hline NMHC & 0.04 & $<0.01$ & $<0.01$ & 0.01 & 0.06 & $27 \%$ \\
\hline Ethanol & 0.09 & $<0.01$ & $<0.01$ & $<0.01$ & 0.09 & $56 \%$ \\
\hline Acetaldehyde & 0.01 & $<0.01$ & $<0.01$ & $<0.01$ & 0.01 & $10 \%$ \\
\hline
\end{tabular}

These data show that unburned ethanol in Bag $1 \mathrm{~A}$ (first $140 \mathrm{~s}$ of FTP) accounts for 56 percent of all FTP nonmethane organic gases (NMOG) emissions, and acetaldehyde in Bag $1 \mathrm{~A}$ accounts for approximately 10 percent of all NMOG emissions. In addition, Bag $1 \mathrm{~A}$ NMHC emissions contribute 27 percent to total NMOG. Thus, approximately 93 percent of all NMOG emissions from this vehicle occur in the first $140 \mathrm{~s}$ of the FTP, of which 66 percent are caused by unburned ethanol and acetaldehyde. These data suggested the need for supplemental catalyst heating at vehicle start, to quickly light off the catalyst. In addition, the main catalyst needed to be formulated to specifically target unburned ethanol and acetaldehyde.

\section{Modifications to Aftertreatment Systems}

To improve the exhaust emissions from the test vehicle, an electrically heated catalyst was obtained from WR Grace, and a main catalyst specially formulated for operation on alcohol vehicles was obtained from Degussa. A summary of catalyst characteristics is presented in Table 13.

Table 13. Catalyst Characteristics

\begin{tabular}{|c|c|c|c|c|}
\hline Catalyst System & \multicolumn{2}{|c|}{$\begin{array}{c}\text { Ford OEM } \\
\text { (one catalyst per bank) }\end{array}$} & Grace EHC & $\begin{array}{l}\text { Degussa Main } \\
\text { Catalyst }\end{array}$ \\
\hline Catalyst Designation & Front Brick & Rear Brick & M930037 Cam-E-Lite & OM 6902 Lot 40512 \\
\hline $\begin{array}{l}\text { Substrate: } \\
\text { Material } \\
\text { Cell Density }\end{array}$ & \multicolumn{2}{|c|}{$\begin{array}{c}\text { ceramic } \\
400 \text { cells } / \text { in. }^{2}\end{array}$} & $\begin{array}{l}\text { stainless steel foil } \\
180 \text { cells/in. }{ }^{2}\end{array}$ & $\begin{array}{c}\text { ceramic } \\
400 \text { cells/in. }{ }^{2}\end{array}$ \\
\hline $\begin{array}{l}\text { Precious Metals: } \\
\text { Precious Metal types } \\
\text { Loading (combined) } \\
\text { Precious Metal Ratio }\end{array}$ & $\begin{array}{c}\mathrm{Pt} / \mathrm{Rh} \\
60 \mathrm{~g} / \mathrm{ft}^{3} \\
\mathrm{Pt} / \mathrm{Rh}=9 / 1\end{array}$ & $\begin{array}{c}\mathrm{Pt} / \mathrm{Rh} \\
28 \mathrm{~g} / \mathrm{ft}^{3} \\
\mathrm{Pt} / \mathrm{Rh}=5 / 1\end{array}$ & $\begin{array}{c}\mathrm{Pt} / \mathrm{Rh} \\
80 \mathrm{~g} / \mathrm{ft}^{3} \\
\mathrm{Pt} / \mathrm{Rh}=5 / 1\end{array}$ & $\begin{array}{c}\mathrm{Pt} / \mathrm{Rh} \\
70 \mathrm{~g} / \mathrm{ft}^{3} \\
\mathrm{Pt} / \mathrm{Rh}=5 / 1\end{array}$ \\
\hline Core Length & $\mathrm{NA}$ & NA & $\begin{array}{l}5.5 \text { in. } \\
\text { (front } 0.7 \text { in. heated) }\end{array}$ & $6.0 \mathrm{in.}$ \\
\hline Core Diameter & $\mathrm{NA}$ & NA & $2.7 \mathrm{in.}$ & $5.66 \mathrm{in.}$ \\
\hline Brick Active Volume & 38 in. $^{3}$ & 38 in. $^{3}$ & 31.5 in. $^{3}$ & 151 in. $^{3}$ \\
\hline Total Active Volume & \multicolumn{2}{|c|}{152 in. $^{3}$} & 31.5 in. $^{3}$ & 151 in. $^{3}$ \\
\hline Electrical Energy & - & - & $2000 \mathrm{~W}$ & - \\
\hline
\end{tabular}


The test vehicle was fitted with an exhaust system modified to accommodate the reformulated main catalyst and EHC. Because of space constraints under the vehicle and the large diameter of the reformulated main catalyst, it was installed much further downstream in the exhaust system than the OEM catalysts. Figure 22 shows the OEM and experimental exhaust system configurations. The twin OEM catalysts both reside approximately $355 \mathrm{~mm}$ (14 in.) downstream of the exit end of the exhaust manifold flange. In the experimental exhaust system, blank pipes are installed where the OEM catalysts were, and the $\mathrm{EHC} /$ reformulated main catalyst set was installed at the termination of the $\mathrm{Y}$-pipe. This placed the face of the reformulated main catalyst approximately $940 \mathrm{~mm}(37 \mathrm{in}$.) from the exhaust manifold flange on one side of the exhaust system, and $1.47 \mathrm{~m}$ (58 in.) downstream of the manifold flange on the other side. To compensate for the heat loss, the exhaust system was wrapped with insulated fiber tape from the exhaust manifold flange to the end of the Y-pipe.

\section{Electrically Heated Catalyst Emissions Testing}

After work on the exhaust system was completed, the vehicle was prepared for a series of FTP tests to determine the effect of the EHC/reformulated main catalyst system on exhaust emissions. First, the OEM exhaust system was installed on the vehicle to establish a current baseline for exhaust emissions. Then the fuel composition sensor was replaced with a SwRI-generated signal calibrated for Ed-85. The OEM sensor was calibrated for methanol, and would cause slight over-enrichment during open-loop operation of the vehicle when running on Ed-85. The SwRI circuit was calibrated to provide an appropriate amount of open-loop fuel enrichment for Ed-85. Lastly, the experimental exhaust system was installed incrementally to determine the impact of each component on exhaust emissions. The EHC was operated in a post-crank heating mode with an electrical power of $2 \mathrm{~kW}$. Secondary air was injected for the duration of open-loop operation. A series of three tests were conducted to determine an appropriate air injection flow rate. A summary of the test matrix is given in Table 14.

Table 14. Emissions Test Matrix

\begin{tabular}{|c|c|c|c|c|c|c|}
\hline Test Number & Catalyst & $\begin{array}{l}\text { Fuel } \\
\text { Sensor } \\
\text { Signal }\end{array}$ & $\begin{array}{l}\text { Exhaust } \\
\text { Insulation }\end{array}$ & EHC & EHC Power & $\begin{array}{l}\text { Secondary Air } \\
\text { Injection }\end{array}$ \\
\hline E80-OEM-1 & OEM & OEM & no & no & none & none \\
\hline E80-OEM-2 & OEM & SwRI & no & no & none & none \\
\hline E80-CAT-A & Degussa & SwRI & no & no & none & none \\
\hline E80-CAT-A\&INS & Degussa & SwRI & yes & no & none & none \\
\hline E80-CAT-A\&B & Degussa & SwRI & yes & yes & none & none \\
\hline E80-EHC-7CFM & Degussa & SwRI & yes & yes & $\begin{array}{l}\text { Bag } 1-25 \mathrm{~s} \\
\text { Bag } 3-10 \mathrm{~s}\end{array}$ & $\begin{array}{l}\text { Bag1-115 s@7 cfm } \\
\text { Bag3-10s@7 cfm }\end{array}$ \\
\hline E80-EHC-5CFM & Degussa & SwRI & yes & yes & $\begin{array}{l}\text { Bag } 1-25 s \\
\text { Bag } 3-10 s\end{array}$ & $\begin{array}{l}\text { Bag1-115 s@5 cfm } \\
\text { Bag3-10s@5 cfm }\end{array}$ \\
\hline E80-EHC-2CFM & Degussa & SwRI & yes & yes & $\begin{array}{l}\text { Bag 1-25s } \\
\text { Bag 3-10s }\end{array}$ & $\begin{array}{l}\text { Bag 1-115 s@2 cfm } \\
\text { Bag 3-10s@2 cfm }\end{array}$ \\
\hline
\end{tabular}



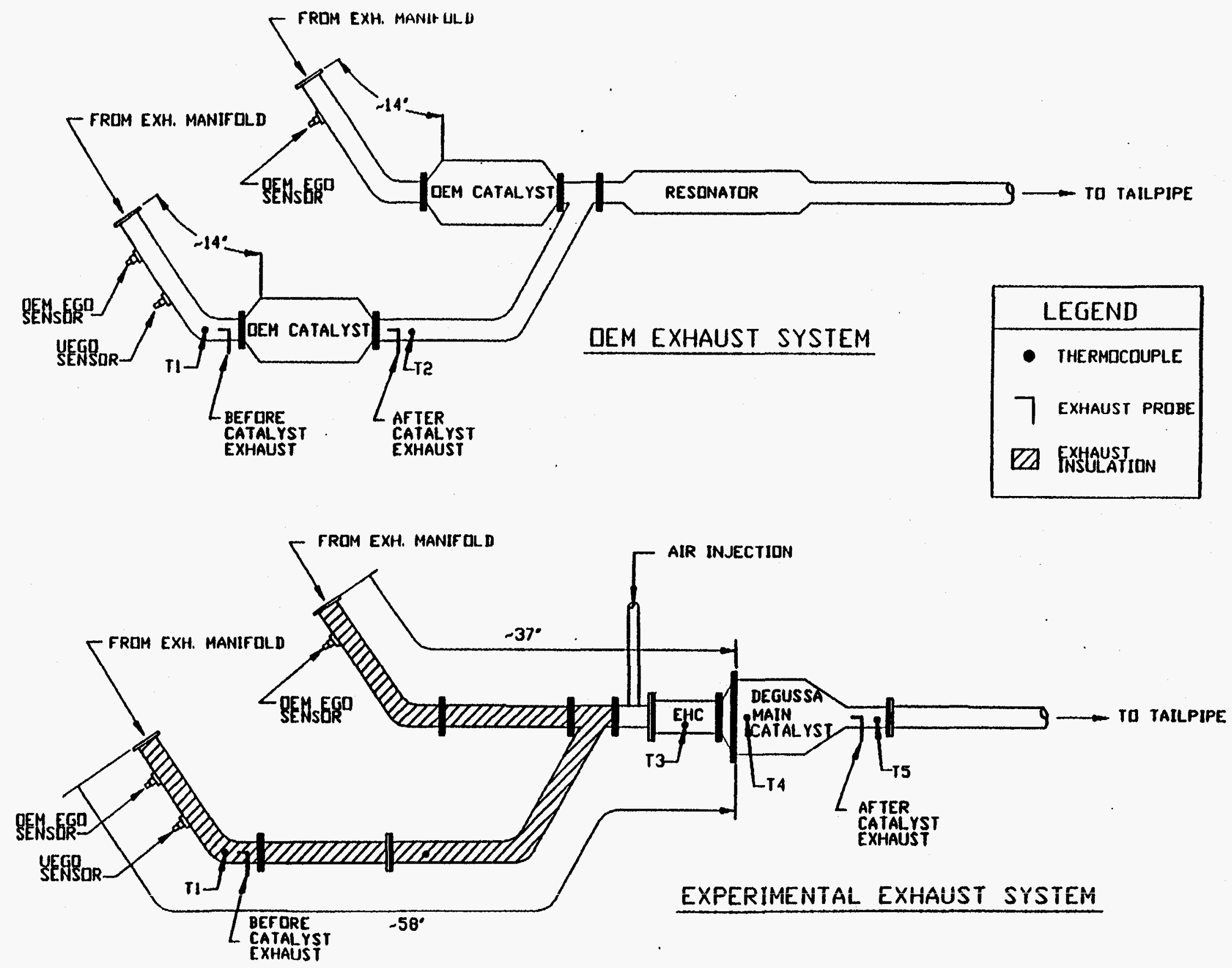

Figure 22. Schematic of Standard OEM Exhaust System and SwRI Experimental Exhaust System 
Results of the exhaust emissions tests conducted to date are given in Table 15.

Comparing the OEM baseline test (E80-OEM-1) with E80-OEM-2, the SwRI-generated fuel sensor signal had a slight positive impact on measured NMOG and $\mathrm{CO}$ emissions; however, a slight increase in $\mathrm{NO}_{\mathrm{x}}$ emissions was detected. Therefore, it seems likely that the change to the SwRI-generated fuel sensor signal caused the vehicle to operate with slightly less open-loop enrichment than in OEM configuration. A change from the OEM exhaust system to the experimental exhaust system with reformulated main catalyst led to a significant increase in NMOG emissions, as shown by the results of test E-80-CAT-A (Table 15). A combination of less available thermal energy (resulting from the placement of the catalyst) and the catalyst formulation likely contributed to the higher emissions results for the reformulated main catalyst as compared to the baseline OEM exhaust emission results. The addition of exhaust insulation in test E-80-CAT-A\&INS resulted in a reduction of all exhaust emissions. Results from test E-80-CAT-A\&B show that the addition of the EHC (no heat, no air injection) into the exhaust stream had little effect on exhaust emissions. With the EHC operational in test E-80-EHC-7CFM, measured exhaust emissions were reduced significantly from the non-heated configuration (E-80-CAT-A\&B). Furthermore, emissions were reduced from OEM baseline levels. During this test, secondary air was injected into the exhaust stream ahead of the EHC at a constant flow fare of $3.9 \mathrm{~g} / \mathrm{s}(7 \mathrm{cfm})$. Tests were also conducted with $2.8 \mathrm{~g} / \mathrm{s}(5-\mathrm{cfm})$ and $1.1 \mathrm{~g} / \mathrm{s}$ (2-cfm) flow rates; however, emissions results from these tests were not as favorable as at $3.9 \mathrm{~g} / \mathrm{s}(7 \mathrm{cfm})$.

Table 15. Federal Test Procedure Exhaust Emissions From Flexible-Fuel Taurus on Ed-85

\begin{tabular}{|l|c|c|c|c|}
\hline Test Number & Est. NMOG $^{*}$ & $\begin{array}{c}\text { Est. NMOG } \\
\text { RAF }^{\mathbf{b}}\end{array}$ & CO & NO $_{\mathbf{x}}$ \\
\hline E80-OEM-1 & 0.152 & 0.102 & 1.701 & 0.077 \\
\hline E80-OEM-2 & 0.147 & 0.098 & 1.548 & 0.130 \\
\hline E80-CAT-A & 0.298 & 0.200 & 1.825 & 0.109 \\
\hline E80-CAT-A\&INS & 0.270 & 0.181 & 1.749 & 0.068 \\
\hline E80-CAT-A\&B & 0.282 & 0.189 & 1.795 & 0.083 \\
\hline E80-EHC-7CFM & 0.077 & 0.052 & 0.795 & 0.068 \\
\hline E80-EHC-5CFM & 0.096 & 0.064 & 0.744 & 0.064 \\
\hline E80-EHC-2CFM & 0.143 & 0.096 & 1.139 & 0.057 \\
\hline
\end{tabular}

a NMOG was estimated using NMHC from the gasoline portion of the fuel as measured by a FID rather than by hydrocarbon speciation.

b RAF $=0.67$ as measured by Kroll at Volkswagen (SAE 932676)

Detailed results from the baseline test (OEM-1) and the best results with the EHC at the $3.9 \mathrm{~g} / \mathrm{s}$ airflow (E-80-EHC-7CFM) are given in Table 16. These data show significant reductions in exhaust emissions with the use of the EHC together with a reformulated main catalyst. Estimated NMOG was reduced by nearly 50 percent, and alcohol emissions were reduced by approximately 65 percent. However, although aftertreatment technology has demonstrated gains in control of exhaust emissions, further improvements were needed to meet ULEV standards. Note that if this EHC aftertreatment system were tested with the modified engine as described under Tasks 3, 5, and 6 discussed above, it likely would have met ULEV. However, these aftertreatment tests were conducted concurrently with those engine modifications, so that combination was not tested. 
Table 16. Federal Test Procedure Exhaust Emissions from Ford Flexible-Fuel Vehicle

\begin{tabular}{|c|c|c|c|c|}
\hline $\begin{array}{c}\text { Exhaust } \\
\text { Constituents }\end{array}$ & $\begin{array}{c}\text { Baseline } \\
\text { Test \# } \\
\text { E80-OEM-1 }\end{array}$ & $\begin{array}{l}\text { EHC Test \# } \\
\text { E80-EHC- } \\
\text { 7CFM }\end{array}$ & $\begin{array}{c}\text { Percent } \\
\text { Reduction with } \\
\text { EHC }\end{array}$ & $\begin{array}{r}\text { ULEV } \\
\text { Standards }\end{array}$ \\
\hline $\mathrm{THC}^{\mathrm{a}}(\mathrm{g} / \mathrm{mi})$ & 0.196 & 0.123 & 37.2 & \\
\hline $\mathrm{CO}(\mathrm{g} / \mathrm{mi})$ & 1.702 & 0.796 & 53.2 & 1.7 \\
\hline $\mathrm{NO}_{x}(\mathrm{~g} / \mathrm{mi})$ & 0.077 & 0.068 & 11.7 & 0.2 \\
\hline $\mathrm{CH}_{4}(\mathrm{~g} / \mathrm{mi})$ & 0.044 & 0.046 & -4.5 & 2.t. \\
\hline $\mathrm{NMHC}^{b}(\mathrm{~g} / \mathrm{mi})$ & 0.047 & 0.033 & 29.8 & 3. \\
\hline Carbonyls ${ }^{\mathrm{c}}(\mathrm{g} / \mathrm{mi})$ & 0.014 & 0.012 & 14.3 & 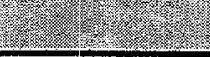 \\
\hline Alcohols $^{\mathrm{d}}(\mathrm{g} / \mathrm{mi})$ & 0.091 & 0.032 & 64.8 & \\
\hline Estimated $\mathrm{NMOG}^{\mathrm{e}}(\mathrm{g} / \mathrm{mi})$ & 0.152 & 0.077 & 49.3 & \\
\hline Est NMOG $\times \operatorname{RAF}^{\mathrm{f}}(\mathrm{g} / \mathrm{mi})$ & 0.102 & 0.052 & 49.0 & 0.040 \\
\hline Formaldehyde (mg/mi) & 1.49 & 0.58 & 61.1 & 8 \\
\hline Acetaldehyde (mg/mi) & 11.19 & 10.93 & 2.3 & 8 \\
\hline \multicolumn{5}{|c|}{$\begin{array}{l}\text { a } \mathrm{THC}=\mathrm{NMOG}+\mathrm{CH}_{4} \\
\text { basoline derived NMHC = FIDHC - }\left(\mathrm{CH}_{4} \times \text { FIDRCH4) - (Ethanol x FIDRETH); FIDHC - hydrocarbon }\right. \\
\text { measured with FID calibrated on propane; FIDRCH4 - FID response factor for methane; FIDRETH - FID } \\
\text { response factor for ethanol } \\
\text { c Summation of all measured aldehydes and ketones including: formaldehyde, acetaldehyde, acrolein, acetone, } \\
\text { propionaldehyde, crotonaldehyde, isobutyraldehyde + methyl ethyl ketone, and hexanaldehyde } \\
\text { d Ethanol only; no methanol was found in exhaust samples } \\
\text { - NMOG = NMHC + Carbonyls + Alcohols } \\
\text { f } \mathrm{RAF}=0.67 \text { as measured by Kroll at Volkswagen (SAE } 932676)\end{array}$} \\
\hline
\end{tabular}

Table 17 gives individually weighted emissions for each phase of the FTP. These data show that, even with an EHC, nearly 70 percent of all NMOG emissions are caused by unburned gasoline-derived NMHC and unburned ethanol present during the first $140 \mathrm{~s}$ of the FTP. These data also show that after $140 \mathrm{~s}$, tailpipe exhaust emissions are well controlled, primarily because the catalyst is completely "lit off" and catalyst conversion efficiency is high. Therefore, a method was needed to either bring the complete catalyst to light-off quicker, or momentarily "store" exhaust emissions until the catalyst was completely lit off.

Table 17. Weighted Federal Test Procedure Exhaust Emissions-EHC Test \# E80-EHC-7cfm

\begin{tabular}{|c|c|c|c|c|c|c|}
\hline \multirow{2}{*}{$\begin{array}{l}\text { Exhaust } \\
\text { Emission }\end{array}$} & \multicolumn{4}{|c|}{ Individually Weighted Exhaust Emissions (g/mi) } & \multirow{2}{*}{$\begin{array}{c}\text { Total } \\
\text { Weighted } \\
\text { FTP } \\
\text { Emissions } \\
\text { (g/mi) }\end{array}$} & \multirow{2}{*}{$\begin{array}{c}\text { Bag 1A } \\
\text { Percentage } \\
\text { of Total NMOG } \\
\text { Emissions }\end{array}$} \\
\hline & $\begin{array}{c}\text { Bag 1A } \\
(0-140 \text { sec })\end{array}$ & $\begin{array}{c}\text { Bag 1B } \\
(141-505 \\
\text { sec) } \\
\end{array}$ & Bag 2 & Bag & & \\
\hline $\begin{array}{l}\text { NMHC } \\
\text { Ethanol } \\
\text { Acetaldehyde }\end{array}$ & $\begin{array}{l}0.02 \\
0.03 \\
0.01\end{array}$ & $\begin{array}{r}0.01 \\
<0.01 \\
<0.01\end{array}$ & $\begin{array}{l}<0.01 \\
<0.01 \\
<0.01\end{array}$ & $\begin{array}{l}<0.01 \\
<0.01 \\
<0.01\end{array}$ & $\begin{array}{l}0.033 \\
0.032 \\
0.011\end{array}$ & $\begin{array}{l}27 \% \\
42 \% \\
13 \%\end{array}$ \\
\hline
\end{tabular}




\section{Tests of Adsorber/EHC and Adsorber/Catalyst}

Before testing the hydrocarbon adsorber, the previously tested EHC/reformulated catalyst system was installed on the vehicle to establish another baseline for exhaust emissions. The system was operated with air injection at flow rates of $3.9 \mathrm{~g} / \mathrm{s}(7 \mathrm{cfm})$ and $5.6 \mathrm{~g} / \mathrm{s}(10 \mathrm{cfm})$. The vehicle was then tested with an adsorber in front of the EHC/reformulated main catalyst combination. Finally, the adcat system was tested on the vehicle in two configurations. The first configuration placed the adcat system where the OEM catalyst had been located, and the reformulated main catalyst in the underbody position used for previous tests. In the second configuration, the reformulated main catalyst brick was cut in half perpendicular to the cylindrical axis, and each half was placed behind an adcat on each bank of the exhaust system where the OEM catalysts had been. A summary of the test matrix is given in Table 18.

Table 18. Emissions Test Matrix

\begin{tabular}{|l|l|l|c|c|c|c|}
\hline Test Number & Catalyst & $\begin{array}{c}\text { Catalyst } \\
\text { Position }\end{array}$ & $\begin{array}{c}\text { Adsorber/ } \\
\text { Adcat }\end{array}$ & EHC & $\begin{array}{c}\text { EHC } \\
\text { Heating }\end{array}$ & Secondary Air injection \\
\hline EHC-7CFM-B & Degussa & underbody & no & yes & $\begin{array}{l}\text { Bag 1 - 25 s } \\
\text { Bag 3 - 10 s }\end{array}$ & $\begin{array}{l}\text { Bag 1 - 115 s @ 7 cfm } \\
\text { Bag 3 - 10 s @7 cfm }\end{array}$ \\
\hline EHC-10CFM & Degussa & underbody & no & yes & $\begin{array}{l}\text { Bag 1 - 25 s } \\
\text { Bag 3 - 10 s }\end{array}$ & $\begin{array}{l}\text { Bag 1 - 115 s @ 10 cfm } \\
\text { Bag 3 - 10 s @ 10 cfm }\end{array}$ \\
\hline ADS+EHC & Degussa & underbody & adsorber & yes & $\begin{array}{l}\text { Bag 1 - 25 s } \\
\text { Bag 3 - 10 s }\end{array}$ & $\begin{array}{l}\text { Bag 1 - 115 s @ 7 cfm } \\
\text { Bag 3 - 10 s @ 7 cfm }\end{array}$ \\
\hline ADS+EHC-2 & Degussa & underbody & adsorber & yes & $\begin{array}{l}\text { Bag 1 - 45 s } \\
\text { Bag 3 - 10 s }\end{array}$ & $\begin{array}{l}\text { Bag 1 - 115 s @7 cfm } \\
\text { Bag 3 - 10 s @ 7 cfm }\end{array}$ \\
\hline ADCAT+MAIN-A & Degussa & underbody & Adcat & no & none & none \\
\hline ADCAT+MAIN-B & Degussa & $\begin{array}{l}\text { close } \\
\text { coupled }\end{array}$ & Adcat & no & none & none \\
\hline
\end{tabular}

Results of the exhaust emissions tests are given in Table 19.

Table 19. Federal Test Procedure Exhaust Emissions From Flexible-Fuel Taurus on Ed-85

\begin{tabular}{|l|c|c|c|}
\hline \multicolumn{1}{|c|}{ Test Number } & FID HC & CO & NO \\
\hline $\begin{array}{l}\text { E-80-EHC-7CFM } \\
\text { (previous baseline) }\end{array}$ & 0.139 & 0.795 & 0.068 \\
\hline EHC-7CFM-B (new baseline) & 0.178 & 0.831 & 0.073 \\
\hline EHC-10CFM & 0.202 & 0.878 & 0.093 \\
\hline ADS+EHC & 0.407 & 1.935 & 0.201 \\
\hline ADS+EHC-2 & 0.340 & 1.750 & 0.177 \\
\hline ADCAT+MAIN-A & 0.254 & 1.456 & 0.066 \\
\hline ADCAT+MAIN-B & 0.276 & 1.670 & 0.092 \\
\hline
\end{tabular}

Comparing the current baseline (EHC-7CFM-B) with the previous baseline (E-80-EHC-7CFM), exhaust emissions increased slightly, especially hydrocarbon emissions. Examining the individual bag data (Table 20) reveals that hydrocarbon levels are elevated across the entire FTP. This vehicle sat idle for 3 months between 
these tests, and it suggested that the higher $\mathrm{HC}$ emissions reflected a shift in the vehicle's emissions characteristics.

Table 20. Comparison of Hydrocarbon Emissions with EHC

\begin{tabular}{|c|c|c|c|c|}
\hline \multirow{2}{*}{ Test Number } & \multicolumn{4}{|c|}{ FID HC Exhaust Emissions (grams) } \\
\cline { 2 - 5 } & Bag 1A & Bag 1B & Bag 2 & Bag 3 \\
\hline EHC-7CFM & 1.244 & 0.532 & 0.098 & 0.311 \\
\hline EHC-7CFM-B & 1.588 & 0.723 & 0.156 & 0.325 \\
\hline
\end{tabular}

Comparing the EHC tests with $3.9 \mathrm{~g} / \mathrm{s}(7 \mathrm{cfm})$ and $5.6 \mathrm{~g} / \mathrm{s}(10 \mathrm{cfm})$ air injection flow rates, the lower flow rate yielded lower exhaust emissions. These differences were mostly found in Bag 1A-the first $140 \mathrm{~s}$ of the FTP. Apparently, the higher flow rate caused excessive cooling of the EHC during the idle immediately following cranking. This led to lower catalyst temperatures and poorer catalyst efficiency during the first few minutes of the test. Based on the above information, the EHC was operated with an air-injection flow rate of $3.9 \mathrm{~g} / \mathrm{s}$ $(7 \mathrm{cfm})$ for tests with the adsorber.

As shown in Table 19, test results with the adsorber were not as good as the EHC baseline (EHC-7CFM-B). Continuous data showed that catalyst temperatures dropped severely as soon as power to the EHC was turned off. This quick drop in temperature indicated that the catalyst was not chemically active when the EHC was turned off. It was thought that at the time the EHC was turned off, the adsorber was still trapping exhaust emissions. Thus, the exhaust after the adsorber was too lean to maintain catalyst light-off. Therefore, a second test (ADS+EHC-2) was conducted with this configuration, but using a 45-s post-crank heating time on the EHC rather than the previous $25 \mathrm{~s}$. It was hoped that the adsorber would be releasing some of the trapped exhaust constituents by this time, providing an appropriate mixture in the exhaust stream to properly light-off the catalyst. Although this test showed some improvements in Bag $1 \mathrm{~A}$ emissions over the previous test, the temperature of the catalyst still dropped off quickly after the EHC was turned off. It is speculated that the adsorber was oversized for the system, and that even after $45 \mathrm{~s}$ of operation, the exhaust stream reaching the catalyst was too lean and too cool to maintain catalyst light-off. In addition, when the adsorber was installed, it acted as a heat sink in the exhaust stream. Thus, with the adsorber installed, the exhaust stream temperature at the face of the catalyst remained low for the first few minutes of the FTP, contributing to the rapid cooling of the catalyst after the EHC was turned off.

Results from tests with the adcat installed in conjunction with the main catalyst indicated this system also needed further development in order to achieve ULEV emissions levels. It was speculated that the adcat, like the adsorber, was oversized for this vehicle and that the catalyst was not provided with a sufficient amount of fuel to quickly reach light-off temperatures. In addition, the adcat system also acted as a heat sink ahead of the catalyst, causing it to take longer for the catalyst to reach light-off temperatures.

Based on the preliminary testing of advanced aftertreatment systems, the EHC appears to be the most favorable system tested. The scope of this program precludes further investigation of the adsorber or adcat system. Although this type of technology has been successfully proven on gasoline vehicles, most of these systems have used complex valving and routing of the exhaust to achieve ULEV-level exhaust emissions. In addition, exhaust temperatures during operation on gasoline are higher than during operating on alcohols; thus, these systems are more tolerant to some heat loss to the adsorber. This is a new technology that needs to be further developed to properly operate on an ethanol-fueled vehicle. With further development, adsorbers aftertreatment technology may be capable of achieving ULEV exhaust emissions standards on alcohol-fueled vehicles. 


\section{Emissions Tests of Modified Engine and Vehicle with Rapid Exhaust Port Oxidation System}

All of the above tests reported under Task 4 were conducted on the OEM 1993 Ford Taurus except for those conducted with different aftertreatment devices and modified exhaust systems to accommodate those aftertreatment devices. In parallel with those aftertreatment tests, the engine was modified as described under Task 3. The original plan was to take the best of the aftertreatment devices, in this case the EHC, and try it with the vehicle with the modified engine. However, experience on other projects showed that the rapid exhaust port oxidation system was relatively simple and produced very low emissions results, so that aftertreatment approach was tried with the vehicle with the modified engine and controller. That combined engine/aftertreatment system was described under the Task 3 report in the previous section of this report and in Appendix B. Basically the engine is operated fuel-rich of stoichiometric to provide unburned $\mathrm{CO}$ and $\mathrm{H}_{2}$ in the exhaust, and air is pumped into the exhaust port area to react with the combustion products, producing a low-temperature flame in the exhaust. Enough air is added so that the exhaust is slightly fuel-lean of stoichiometric. This oxidizes unburned fuel and adds temperature to the exhaust system and catalyst.

Previous tests had shown that the rapid exhaust port oxidation system operates best with close-coupled catalysts. Unfortunately, no close-coupled catalysts were obtained in time to perform emissions tests. However, the combination of the engine modifications and the rapid exhaust port oxidation system allowed ULEV emissions to be obtained in a single FTP emissions test. Emissions results are shown in Table 21 and Figure 23. These results show that the $\mathrm{NO}_{\mathrm{x}}$ and CO ULEV emissions standards were met easily, but that the NMOG emissions should be lower to provide some cushion between the measured results and the ULEV standards. It should be possible to significantly reduce the NMOG emissions by using close-coupled catalysts combined with the other modifications and strategies discussed in this report. Close-coupled catalysts were obtained for use with this vehicle, but too late to be tested in this project. As an alternative to reducing NMOG without using close-coupled catalysts, the compression ratio could be lowered from the 11:1 value used for this engine.

Table 21. Emissions Results for the FTP -75 for Modified 1993 Ford Taurus, OEM Taurus, and ULEV Standards

\begin{tabular}{|l|c|c|c|}
\hline & Current Vehicle & ULEV Standards & OEM Vehicle \\
\hline $\mathrm{CO}(\mathrm{g} / \mathrm{mi})$ & 0.879 & 1.7 & 1.702 \\
\hline $\mathrm{NO}_{\mathrm{x}}(\mathrm{g} / \mathrm{mi})$ & 0.085 & 0.2 & 0.077 \\
\hline $\mathrm{NMOG} \mathrm{RAF} *(\mathrm{~g} / \mathrm{mi})$ & 0.039 & 0.04 & 0.102 \\
\hline Mileage on Ed -85 (mpg) & 13.56 & - & 14.10 \\
\hline Gasoline Equivalent Mileage $(\mathrm{mpg})$ & 21.2 & - & 22.0 \\
\hline$*$ Reactivity factor of 0.67 according to Kroll et al. $[5]$ & & \\
\hline
\end{tabular}




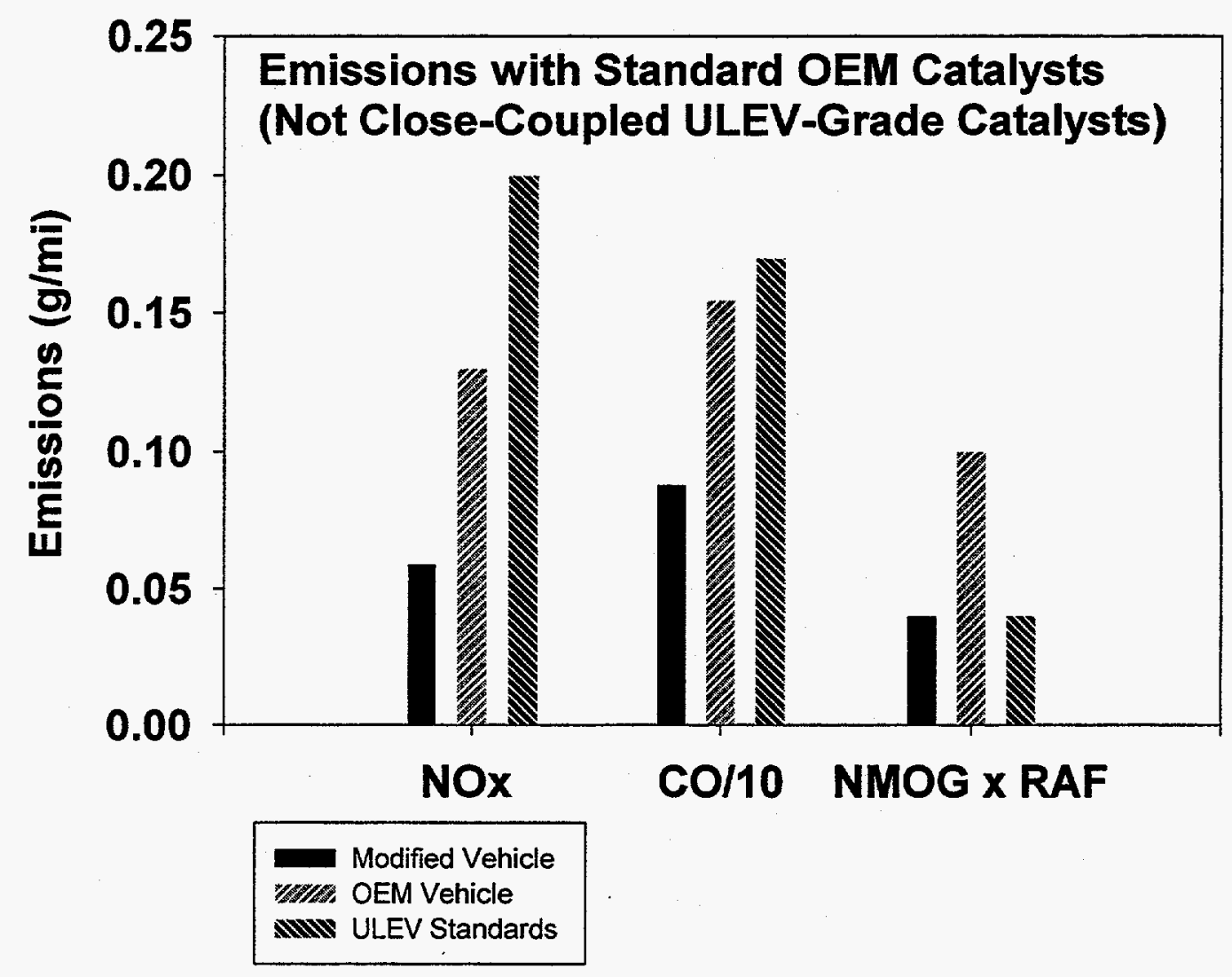

Figure 23. Emissions of modified vehicle compared with baseline vehicle and with ultra-low emissions vehicle standards 


\section{Task 7-High-Speed Data Acquisition and Control}

\section{Objectives}

The objective of Task 7 was to develop a high-speed data acquisition, combustion analysis, and control capability in SwRI's RPECS, with particular emphasis on tailoring such a capability for use in the Dedicated Ethanol-Fueled ULEV project itself.

\section{Introduction}

One critical capability required for the efficient and successful calibration of an engine and vehicle is the ability to acquire high-speed data (in particular in-cylinder pressure data during combustion), and the ability to analyze such data to determine characteristics of the combustion itself. For tuning of cold-start, ignition timing with EGR, and idle stability, among others, this high-speed acquisition and analysis capability allows the calibration engineer to see directly the results of the calibration tuning efforts. Such a feedback mechanism is of great assistance to this calibration effort.

A natural extension of this acquisition and analysis capability is the use of the results of the acquisition and analysis for real-time control. The idea is that rather than using this capability to calibrate traditional algorithms, the capability is instead used as direct feedback to the algorithms themselves. Such feedback provides for superior performance compared to the standard method, and has the potential to greatly reduce the overall calibration efforts.

To reap the benefits of both the combustion analysis and the possibility of using combustion analysis results for feedback control, funding for the development of this capability was provided under the Dedicated Ethanol ULEV project. In addition to the funding provided by NREL and DOE, SwRI provided internal funding for capital equipment purchases (approximately $\$ 12,000$ ) and for part of the development (approximately $\$ 25,000$ ).

The basic configuration of the new capability was to add the capability to the existing SwRI RPECS, which was already being used on the ethanol ULEV project for full authority powertrain control in the demonstrator vehicle. The specifics of this effort are described in detail in the sections that follow.

\section{Electronic Hardware}

One of the advantages of RPECS is that it is based on the industry standard personal computer architecture. As such, it can immediately take advantage of the huge selection of off-the-shelf, add-on hardware available for this architecture. So, the development of the electronic hardware for the high-speed data acquisition capability involved only the selection of appropriate off-the-shelf hardware and the writing of low-level drivers for interfacing to the hardware under the QNX operating system used by RPECS. The structure of the system is shown in Figure 24.

As Figure 24 shows, the high-speed acquisition hardware consists of the DAS 58 ISA add-in card from Keithley-Metrabyte, along with a simultaneous sample-and-hold interface box also from Keithley-Metrabyte. This combination provides for eight single-ended inputs with twelve-bit resolution, with a gross throughput of one megasample/second (on all channels combined), with one megasample of on-board buffering. Using this hardware, it is possible to sample a single cylinder engine at quarter crank angle degree resolution at engine speeds exceeding $15,000 \mathrm{rpm}$. Alternately, an eight cylinder engine may be sampled every half crank angle degree at engine speeds in excess of 6,000 RPM. Because of the on-board buffer, it is also possible to acquire over 650 engine cycles ( 1440 samples per cycle, with the 650 being the sum over all channels) with 
no intervention from the PC. This allows the necessary high-speed data to be acquired without overloading the $\mathrm{PC}$ processor with the data transfer, and thus, without interfering with normal RPECS control operation.

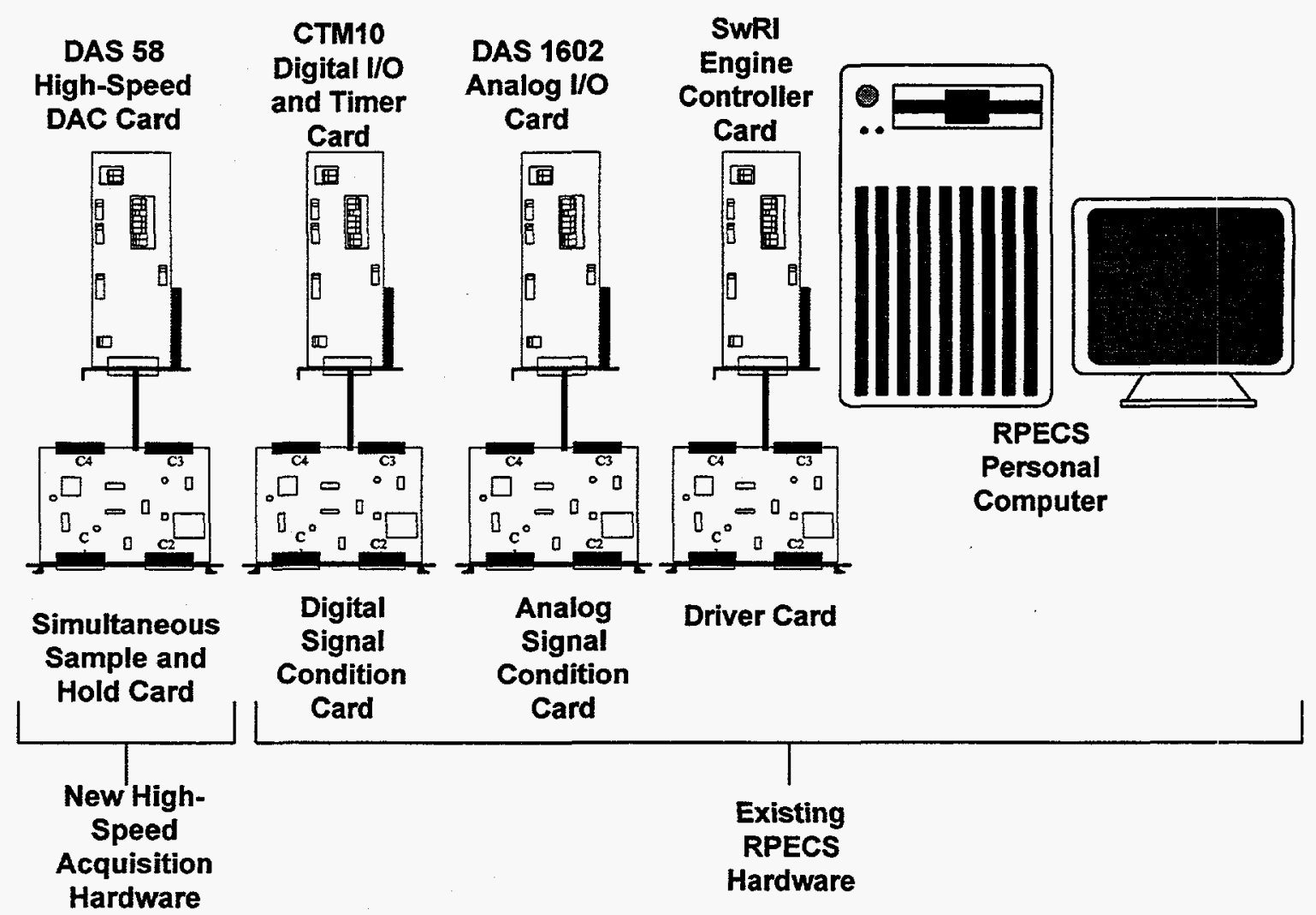

Figure 24. High-speed RPECS hardware

No driver software is available from Keithley-Metrabyte for the DAS 58 under QNX, so it was necessary to write the necessary drivers for interfacing the DAS 58 to the RPECS software. This was done using both technical information from the Keithley-Metrabyte manual and, when the supplied technical information was insufficient, by reverse engineering the existing DAS 58 DOS drivers. From this effort, driver code was written that allows for initial setup of the card, for performing an autozero calibration of the card, and for acquiring data with the card. For the acquisition itself, the driver code allows for:

- Internal (timed) or external (encoder/engine position) based sampling

- Automatic, external digital (rising or falling) or external analog (rising or falling through a userdefined threshold) trigger of the acquisition

- User-defined trigger buffer position (e.g., acquire after trigger, acquire before trigger, or anything in between)

- User-defined number of channels, channel selection, and acquisition length. 


\section{RPECS Software}

In addition to the low-level driver software, it was also necessary to write higher level software that would allow the integration of the high-speed capability into RPECS and its existing software structure, whose main component, rpecs_dis, is shown in Figure 25. Specifically, the higher level software needed to provide for:

- Sharing of high-speed data (raw and processed) among RPECS loops and the RPECS network interface

- Combustion analysis routines

- A means of viewing plots of both raw and processed data in near real-time.

To accomplish the first goal (and to provide support for the third), a new class of shared variable, the HSBuffer, was added to the existing Double, OneDMap, TwoDMap, and Mode shared variables already in the RPECS code. This HSBuffer type is used to pass buffer type information (be it raw cylinder pressures or a buffer of IMEPs) between RPECS loops. It is also the type that allows the third objective, the viewing of plots, to be achieved. The buffer plotter interface is implemented in the rpecs_hs_plot program shown in Figures 26 and 27 . With this interface, buffer data can be locally or remotely (or both simultaneously) plotted or logged to the disk or both.

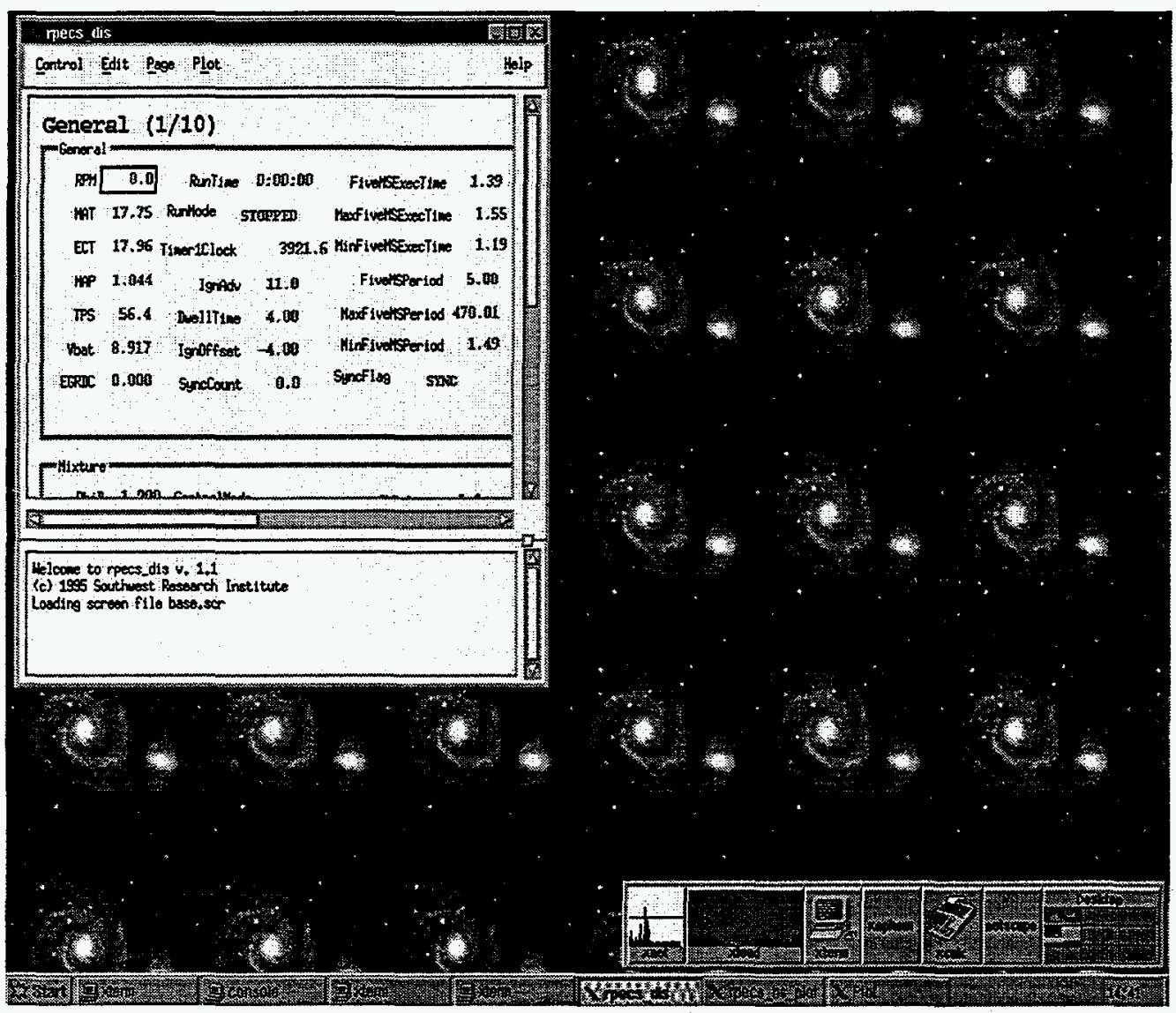

Figure 25. RPECS_dis interface screen 
Toward the second goal, the writing of combustion analysis routines for the high speed RPECS, existing SwRI Pressure Analysis (PANAL) code was ported from existing DOS based code to run under RPECS with the HSBuffer type. PANAL provides for computation of start of combustion, peak pressure, location of peak pressure determination, heat release determination, and computation of IMEP. This code has been ported to the RPECS (in part using internal SwRI funding), but it has yet to be fully tested.

\section{Conclusion}

As part of the Dedicated Ethanol ULEV project, and with capital funding from SwRI, a high-speed data acquisition capability was developed for SwRI's RPECS system. Using this capability, combustion analysis can be performed, both for calibration purposes and for use as real-time feedback control.

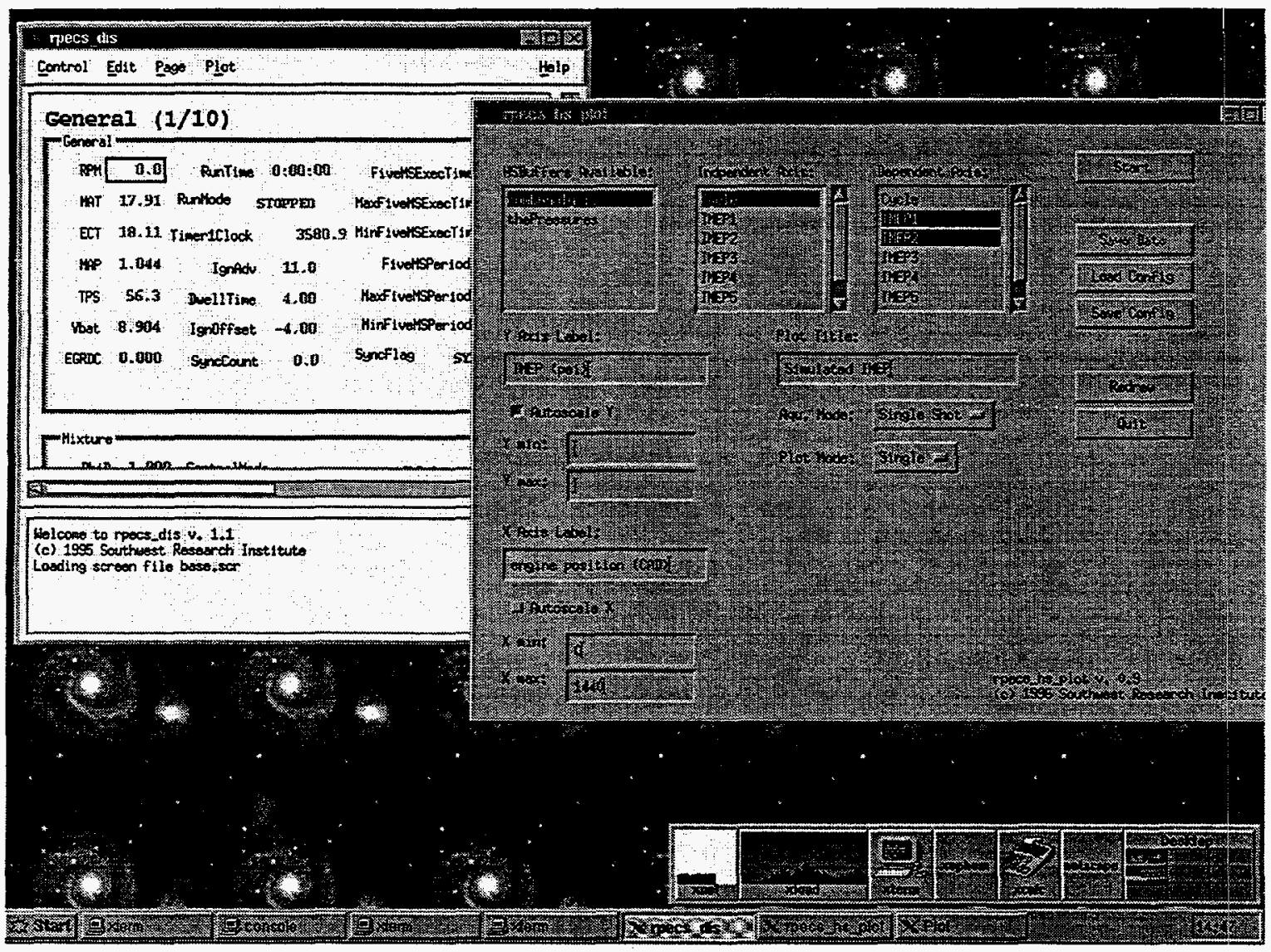

Figure 26. RPECS_HS_PLOT dialog box 


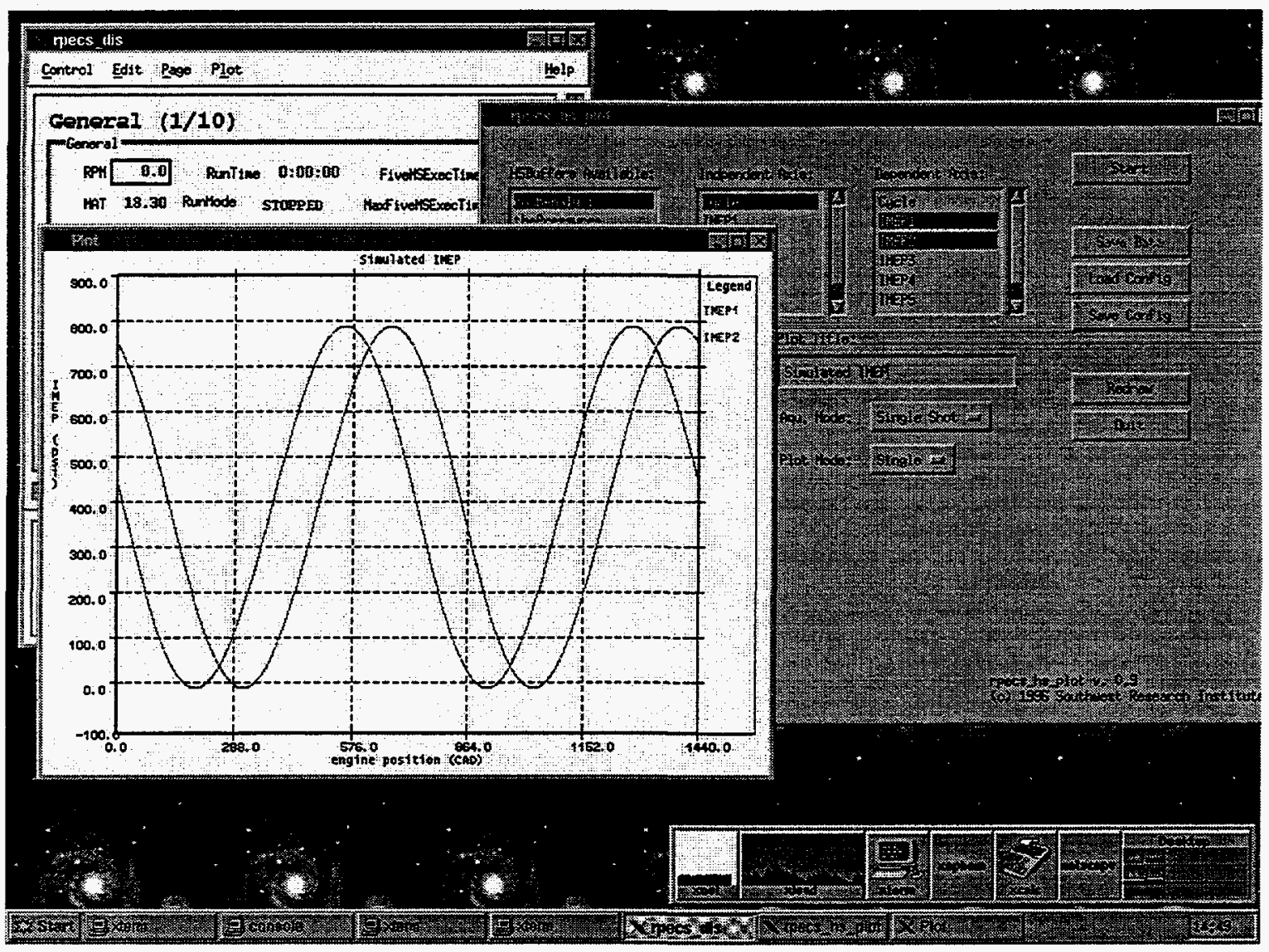

Figure 27. High-speed plot 


\section{References}

Bourn, G.D., Callahan, T.J., Dodge, L.G., Mulik, J., Naegeli, D.W., Shouse, K.R., Smith, L.R., and Whitney, K.A. (February 1994). Development of a Dedicated Ethanol Ultra-Low Emission Vehicle (ULEV)-System Design, Subcontract No. YAW-3-12243-01. Work performed by Southwest Research Institute, San Antonio, TX.

Cook, P.D., Karlson, S., Aspinall, E., and Sherwood, T. (1994). "Systems Enhanced by Software for LEV," SAE Paper No. 940931, Society for Automotive Engineers (SAE): Warrendale, PA.

Coward, H.F., and Jones, G.W. (1952). Bureau of Mines Bulletin 503, pp. 2, 84, 131.

Fanick, E.R., Smith, L.R., Russell, J.A., Likos, W.E., and Ahuja, M. (October 1990). "Laboratory Evaluation of Safety-Related Additives for Neat Methanol Fuel," SAE Paper No. 902156. Presented at the International Fuels and Lubricants Meeting and Exposition, Tulsa, Oklahoma.

Goodger, E.M. (1980). Alternative Fuels. London: Halsted Press.

Hamrin, D.A., and Heywood, J.B. (1995). "Modeling of Engine-Out Hydrocarbon Emissions for Prototype Production Engines," SAE Paper No. 950984, SAE: Warrendale, PA.

Hodgman, C.D. (1957-1958). Handbook of Chemistry and Physics, 39th Ed.

Kulkarni, A.V. (1992). "New Generation Small Block V8 Engine," SAE Paper No. 920673, SAE: Warrendale, PA.

Lawson, A., Simmons, E.W., and Athey, J.A.B. (March 1987). Safety Aspects of the Use of Alcohol Fuels in Road Vehicles, Phase 1, Final Report No. 4439. Celanese Canada Inc., Engineering Sciences Division, Centre for Alternative Fuel Utilization.

Naegeli, D.W. and Weatherford, W.D. (1989). "Practical Ignition Limits for Low Molecular Weight Alcohols." Fuel 68, 45-48.

Russ, S.G., Kaiser, E.W., Siegl, W.O., Podsiadlik, D.H., and Barrett, K.M. (1995). "Comapression Ratio and Coolant Temperature Effects on HC Emissions from a Spark-Ignition Engine," SAE Paper No. 950163, SAE: Warrendale, PA.

van Dolah, R.W., Zabetakis, M.G., Burgess, D.S., and Scott, G.S. (1963). Bureau of Mines, Information Circular 8137, p. 5 .

Zabetakis, M.G. (1952). Bureau of Mines Bulletin 647, pp. 3, 20.

Marshall, W. (1995). Personal conversation. Recent testing at the National Institute for Petroleum and Energy Research (NIPER), BDM Oklahoma, on a fleet of several cars fueled by E85 has resulted in a suggested ozone forming reactivity factor for ethanol-fueled exhaust of 0.68 . 


\section{APPENDIX A}

SAE PAPER NO. 970531

"MODEL-BASED CONTROL AND CYLINDER-EVENT-BASED

LOGIC FOR AN ULTRA-LOW EMISSIONS VEHICLE

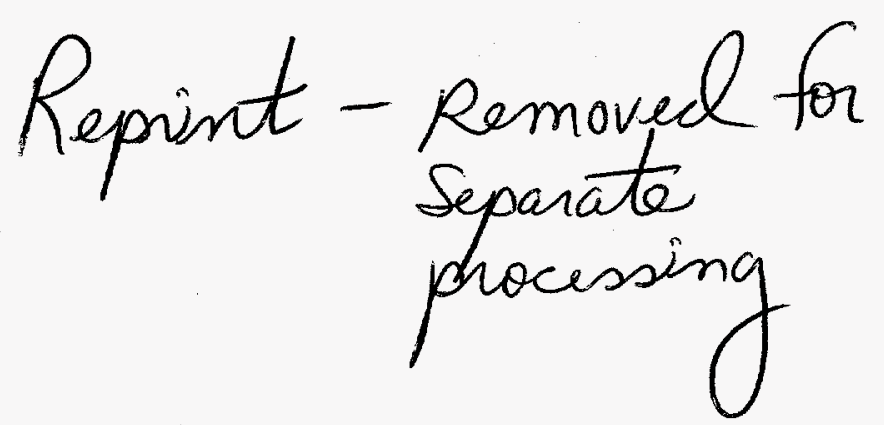




\section{APPENDIX B}

DRAFT SAE PAPER, "DEVELOPMENT OF AN ETHANOL-FUELED ULTRA-LOW EMISSIONS VEHICLE

Society of

Cutomative

Engineens

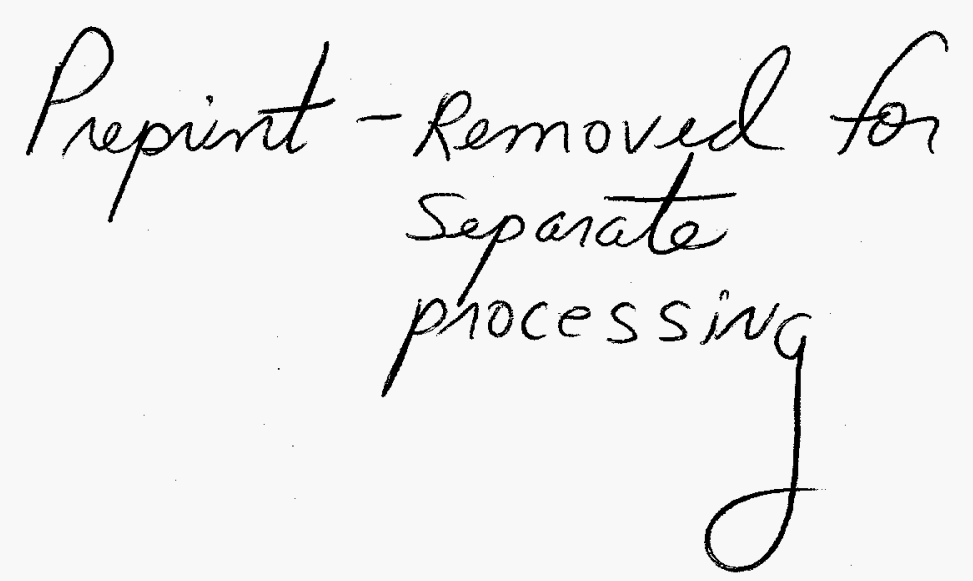

